Aus der Klinik für Nephrologie und Rheumatologie

(Prof. Dr. med. G. A. Müller)

der Medizinischen Fakultät der Universität Göttingen

\title{
Die Effekte von PPARa auf die therapeutische Effektivität von eEOCs beim ischämisch bedingten akuten Nierenversagen von eEOC-behandelten C57BI/6N-Mäusen
}

\author{
INAUGURAL-DISSERTATION \\ zur Erlangung des Doktorgrades \\ der Medizinischen Fakultät der \\ Georg-August-Universität zu Göttingen
}

vorgelegt von

Roman Scheidmann

aus Berlin 
Dekan

Referent

Ko-Referent/in

Drittreferent/in
: $\quad$ Prof. Dr. rer. nat. H. K. Kroemer

: $\quad$ Prof. Dr. med. D. Patschan

: PD Dr. med. M. Schroeter

: $\quad$ Prof. Dr. med. M. Schön

(Promotor-Vertreterin) 


\section{Inhaltsverzeichnis}

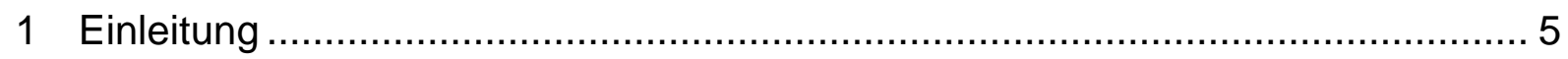

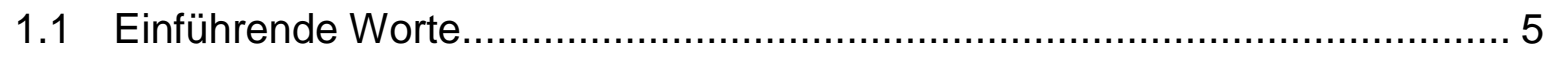

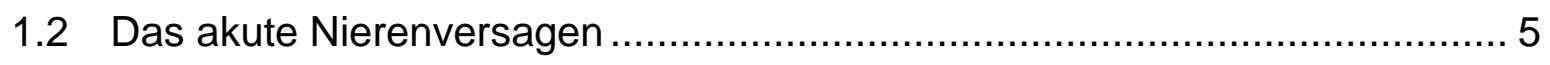





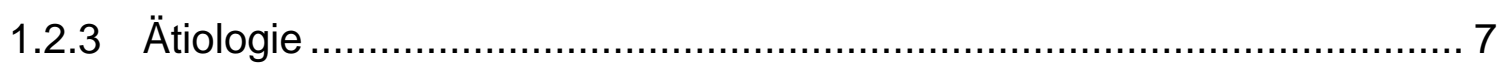



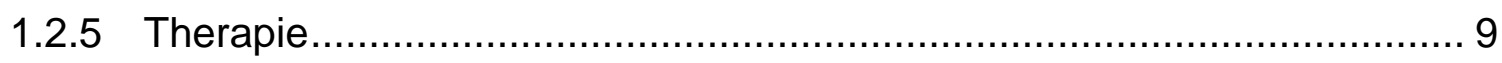

1.3 Endothelvorläuferzellen als alternativer Therapieansatz des iANVs ............. 9

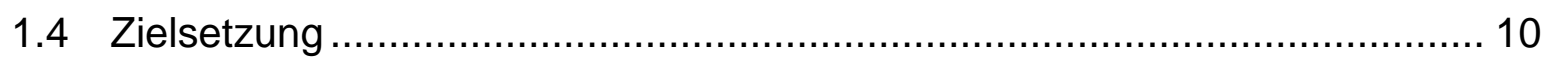

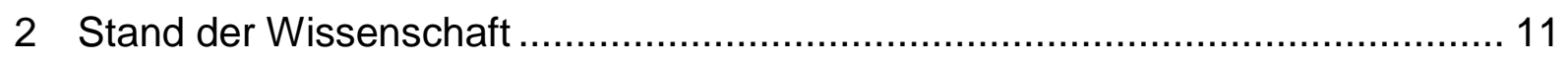

2.1 Überblick über die für diese Arbeit bedeutsamen renalen Strukuren............ 11

2.2 Das ischämisch bedingte akute Nierenversagen (iANV) ............................ 12

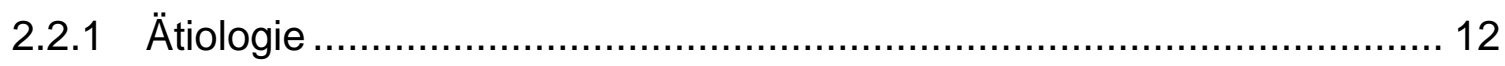

2.2.2 Pathophysiologie: Ischämie-Reperfusionsschaden............................. 12

2.2.3 Die Rolle von Wachstumsfaktoren ................................................... 17

2.2.4 Anwendbarkeit des Tiermodells .................................................... 17

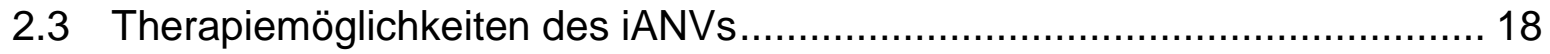

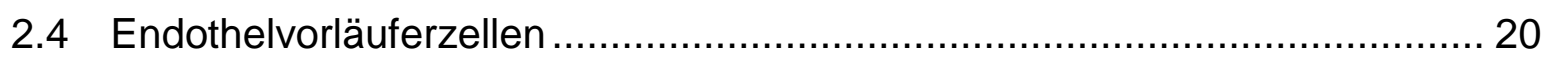

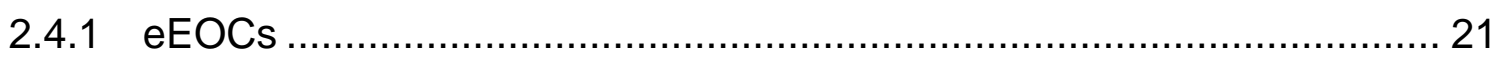

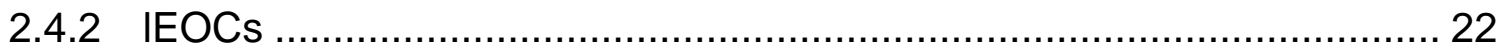



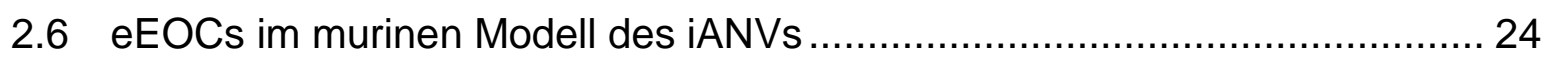





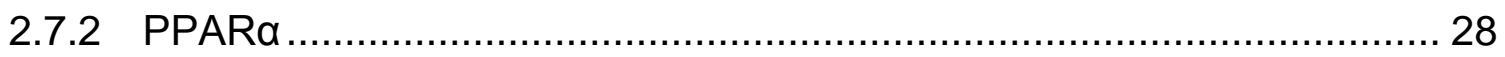

2.7.3 Klinische Studien und Auswirkung der PPARa-Aktivierung auf renale

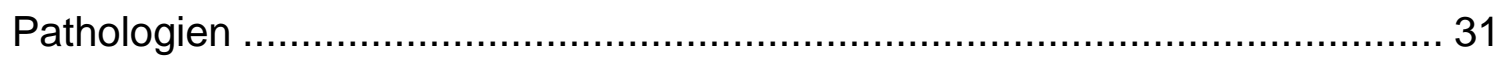

2.8 Erläuterung und gezielte Fragestellung ................................................ 34 


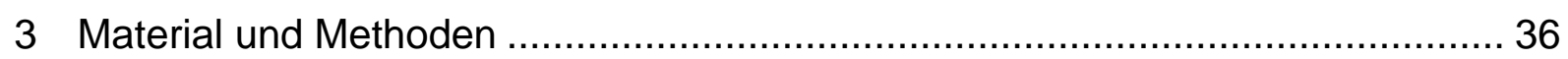

3.1 In-vivo-Tierversuchsreihe: Postischämische Nierenfunktion ...................... 36

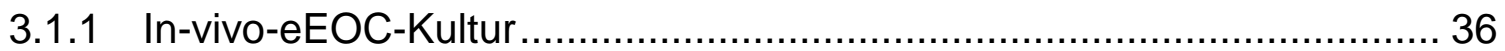

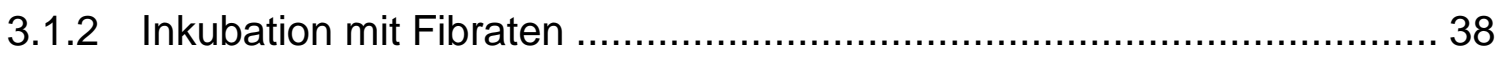

3.1.3 Tierexperimentelle Simulation des iANVs und eEOC-Injektion .............. 39

3.1.4 Materialgewinnung für die Auswertung ............................................ 43

3.1.5 Bestimmung der Kreatininkonzentration im Mausserum ....................... 44



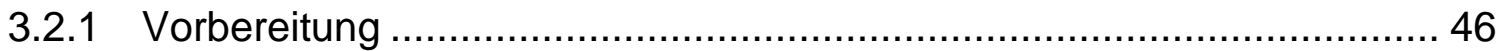

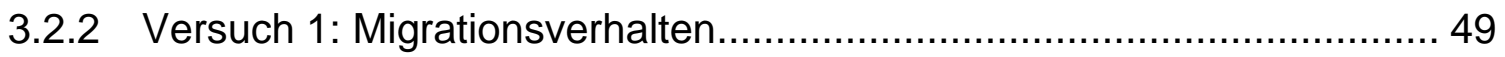

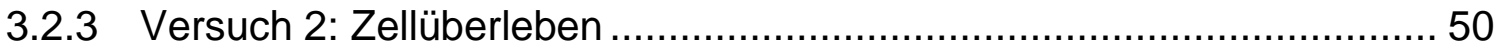

3.2.4 Versuch 3: Proangiogenität............................................................ 52

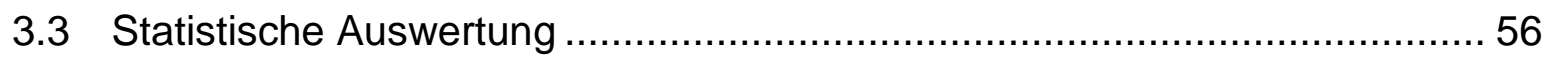

3.4 Tabellarische Zusammenfassung verwendeter Materialien und Substanzen57

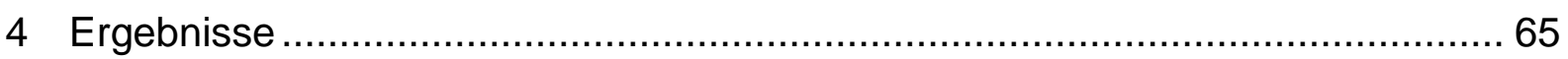

4.1 In-vivo-Tierversuchsreihe: Postischämische Nierenfunktion ...................... 65

4.1.1 Gruppe 1 - unbehandelte Kontrollen ............................................... 65

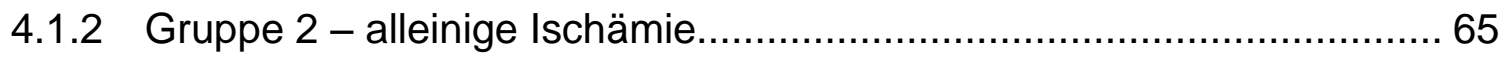



4.1.4 Gruppe 4 - Fenofibrat-vorbehandelte Zellen .................................... 66

4.1.5 Gruppe 5 - Clofibrat-vorbehandelte Zellen ........................................ 66

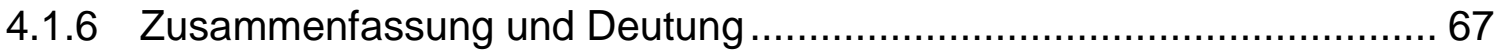

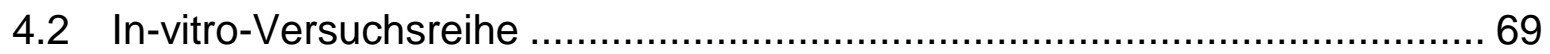

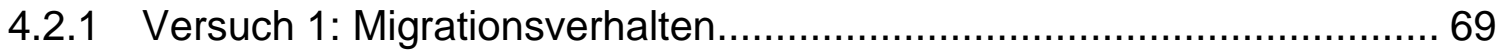

4.2.2 Versuch 2: Zellüberleben ......................................................... 79

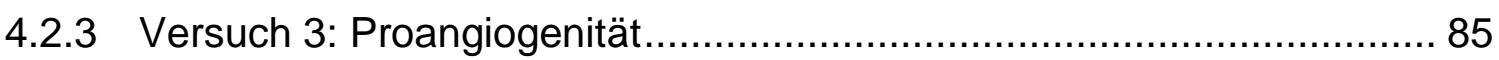




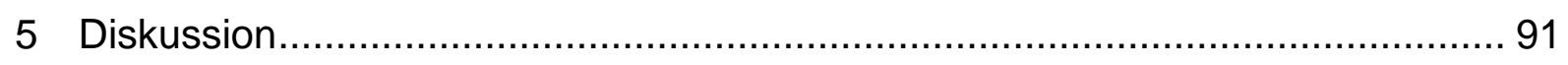

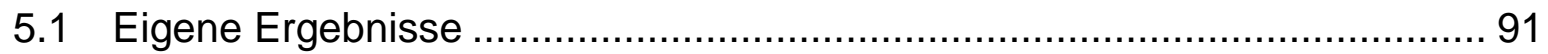

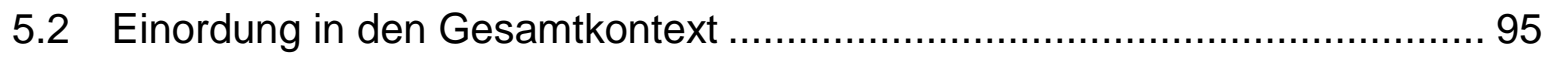

5.3 Schlussfolgerung, Beantwortung der zu Anfang gestellten Fragen und

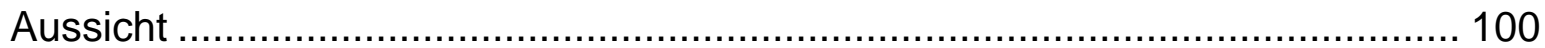

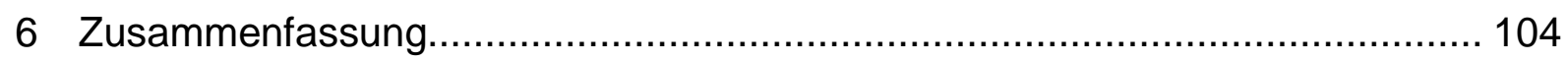

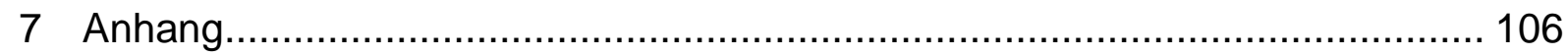

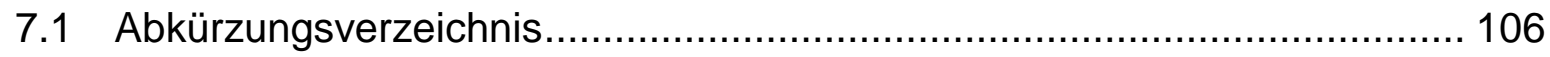

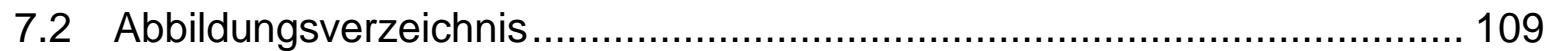

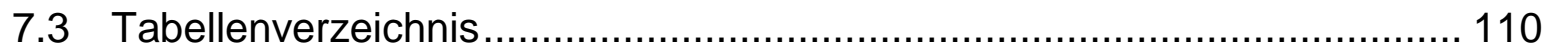

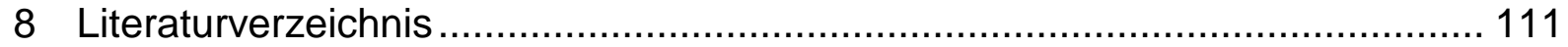




\section{Einleitung}

\subsection{Einführende Worte}

Diese Arbeit beschäftigt sich mit der therapeutischen Effektivität so benannter Endothelvorläuferzellen (Endothelial Progenitor Cells - EPCs) beim akuten ischämischen Nierenversagen (iANV). Es wurde mit einer speziellen EPC-Unterpopulation, den early Endothelial Outgrowth Cells (eEOCs) gearbeitet. Diese werden im Einleitungsteil der Einfachheit halber als "EPCs" bezeichnet. Anstelle der neueren Bezeichnung Acute Kidney Injury - AKI wird der ältere Terminus „Akutes Nierenversagen - ANV“ verwendet.

\subsection{Das akute Nierenversagen}

\subsubsection{Definition}

Das akute Nierenversagen (ANV), seit dem Jahr 2007 etwas zutreffender als „akute Nierenschädigung" (Acute Kidney Injury - AKI) bezeichnet, ist definiert als eine prinzipiell reversible, über Stunden bis Tage andauernde Insuffizienz der Nierenfunktion.

In der Literatur lassen sich über die letzten zwei bis drei Jahrzehnte viele verschiedene Definitionen zur Erfassung der Diagnose "ANV“ finden. Aus diesem Grund war es in der Vergangenheit oftmals schwierig, einheitliche und vergleichende Aussagen zu Epidemiologie, Risikofaktoren oder der Prognose zu machen (Kellum et al. 2002).

Daher wurden in den letzten Jahren international weitestgehend akzeptierte Definitionen geschaffen, welche die vielen einzelnen ersetzten und eine allgemein gültige Stadieneinteilung möglich machten. Die von der ADQI-Gruppe (Acute Dialysis Quality Initiative) erstmals 2004 aufgestellten Kriterien zur Beschreibung der akuten Funktionsverschlechterung stehen als Akronym für die an Schwere zunehmenden Stadien: RIFLE - Risk, Injury, Failure, Loss und ESRD (End Stage Renal Disease) (Bellomo et al. 2004). Das Acute Kidney Injury Network führte 2007 eine erweiterte Definition und Stadieneinteilung ein (AKIN-Kriterien), um dem breiten Spektrum des ANVs gerecht zu werden. In diesem Zuge wurde die Bezeichnung AKI (Acute Renal Injury) in der englischsprachigen Literatur eingeführt (Mehta et al. 2007). Die neueste Klassifikation nach KDIGO (Kidney Disease: Improving Global Outcomes - KDIGO) von 2012 berücksichtigt die zwei Parameter Kreatininanstieg im Serum und Menge der Urinausscheidung und teilt je nach Höhe beziehungsweise Menge drei Stadien ein. Nach dieser Einteilung liegt definitiongemäß ein ANV vor, wenn einer der folgenden drei Punkte erfüllt ist: (I) Anstieg des Serumkreatinins um mindestens $0,3 \mathrm{mg} / \mathrm{dl}$ in 48 Stunden, (II) Anstieg des Serumkreatinins um mindestens das 1,5-fache vom Ausgangswert innerhalb der letzten sieben Tage, (III) Reduktion der Urinausscheidung auf unter $0,5 \mathrm{ml} / \mathrm{kgKG} /$ Stunde für mindestens sechs Stunden (Bienholz und Kribben 2013). 
Allen Kriterien liegt das gleiche Maß für die Stadieneinteilung zu Grunde: Die Bestimmung beziehungsweise der prozentuale Anstieg der Konzentration des Serumkreatinins (Retentionsparameter).

Die neueren Kriterien konnten zwar bei einem großen Patientenkollektiv von über 500.000 Patienten weltweit angewandt und validiert werden (Srisawat et al. 2010), jedoch bleibt das Problem der Maßeinheit, der Einheit zu Objektivierung des Schadens. Das Serumkreatinin, wie auch die Albuminurie bei der Bewertung des chronischen Nierenversagens, sind nur indirekte Marker der renalen Funktion und zeigen nicht unmittelbar den renalen Zellschaden an. Das Kreatinin ist zudem abhängig vom individuellen Geschlecht, dem Alter, der körperlichen Aktivität und Muskelmasse, sowie Leberfunktion und Darmflora (Fiedler 2015).

Hinzukommend ist bei der Beurteilung der Nierenfunktion anhand der Kreatininkonzentration unbedingt zu beachten, dass sich diese im Blutplasma erst ab einer Einschränkung der Nierenfunktion von ca. 50 \% erhöht. Dieser sogenannte „Kreatinin-blinde Bereich“ beschreibt das Nichtansteigen der Kreatininkonzentration bei schon eingetretener Nierenfunktionseinschränkung im Bereich zwischen $90-50 \mathrm{ml} / \mathrm{min}$ glomerulärer Filtrationsrate - GFR. Das heißt, dass vor allem die Anfangsphase eines ANVs beziehungsweise leichte und moderate Nierenfunktionseinschränkungen mittels der Kreatininbestimmung gar nicht oder nicht früh genug erkannt werden.

Trotz oben beschriebener individueller Unterschiede und Einflussfaktoren hat sich die Bestimmung des Serumkreatinins als Screeningparameter in der klinischen Praxis bis dato durchgesetzt.

Für ein besseres "Handling“ des ANVs bräuchte es aber einen sensitiveren, spezifischeren und zeitnäheren Marker. Bestrebungen zur Suche nach Biomarkern des renalen Zellunterganges könnten diese Problematik entschärfen (Siew et al. 2011). Vielversprechende Ergebnisse zeigen die beiden tubulären Zellzyklusarrestmarker Insulin-like Growth-Factor Binding Protein 7 - IGFBP7 und Tissue Inhibitor of Metalloproteinases-2 - TIMP-2, die sich auch in ersten klinischen Studien bewährt haben (Bihorac et al. 2014, Gocze et al. 2015, Kashani et al. 2013). An dieser Stelle soll aber nicht im Detail über neue Marker der glomerulären Filtrationsrate geschrieben werden.

\subsubsection{Epidemiologie}

Eine Vielzahl an Studien konnten in den letzten Jahren zeigen, dass das ANV eine weltweit vorkommende medizinische Komplikation darstellt, verbunden mit einer zunehmenden Häufigkeit sowie beträchtlicher Morbidität und Mortalität (Murugan und Kellum 2011).

Die Inzidenz des ANVs liegt weltweit bei ungefähr 0,21\% (2100/1.000.000 Einwohner) (Srisawat und Kellum 2011), bei Hospitalisierten zwischen 3,2 \% und $20 \%$ (Fang et al. 2010, Lafrance und Miller 2010, Uchino et al. 2006) und erreicht 
Werte von bis zu $67 \%$ bei intensivmedizinisch betreuten Patienten (Hoste et al. 2006, Thakar et al. 2009). Ein besonders hohes Risiko, ein akutes Nierenversagen zu entwickeln, haben septische Patienten beziehungsweise Patienten mit einem septischen Schock (Rangel-Frausto et al. 1995, Riedemann et al. 2003, Uchino et al. 2005). Trotz der Fortschritte auf den Gebieten der Nierenersatztherapie und Intensivmedizin ist die Mortalität und Letalität weiterhin sehr hoch. Die ANVassoziierte Mortalität steigt prinzipiell mit zunehmendem Schweregrad der Nierenparenchymschädigung an (Hoste und Kellum 2006, Thakar et al. 2009). Sie erreicht Werte von bis zu $60 \%$ bei Intensivpatienten (Uchino et al. 2005), aber auch schon kleinere Funktionseinschränkungen (AKIN Stadium 1, RIFLE R) gehen mit einer bemerkenswert hohen Sterblichkeit einher (Kellum und Angus 2002). Auch ältere Veröffentlichungen decken sich mit diesen Daten (Brady und Singer 1995, Corwin et al. 1987, Esson und Schrier 2002, Kellum et al. 2002, Levy et al. 1996, Turney 1990, Woodrow und Turney 1992). Zusammengenommen veranschaulichen diese Zahlen, dass die Prognose des nosokomialen ANVs in den letzten Jahrzehnten nicht substantiell verbessert werden konnte.

Ein weiteres, über die akute Schädigungsphase hinausgehendes Problem des ANVs ist die Gefahr der Chronifizierung der Nierenfunktionseinschränkung. In neueren Studien konnte der Zusammenhang zwischen akutem und chronischem Versagen aufgezeigt werden: Je schwerer der Verlauf des akuten Schadens, desto höher ist auch das Risiko eines fibrotischen Umbaus der Niere. Besonders hoch ist das Risiko für die Entwicklung einer chronischen Niereninsuffizienz bei akuten Verläufen mit Inanspruchnahme einer Dialysetherapie (Chawla et al. 2011).

\subsection{3 Ätiologie}

Das ANV wird eingeteilt in ein prä-, intra- und postrenales Nierenversagen, wobei es Überschneidungen vor allem zwischen dem prä- und dem intrarenalen Versagen gibt. Das prärenale Nierenversagen tritt mit ca. $60 \%$ am häufigsten auf. Das intrarenale Versagen folgt mit ca. $35 \%$. Postrenale Ursachen treten mit ca. $5 \%$ hingegen seltener auf.

Auf eine detaillierte ätiologische Darstellung aller Formen des ANVs soll an dieser Stelle verzichtet und auf Kapitel 2.2 verwiesen werden, in dem eingehend über das ischämische ANV (iANV) berichtet wird. Eine Orientierung gibt die Auswertung von Uchino et al. bei intensivmedizinisch betreuten Patienten. In der Analyse dominierte die Sepsis mit $50 \%$ als Hauptverursacher. Als weitere Ursachen werden vorangegangene große Operationen, ein kardiogener Schock, die Hypovolämie, unerwünschte Nebenwirkungen von Medikamenten (v.a. NSAIDs, aber auch Aciclovir, Breitband- und Reserveantibiotika wie Aminoglykoside, Sulfonamide, Vancomycin), das Hepatorenale Syndrom sowie obstruktive Uropathien genannt (Uchino et al. 2005).

Alle Formen des prärenal ausgelösten Nierenversagens beruhen auf einer Verminderung des effektiven intravasalen Blutvolumens, wodurch sekundär eine 
ischämisch bedingte Schädigung des Nephrons beziehungsweise insbesondere des Tubulussystems herbeigeführt wird (definitionsgemäß intrarenales Nierenversagen). Deshalb ist das prärenale ANV ein Hauptrisikofaktor zur Entwicklung eines iANVs mit akuter Tubulusnekrose (Acute Tubular Necrosis - ATN) (Cameron 1986, Corwin et al. 1987, Hou et al. 1983, Liano et al. 1996, Myers und Moran 1986).

Vor allem ältere Menschen sind anfällig für das prärenale ANV, da die alternde Niere ihre funktionellen Reserven verliert, die Prävalenz der Arteriosklerose der Nierenarterien mit dem Alter steigt und Menschen höheren Alters eher zu hypovolämen Kreislauflagen neigen (Elasy und Anderson 1996, Pascual et al. 1995).

Die unverändert große klinische Bedeutung des ANVs begründet sich dementsprechend auf der zunehmenden Inzidenz, der weiterhin sehr hohen Morbidität und Mortalität von stationären Patienten und der aus der Therapie und den Folgekosten (chronische Dialysetherapie, Nierentransplantation) resultierenden ökonomischen Last.

\subsubsection{Symptome und Diagnostik}

Die in diesem und dem folgenden Kapitel beschriebenen Sachverhalte sind allgemein anerkannte Fakten. Sie dienen der Vollständigkeit halber als rein orientierende Aufarbeitung des ANVs und können in einer Vielzahl medizinischer Lehrbücher nachgelesen werden.

Die Klinik des ANVs ist unspezifisch und wird meist durch die Symptome der Grundkrankheit überlagert.

Als Leitsymptom gilt die Oligurie (<500 ml Harnausscheidung / Tag) beziehungsweise die Anurie ( $<100 \mathrm{ml}$ Harnausscheidung / Tag) als Ausdruck der Nierenfunktionseinschränkung. Klassischerweise kann das ANV mehrere klinische Stadien durchlaufen: Die symptomlose Initiationsphase, gefolgt von der Oligurie Anurie, der Polyurie (>2000 ml Harnausscheidung/Tag) als Zeichen einer beginnenden renalen Erhohlung und schlussendlich der Wiederherstellungsphase. Gerade in der zweiten Phase sind die Patienten durch die fehlende Wasserausscheidung und folglich einer Überwässerung gefährdet, dass sich begleitende Grunderkrankungen verschlechtern und zu potenziell lebensgefährlichen Komplikationen führen können. Ein Beispiel hierfür sei die Herzinsuffizienz mit der Entwicklung eines Lungenödems. Grundsätzlich kann einer Änderung der Urin-, also Wasserausscheidung auch eine Verschiebung im Elektrolyt- und Säure-BaseHaushalt folgen. Im weiteren Verlauf kann es zur Urämie, der Kumulation harnpflichtiger Substanzen im Blut mit negativen Auswirkungen auf so ziemlich jedes menschliche Organsystem kommen (Herold 2012).

Auf die Darstellung von Anamnese und körperlicher Untersuchung als Bestandteil einer vollständigen Diagnostik soll an dieser Stelle verzichtet werden. 
Diagnostisch wegweisend ist neben der Messung des Urinvolumens, die Bestimmung des Retentionsparameters Kreatinin im Patientenserum. In Kapitel 3.1.5 wird genauer auf das Stoffwechselendprodukt Kreatinin eingegangen.

Weitere Untersuchungen, je nach Ätiologie und Komplikation, können erneute Blutund Urinuntersuchungen, bildgebende Verfahren (unter anderem Sonographie) bis hin zur Nierenbiopsie sein.

\subsubsection{Therapie}

Bestehende Therapieprinzipien zielen allgemein auf die Meidung beziehungsweise Behebung der Ursachen des ANVs, die Kontrolle des Wasser-, $\mathrm{pH}-$ und Elektrolythaushaltes, die Behandlung lebensgefährlicher Komplikationen sowie die überbrückende Nierenersatztherapie. Eine spezifische kausale Therapie, die an den pathologischen Veränderungen der Niere ansetzt, ist bis dato leider immer noch nicht verfügbar. Deswegen spielt vor allem die Prävention eine entscheidende Rolle.

\subsection{Endothelvorläuferzellen als alternativer Therapieansatz des iANVs}

Ein neuer Therapieansatz in der Behandlung des iANVs könnte die Anwendung von sogenannten Endothelvorläuferzellen (Endothelial Progenitor Cells - EPCs) sein. EPCs entwickeln sich im Knochenmark unter anderem aus pluripotenten hämatopoetischen Stammzellen und können sowohl unter physiologischen als auch unter pathologischen Umständen im peripheren Blut nachgewiesen werden. Studien haben gezeigt, dass EPCs in der Lage sind, die Bildung neuer Blutgefäße zu unterstützen. Somit umfasst der Prozess der Gefäßneubildung nicht alleine ein „Aussprossen“ bereits vorhandener reifer Blutgefäßwandzellen sondern gleichfalls das supportive (indirekte) Wirksamwerden anderer, nicht primär vaskulärer Zellen (Asahara et al. 1999, Asahara et al. 1997, Khakoo und Finkel 2005, Urbich und Dimmeler 2004a, b).

Aufbauend auf diesen Erkenntnissen wurden die EPCs weiter charakterisiert und inr vasoprotektives Potenzial sowie ihre Funktion spezifiziert.

Im Jahr 2006 konnte erstmals nachgewiesen werden, dass EPCs nach passagerer renaler Ischämie vermehrt aus dem Knochenmark ausgeschwemmt werden und in der ischämisch geschädigten Niere eine protektive Wirkung entfalten (Patschan et al. 2006a). 


\subsection{Zielsetzung}

Die in der vorliegenden Arbeit dargestellten Versuche wurden im Rahmen eines Forschungsprojektes zur Untersuchung der therapeutischen Wertigkeit endothelialer Vorläuferzellen beim akuten ischämischen Nierenversagen durchgeführt.

Diese Arbeit gliedert sich in zwei Versuchsreihen. Eine In-vivo-Tierversuchsreihe und drei In-vitro-Versuche.

Im Rahmen der In-vivo-Versuche wurde speziell analysiert, ob durch die pharmakologische Aktivierung des „Peroxisomen-Proliferator-aktivierten Rezeptors alpha" (kurz PPARa), agonisiert durch Feno- und Clofibrat (kurz FF und CF), eine Modulation der EPC-vermittelten Nephroprotektion im murinen Modell beim iANV erzielt werden kann. Die Qualität der Behandlung, also die postischämische Nierenfunktion nach simuliertem iANV, wurde mittels Kreatininbestimmung im Serum ermittelt.

Um einen genaueren Eindruck der zellulären Konsequenzen einer Fibrat-Behandlung von EPCs zu erhalten, wurden drei Parameter in Rahmen der In-vitro-Versuchsreihe an kultivierten Zellen erhoben:

- Migrationsverhalten,

- Zellüberleben sowie

- Proangiogenität durch Freisetzung des Wachstumsfaktors VEGF (Vascular Endothelial Growth Factor - VEGF). 


\section{Stand der Wissenschaft}

\section{1 Überblick über die für diese Arbeit bedeutsamen renalen Strukuren}

Als Nephron wird die funktionelle Einheit der Niere, bestehend aus Glomerulus, proximalem Tubulus, Intermediärtubulus mit Henle-Schleife und distalem Tubulus, bezeichnet. Im weiteren Sinne können auch der Verbindungstubulus und das Sammelrohr sowie die blutführenden Gefäßschlingen zur funktionellen Einheit hinzu gezählt werden. Aufgabe der Tubuli ist die Umwandlung des Primärharnes in den Endharn durch Rückresorption von Wasser und anderer "nützlicher" Stoffe (z. B. Elektrolyte, Glukose, Proteine) sowie die Sekretion von Abfallstoffen. Für diese Arbeit von besonderem Stellenwert ist das System aus proximalem Tubulus, den begleitenden Gefäßen und dem interstitiellen Raum. Der proximale Tubulus wird histologisch in zwei Anteile oder auf zellulärer Ebene in drei Segmente eingeteil: Die sich direkt an das Glomerulum anschließende Pars convoluta und die Pars recta oder in S1-, S2- und S3-Segment. Eine Übersicht über die Standardnomenklatur renaler Strukturen gibt die Arbeit von Kriz und Bankir (Kriz und Bankir 1988). Das Epithel des proximalen Tubulussystems ist gekennzeichnet durch seine hohe Anzahl transportierender Vorgänge: Zur Schaffung einer Barriere zwischen Tubuluslumen und Interstitium bilden die Epithelzellen Tight-Junctions untereinander aus. Die basolaterale Zellmembran ist stark aufgefältet und somit vergrößert. Dies dient der Unterbringung der vielen $\mathrm{Na}^{+} / \mathrm{K}^{+}$-ATPasen zur Schaffung von transepithelialen Gradienten, die die transtubulären Resorptionsvorgänge möglich machen. Die Energie für die $\mathrm{Na}^{+} / \mathrm{K}^{+}$-ATPasen liefern die vielen intrazellulären Mitochondrien- und Peroxisomen. Des Weiteren charakterisieren lange Mikrovilli, Endozytose-Grübchen und Lysosomen die Epithelzellen der proximalen Tubuli. Das hier resorbierte Wasser macht ca. $65 \%$ des Primärharns aus und wird in das kortikale Kapillarnetz drainiert. Dieses weist typischerweise fenestrierte Endothelzellen mit Diaphragma auf, um gut wasserdurchlässig zu sein (Lüllmann-Rauch 2009).

Hauptlokalisation pathophysiologischer Veränderungen im Rahmen des iANVs ist das proximale Tubulussystem, genauer das S3-Segment (Lieberthal und Nigam 1998). 


\subsection{Das ischämisch bedingte akute Nierenversagen (iANV)}

\subsection{1 Ätiologie}

Das ischämisch bedingte akute Nierenversagen lässt sich durch die prärenal bestehende arterielle Minderperfusion als Hauptursache sowie sekundär durch die akute Tubulusnekrose (Acute Tubular Necrosis - ATN), ätiologisch dem intrarenalen Versagen zugeordnet, erklären. Die Tubulusnekrose stellt mit ca. $50 \%$ den Hauptanteil am intrinsischen Versagen dar. Es ist, wie zuvor erwähnt, meist die Folge einer prärenal bedingten Minderversorgung des Organs mit Blut.

Ein großes Spektrum an klinischen Konstellationen kann zur Reduktion des effektiven Blutflusses der Nieren und somit zur Ischämie des Nierenparenchyms führen.

Ursachen sind zum Beispiel eine Hypovolämie oder Hypotension, durch massive Diarrhoen oder Erbrechen, eine inadäquate Flüssigkeitaufnahme, ein sogenannter third space-Flüssigkeitsverlust (in die Peritoneal- oder Pleurahöhle), ein reduziertes effektives Kreislaufvolumen, zum Beispiel durch eine Herzinsuffizienz beziehungsweise einen Herzfehler, einen septischen Schock oder durch Leberzirrhose, Medikamente (NSAIDs, ACE-Hemmer), oder eine Stenose der Nierenarterie $(n)$ durch Arteriosklerose oder fibromuskuläre Dysplasie.

Im Einleitungsteil dieser Arbeit wurde bereits orientierend auf die Ursachen des ANVs eingegangen. Hervorgehoben sei noch einmal die schwere Sepsis, die mit $50 \%$ als Hauptverursacher des ANVs bei Intensivpatienten gilt (Uchino et al. 2005).

\subsubsection{Pathophysiologie: Ischämie-Reperfusionsschaden}

Die Pathophysiologie ist nach wie vor nicht vollständig verstanden. Nierenbiopsien bei kritisch Kranken mit einem akuten Nierenversagen zur Abklärung der Histopathologie sind häufig nicht durchführbar, weshalb die Datenlage bezüglich des humanen ANVs sehr knapp ist. Die meisten Erkenntnisse beruhen auf Tiermodellen, bei denen vor allem große histologische Veränderungen im Vordergrund stehen.

Diese Veränderungen sowie die Entstehung der Entzündungsreaktion werden durch das „warme Ischämie-Reperfusions-Modell“ (I/R-Modell) erklärt: Initial kommt es durch die Ischämie und folglich der zellulären Hypoxie zu Parenchymschäden, welche dann sekundär durch die reperfusionsbedingt vermehrte Bildung sogenannter freier Sauerstoffspezies (Reactive Oxygen Species - ROS) verstärkt werden.

Hauptlokalisation der pathophysiologischen Veränderungen im Rahmen des iANVs ist das S3-Segment des proximalen Tubulussystems (Lieberthal und Nigam 1998).

Der folgende Abschnitt beschreibt die Vorgänge etwas genauer: Das proximale Tubulussystem ist auf Grund der vielen Adenosintriphosphat (ATP)-verbrauchenden Reaktionen und Stoffwechselvorgänge auf eine intensive Sauerstoffversorgung angewiesen, weshalb eine Minderperfusion der Nierenrinde und des äußeren Nierenmarkes schnell zur Störung der Zellhomöostase (Kribben et al. 2003) und Einstellung zellulärer Funktionen führt. Infolge der Hypoxie verbrauchen die Zellen 
ihre ATP-Speicher, die $\mathrm{Na}^{+} / \mathrm{K}^{+}$-ATPase als treibende Kraft der Resorptionsvorgänge stellt ihre Arbeit ein, es kommt zur Verschiebung im Elektrolythaushalt mit Hyperkaliämie und Azidose. Darauf folgt der Zusammenbruch des aktiven lonentransportes über die Zellmembran und somit der unkontrollierte lonen- und Wassereinstrom in die Zellen. Hinzukommend wird der Ausstrom von Makromolekülen und Blutplasma ins Interstitium mit Ödembildung und Gewebedruckerhöhung aufgrund vermehrt durchlässiger Kapillarendothelien begünstigt. Durch Neutrophilenadhäsion an denselben wird eine Entzündungskaskade angestoßen. Diese Veränderungen führen sekundär zu Blutstauungen und einer weiteren Reduktion des Blutflusses, sodass sich das Gleichgewicht zwischen Energieversorgung und Energiebedarf zu Ungunsten der Tubuli verschiebt (Brezis und Rosen 1995, Mason et al. 1989, Schmid-Schonbein 1987, Vetterlein et al. 1986). Auf subzellulärer Ebene kommt es zu strukturellen und funktionellen Schäden unter anderem an Peroxisomen und Mitochondrien (Gulati et al. 1992). Über die Peroxisomen soll in Kapitel 2.7 näher berichtet werden. Vereinfacht gesagt, sind neben einer eingeschränkten Energiebereitstellung aus der $\beta$-Oxidation die peroxisomalen Antioxidantien-Mechanismen (unter anderem verminderte Aktivität der Katalase) außer Kraft gesetzt, wodurch vermehrt ROS entstehen, die zu oxidativem Stress und somit weiteren pathologischen Veränderungen an vielen zellulären Bestandteilen, insbesondere der Zellmembran, an Proteinen, den Mitochondrien und der DNA führen und so proapoptotisch wirken (Gulati et al. 1992). Bei der sich anschließenden Reperfusion und dem damit verbundenen hohen Angebot an Sauerstoff kommt es zu einer erneuten und sehr ausgeprägten Bildung aggressiver ROS, die aufgrund der ohnehin schon verminderten peroxisomalen Funktionsweise zu erheblichen Schäden führen. Diese unterstützen unter anderem auch die Adhäsion und sekundäre Invasion von neutrophilen Granulozyten (Neutrophilen) und Mediatorenfreisetzung aus denselben, was die ohnehin schon ablaufende interstitielle Entzündungsreaktion noch verstärkt (Devarajan 2006).

Zusammengefasst charakterisieren drei Prozesse die pathophysiologischen Veränderungen beim iANV: Zum ersten kommt es direkt zu strukturellen und funktionellen tubulären Veränderungen mit Zelltod durch Apoptose, Desquamation und Lumenobstruktion. Zum zweiten kommt es zur kapillären Vasokonstriktion und anhaltenden Endothelschwellung von Blutgefäßen, was eine verminderte Reperfusion nach sich zieht. Zum dritten kommt es zu der bereits erwähnten Entzündungsreaktion im renalen Interstitium.

Alle Veränderungen führen zu einer verminderten Organfunktion, somit einer verringerten GFR und konsekutiv erhöhten Retentionsparametern. 


\subsubsection{Tubuläre Veränderungen}

Wie bereits beschrieben, ist das proximale Tubulussystem auf eine intensive Sauerstoffversorgung angewiesen, weshalb eine Minderperfusion schnell zu einer sich selbst verstärkenden Abfolge zellschädigender Veränderungen führt. Zusammengefasst kommt es zur Störung der Zellhomöostase (Kribben et al. 2003), Einstellung zellulärer Funktionen, Destabilisierung der Zellmembran, Zellschwellung, kapillärer Vasokonstriktion sowie Entstehung einer Entzündungsreaktion (Brezis und Rosen 1995, Mason et al. 1989, Schmid-Schonbein 1987, Vetterlein et al. 1986). Unter physiologischen Bedingungen sichert die $\beta$-Oxidation von Fettsäuren in Peroxisomen und Mitochondrien den hohen Energiebedarf der Tubuluszelle. Aufgrund der Ischämie ist die Aktivität dieser Enzyme jedoch deutlich verringert, wodurch weniger ATP gebildet werden kann und die vielen Fettsäuren als freie Fettsäuren zurück bleiben. Diese freien Fettsäuren werden dann vermehrt zu LipidPeroxiden (ROS) oxidiert und verstärken die ohnehin schon ablaufenden pathologischen Veränderungen durch ROS (Ruidera et al. 1988). In der Konsequenz sterben einige Tubulusendothelzellen ab und obstruieren das Lumen.

Die Desquamation von Tubulusepithel als das Charakteristikum der Tubulusnekrose beim iANV beruht auf strukturellen Veränderungen. Diese sind gekennzeichnet durch Verlust der zellulären Polarität prinzipiell, Umverteilung der $\mathrm{Na}^{+} / \mathrm{K}^{+}$-ATPase vom basalen zum apikalen Membrankompartiment und Verlust der interzellulären Zonulae adherentes und Zonulae occludentes (Tight-Junctions), Blasenbildungen unterhalb der apikalen Membran, Verlust der langen Mikrovilli sowie der Zellkerne (Kellerman et al. 1990, Molitoris 1991, Spencer et al. 1991). Zusätzlich werden Integrine umverteilt und führen zur Abschilferung toter (apoptotischer / nekrotischer) und vitaler Tubuluszellen mit intraluminaler Verklumpung und Obstruktion der Tubuli (Goligorsky und DiBona 1993, Racusen et al. 1991).

Zusätzlich wird durch den Verlust der Zellpolarität über den tubuloglomerulären Feedback-Mechanismus (TGF) eine die Ischämie verstärkende Kaskade angestoßen. An dieser Stelle soll auf das Kapitel 2.2.2.4 verwiesen werden, in dem noch eingehender über den TGF berichtet wird.

Es sei darauf hingewiesen, dass trotz Nutzung des Begriffes „Akute Tubulusnekrose" der führende Prozess des Zelltodes die Apoptose ist (Devarajan 2006). Die Hemmung der Apoptose und Bereitstellung von ATP ist Angriffspunkt der in dieser Arbeit genutzten Aktivierung von PPARa (siehe Kapitel 2.7.2). 


\subsubsection{Mikrovaskuläre Veränderungen}

Die Vasokonstriktion der kleinen Nierengefäße und Veränderung der Endothelzellfunktion ist direkt durch den ischämischen Prozess bedingt (Conger et al. 1991, Malis et al. 1991). Es kommt zu einer geringeren Produktion von und verminderte Antwortpotenziale auf vasodilatatorische Substanzen. Zusätzlich führt der pathologisch bedingte tubuloglomeruläre Feedback-Mechanismus (TGF) zu einer weiteren Vasokonstriktion der Vasa afferentia (siehe Kapitel 2.2.2.4). Die entzündungsfördernden Prozesse werden im folgenden Kapitel erläutert.

Das No-Reflow-Phänomen beschreibt die verminderte Reperfusion der Endstrombahn durch Endothelschwellung kleiner peritubulärer Arteriolen und Kapillaren (Endothelial cell Dysfunction - ED) (Goligorsky 2005, Leaf 1973, Patschan et al. 2012b), obwohl die eigentliche Ursache der renalen Minderversorgung mit Sauerstoff beseitigt wurde. Dies führt dazu, dass sich das geschädigte Organ insgesamt verzögert erholt und das ANV dadurch einen prolongierten Verlauf aufzeigt (Brodsky et al. 2002). Die renale Mikrozirkulation erholt sich über einen Zeitraum von ca. 24 Stunden, wobei die Endothelien oszillierend anund abschwellen (Yamamoto et al. 2002).

Dieses „Phänomen“ beschränkt das Regenerationspotenzial der vaskulären und tubulären Endothelzellen und ist Angriffspunkt der in dieser Arbeit genutzten Therapie mit endothelialen Vorläuferzellen (siehe Kapitel 2.6).

\subsubsection{Interstitielle Entzündungsreaktion}

Jede renale Ischämie induziert eine variable interstitielle Entzündungsreaktion in der Niere. Die Aktivierung des Komplementsystems (v.a. Faktor 5a), die Expression von interzellulären Adhäsionsmolekülen (ICAM-1, VCAM-1) und die Freisetzung von Zytokinen (v.a. IL-6), mobilisiert eine Vielzahl an Entzündungszellen, welche am Kapillarendothel adhärieren und ins Interstitium invadieren (Delerive et al. 1999, Devarajan 2006). Dies sind vor allem neutrophile Granulozyten, B- und CD4 $4^{+}$-TLymphozyten aber auch Makrophagen und natürliche Killerzellen. Daraus resultiert primär ein reduzierter medullärer Blutfluss, da die Zellen das kleine Kapillarlumen verengen und führen sekundär zu einer Entzündungsreaktion im Interstitium mit erhöhter Endothelpermeabilität. Die erhöhte Permeabilität des Endothels wird durch Freisetzung von Mediatoren, wie ROS, Leukotriene, Elastasen, Proteasen und weitere gewebezerstörende Enzyme hervorgerufen (Grino 1994, Klausner et al. 1989, Weisman et al. 1990). Hervorgehoben sei an dieser Stelle die gesteigerte Suszeptibilität der Membranlipide für die katalytische Aktivität der Phospholipase $\mathrm{A}_{2}$. Letztere wird durch die Ischämie aktiviert. Nachfolgend erhöht sich zum einen die Konzentration freier Fettsäuren, die zu Lipid-Peroxiden (ROS) oxidiert werden (siehe Kapitel 2.2.2.1), zum anderen erhöht sich die membranöse Permeabilität von einzelnen Endothelzellen und intrazellulären Mitochondrien, woraus weitere Elektrolytverschiebungen und die Destabilisierung der Zellen resultieren. Dies führt wiederkehrend zur Vasokonstriktion der Kapillaren und Neutrophilen-Chemotaxis. 
Am Ende verursacht diese Abfolge von Veränderungen eine verstärkte Entzündungsreaktion. Vasokonstriktion und Chemotaxis werden durch Eikosanoide, Stoffwechselprodukte der aus den Phospholipiden der Membran durch die Phospholipase $A_{2}$ freigesetzten Arachidonsäure, hervorgerufen. (Bonventre 1993, Klausner et al. 1989, Sevanian und Kim 1985).

Die Hemmung der Entzündungsreaktion ist Angriffspunkt der in dieser Arbeit genutzten Aktivierung von PPARa (siehe Kapitel 2.7.2).

\subsubsection{Die verminderte glomeruläre Filtrationsrate}

Die Verminderung der GFR ist die Konsequenz einer Vielzahl von ischämiebedingten, vaskulären und tubulären Vorgängen: Grundsätzlich führt die verminderte Nierendurchblutung von sich aus zu einer geringeren GFR. Der Blutstau in der Rinde und dem äußeren Mark führt sekundär über Tubulusnekrose und Lumenobstruktion zu einer weiteren Reduktion der GFR.

Die pathologisch geringe transtubuläre Rückresorption des Ultrafiltrats ist Ergebnis struktureller Veränderungen. Hierzu zählt der Verlust der Zellintegrität auf Grund der tubulären Desquamationsvorgänge (Ausfall der Zonulae adherentes und occludentes und Umverteilung der $\mathrm{Na}^{+} / \mathrm{K}^{+}$-ATPase vom basalen zum apikalen Membrankompartiment), was zu einer verminderten $\mathrm{Na}^{+}$-Rückresorption sowie des $\mathrm{Na}^{+}$-gekoppelten vektoriellen Transportes (Wasserrückresorption) führt (Brady und Singer 1995, Molitoris et al. 1992). Der tubuloglomeruläre Feedback-Mechanismus als physiologischer Kompensationsmechanismus bei inadäquat hoher Nephrondurchblutung, gemessen an der konsekutiv zu hohen NaCl-Konzentration im distalen Tubulussystem, ist gekennzeichnet durch eine Adenosin-vermittelte mesangiale Zellkontraktion und Vasokonstriktion der Vasa afferentia, die direkt zu einer Reduktion des Filtrationsflusses und -druckes und somit der GFR bei Hyperfiltration führt. Bei gestörter Natriumrückresorption, wie sie im Rahmen des iANVs auftritt, verursacht dieser Mechanismus eine inadäquate Vasokonstriktion und verstärkt den ischämischen Prozess durch Minderdurchblutung (Singh und Okusa 2011). Konsekutiv steigen die Retentionsparameter im Serum an. 


\subsubsection{Die Rolle von Wachstumsfaktoren}

Im Gegensatz zum Myokard und dem Gehirn kann die Niere ihre Struktur und Funktion nach schweren Schäden potenziell wieder komplett herstellen. Es konnten im humanen postischämischen Organ erhöhte Mitoseraten und eine Endothelregeneration, unter anderem gekennzeichnet durch erhöhte Expression von Proteinen, die sonst nur in der frühen Wachstumsphase von Nephronen zu finden sind, nachgewiesen werden. Im Tierversuch konnte schon 1994 und 1995 gezeigt werden, dass die verabreichten Wachstumsfaktoren (WFs) „epidermaler WF“, „Hepatozyten-WF“ und der Insulin-like Growth Factor 1 - IGF-1 den Funktionsverlust, also die Schwere des iANVs verringern und die Erholung fördern können (Hammerman und Miller 1994, Safirstein und Bonventre 1995). Diese Erkenntnis ist Grundlage der Bemühungen zur Therapieoption mit eEOCs, die ihre protektive Wirkung vor allem durch die Produktion und Sekretion von proangiogenen WFs entfalten.

\subsubsection{Anwendbarkeit des Tiermodells}

Die eingeschränkte Anwendbarkeit des Modells auf den Menschen ist nach wie vor problematisch, vor allem bei der häufig auftretenden Kombination von Sepsis und akutem Nierenversagen (Langenberg et al. 2006, Wan et al. 2008). Denn das humane ANV, so zeigen es die wenigen verwertbaren Biopsien, ist gekennzeichnet durch begrenzte histologische Veränderungen, aber einer großen Abnahme der Nierenfunktion (Heyman et al. 2010, Rosen und Heyman 2001). Dies kontrastiert zu den deutlichen histologischen Veränderungen im Tiermodell. 


\subsection{Therapiemöglichkeiten des iANVs}

Bestehende Therapieprinzipien zielen auf die Meidung beziehungsweise die Behebung der Ursachen des ANVs, die Behandlung lebensgefährlicher Komplikationen, bedingt durch Elektrolytverschiebungen (Hyperkaliämie), Störungen des Säure-Base-Haushaltes (metabolische Azidose) und Symptome der Überwässerung (Hypertonie, Lungen- und Hirnödem) sowie schließlich die überbrückende Nierenersatztherapie, bis die Niere ihre Funktion wieder vollständig alleine übernehmen kann. Eine spezifische kausale Therapie, die an den pathologischen Veränderungen der Niere ansetzt, ist bis jetzt leider immer noch nicht verfügbar.

Neuere Überlegungen zielen verstärkt auf die Behandlung der lokalen Entzündungsreaktion. Bestrebungen, die Entzündungsreaktion direkt durch definierte Substanzen zu beeinflussen, zeigen in l/R-Tiermodellen ihre Wirkung:

- Bone Morphogenetic Proteins - BMPs, Proteine aus der TGF- $\beta$-Familie (Transforming Growth Factor- $\beta$ - TGF- $\beta$ ), können durch ihre antiinflammatorische Wirkung zur Prävention und Behandlung des ANVs eingesetzt werden. Die direkte Agonisierung von BMPs führt in l/R-Modellen $z u$ einer niedrigeren Serumkreatininkonzentration und zu geringeren histologischen Veränderungen als in Kontrollgruppen (Sugimoto et al. 2012, Vukicevic et al. 1998). Die Gruppe der BMPs, vor allem BMP-5, zeigt auch im Rahmen der endothelialen Vorläuferzelltherapie beim murinen Modell des iANVs nephroprotektive Wirkung (Patschan et al. 2013c).

- Das Enzym Alkalische Phosphatase (AP) hat eine antiinflammatorische Wirkung, indem es proinflammatorische Substanzen wie Lipopolysaccharide (LPS) dephosphorilisiert (Pickkers et al. 2012). Rekombinante humane AP zeigt antiinflammatorische und gewebeschützende Effekte in I/R-Modellen an Ratten (Ince et al. 2013). 
Andere Überlegungen betreffen die Therapie mit Stamm- beziehungsweise Vorläuferzellen beim ANV:

- Mesenchymale Stammzellen (Mesenchymal Stem Cells - MSCs) sind fibroblastenähnliche Zellen aus dem Knochenmark, die sich in Osteozyten, Chondrozyten und Adipozyten differenzieren können. Sie wirken parakrin und können so Zellschutz und Regeneration beeinflussen (Togel und Westenfelder 2012). Sie zeigen im ANV-Modell an Ratten nach intrakarotidaler Injektion protektive Wirkung: Die renale Funktion bessert sich und der Tubulusschaden wird geringer (Tögel et al. 2005).

- Endotheliale Progenitorzellen (EPCs) entwickeln sich unter anderem aus pluripotenten hämatopoetischen Stammzellen. Studien haben gezeigt, dass die EPCs in der Lage sind, die Gefäßeneubildung über direkte und indirekte Mechanismen zu fördern.

In Vorwegnahme sei an dieser Stelle erneut bemerkt, dass sich das zuvor beschriebene Phänomen der postischämischen Zellschwellung von peritubulären Kapillaren (No-Reflow-Phänomen) durch die systemische Gabe von diesen endothelialen Progenitorzellen verbessern lässt.

In den folgenden Kapiteln soll eingehender über Endothelvorläuferzellen und deren Nutzen berichtet werden. 


\subsection{Endothelvorläuferzellen}

Zentrale Begriffe der Neubildung von Blutgefäßen sind „Angiogenese" und „Vaskulogenese“. Beide Prozesse laufen zeitlebens im Organismus von Säugetieren ab.

„Angiogenese“ beschreibt den Prozess der Aussprossung ortsständiger reifer Endothel- und anderer Gefäßwandzellen aus bereits bestehenden Gefäßen zur Bildung von Arteriolen, Venolen und Kapillaren (Khakoo und Finkel 2005, Risau 1997, Urbich und Dimmeler 2004a, b). Dieser Prozess kommt sowohl physiologisch im Rahmen von Anpassungsvorgängen an erschwerte Bedingungen, veranschaulicht durch die Erhöhung der Kapillardichte in Herz- und Skelettmuskel als Folge körperlichen Trainings, als auch pathologisch zum Beispiel während der Vaskularisierung maligner Tumoren vor.

„Vaskulogenese“ beschreibt den Prozess der de-novo Gefäßbildung aus im Blut frei vorkommenden, unreifen Vorläufer- beziehungsweise Stammzellen (Bailey et al. 2004, Patschan et al. 2006a).

Eine zentrale Rolle kommt hierbei den so benannten endothelialen Vorläuferzellen (Endothelial Progenitor Cells - EPCs) zu.

Erstmals wurden EPCs 1997 von Asahara et al. als im Blut frei zirkulierende Bestandteile identifiziert. Humane $\mathrm{CD} 34^{+}$-Leukozyten wiesen nach Isolierung aus dem Blut und entsprechender Kultivierung morphologische Merkmale und Bestandteile des Oberflächenmarkerprofils von endothelialen Zellen auf. Auch funktionell erfüllten sie Kriterien von endothelialen Stammzellen: Die Zellen wurden Versuchstieren mit Ischämien in den Extremitäten injiziert. Die funktionelle Erholung des reperfundierten Gewebes schritt bei der EPC-behandelten Gruppe schneller voran, als bei der unbehandelten Kontrollgruppe. Ebenso konnten die EPCs in erhöhter Anzahl mikroskopisch an den Endothelwänden der Kapillaren des postischämischen Gewebes nachgewiesen werden (Asahara et al. 1997).

Diese und weitere Studien konnten zeigen, dass EPCs in der Lage sind, neue Gefäße zu bilden, als auch beschädigte zu reparieren und somit die Regeneration von Gewebe voran zu treiben. Damit wurde bewiesen, dass Gefäßneubildung nicht nur auf Aussprossung schon vorhandener Gefäße beruht (Angiogenese), sondern auch Gefäße postnatal de-novo gebildet werden (postnatale Neovaskulogenese) (Asahara et al. 1999, Asahara et al. 1997, Khakoo und Finkel 2005, Urbich und Dimmeler 2004a, b).

EPCs werden in zwei Hauptgruppen unterteilt:

- early Endothelial Outgrowth Cells (eEOCs)

- late Endothelial Outgrowth Cells (IEOCs) 


\subsection{1 eEOCs}

Die erste Gruppe der EPCs wird als early Endothelial Outgrowth Cells - eEOCs bezeichnet (Goligorsky et al. 2010, Lapergue et al. 2007, Povsic und GoldschmidtClermont 2008), da sie nach kurzer Zeit von fünf bis sieben Tagen in Kultur wachsen. Eine weitere Bezeichnung dieser Zellen lautet Colony Forming Unit Endothelial Cells - CFU-ECs (Case et al. 2007, Yoder et al. 2007).

Sie repräsentieren die Gruppe der vormals als "klassische“ endotheliale Vorläuferzellen (EPCs) bezeichneten Zellen.

eEOC sind innerhalb der Monozytenfraktion des Blutes zu finden (Romagnani et al. 2005) und entwickeln sich vorzugsweise aus pluripotenten hämatopoetischen Stammzellen im Knochenmark (Bailey et al. 2004, Grant et al. 2002). Ihre Konzentration wird im Verhältnis zur Anzahl aller mononukleären Zellen angegeben. Sie variiert stark zwischen Werten von $0,0001 \%$ (Ingram et al. 2005) und 12\% (Hiasa et al. 2004).

Als Vorläufer dieser Zellen werden aber auch bestimmte Subtypen von Fettzellen (Cultures Stromal-Vascular Fraction Cells - SVF-cells) (Planat-Benard et al. 2004), kardiale Progenitorzellen (Beltrami et al. 2003) und multipotente adulte Vorläuferzellen (Multipotent Adult Progenitor Cells - MAPCs) (Reyes et al. 2002, Urbich und Dimmeler 2004b) diskutiert. eEOCs besitzen sowohl Marker unreifer hämatopoetischer und endothelialer Zellen als auch reifer Endothelzellen.

Marker unreifer, also nicht enddiffenzierter Zellen, sind die Oberflächenmerkmale CD34, CD117-kit und CD133 (Rafii und Lyden 2003). Als Marker von reifen Zellen sind auf den eEOCs folgende nachzuweisen: Der humane beziehungsweise murine VEGF-Rezeptor Typ 2 („KDR / Flk-1“) (Khakoo und Finkel 2005), das Oberflächenmerkmal CD31 oder PECAM-1 („endotheliales Zelladhäsionsmolekül“) (Baldwin et al. 1994) und CD202B oder "Tie-2“, der Angiopoetin-1-Rezeptor (Wakui et al. 2006).

eEOCs lassen sich in EBM-2 Medium auf Fibronektin-beschichteten Platten (Patschan et al. 2009) in 5 bis 7 Tagen kultivieren. Zwei Verfahren eignen sich zur Isolierung, Detektion und Quantifizierung von eEOCs. Zum einen werden die in Kultur koloniebildenen Zellen im Rahmen eines Colony Forming Unit Assay auf endotheliale Marker untersucht (Heeschen et al. 2003), zum anderen können eEOCs auch durchflusszytometrisch in der Monozytenfraktion (Flourescence Activated Cell Sorter Analysis - FACS-Analyse) detektiert werden (Lambiase et al. 2004). Bei der FACS-Analyse sollen diejenigen Zellen erkannt werden, die sowohl reife, also endotheliale (KDR / Flk-1, CD31, CD202B), als auch unreife (CD34, CD117, CD133) Oberflächenmerkmale exprimieren. Dadurch wird gewährleistet, dass genau jene Zellen erfasst werden, die noch Vorläufer- beziehungsweise Stammzellcharakter aufweisen, aber schon phänotypisch in Richtung Endothelzelle differenziert sind.

In Tiermodellen zeigen eEOCs eine ischämieprotektive Wirkung. Während des postischämischen Verlaufs nach iatrogenem Herzinfarkt konnten sie in den sogenannten "Grenzzonen", den Randbereichen des infarzierten Myokards, von 
knochenmarkstransplantierten Mäusen nachgewiesen werden. Die Mehrzahl der eEOCs ließ sich eindeutig dem Spenderorganismus zu ordnen (Asahara et al. 1999, Schuster et al. 2004). Im Jahre 2004 konnte zudem gezeigt werden, dass die Konzentration von frei zirkulierenden eEOCs beim Menschen mit KHK (koronarer Herzkrankheit) vermindert ist (Adams et al. 2004, Lambiase et al. 2004). Dies könnte, trotz Fehlens eines ausnahmslos sicheren Nachweises des Einbaus von eEOCs in geschädigte Endothelwände, für einen vermehrten Verbrauch dieser Zellen für Reparaturmechanismen sprechen.

Allerdings ist davon auszugehen, dass es sich bei den eEOCs nicht um "wirkliche" endotheliale Stammzellen handelt. Sie weisen zwar proangiogene und somit ischämieprotektive Wirkungen auf (Goligorsky et al. 2010), doch fehlt erstens ein sicherer Nachweis des Einbaus dieser Zellen in ischämiegeschädigtes Endothel, und zweitens begründet sich ihre vasoprotektive Eigenschaft vor allem auf der Produktion und Sekretion proangiogener Wachstumsfaktoren: 2003 konnte gezeigt werden, dass der proangiogene Effekt von in vitro kultivierten endothelialen Stammzellen aus der Monozytenfraktion nicht aus einem direkten Einbau in Gefäßwände und Proliferation zu reifen Endothelzellen resultiert, sondern vielmehr durch die Sekretion der Wachstumsfaktoren VEGF (Vascular Endothelial Growth Factor), HGF (Hepatocyte Growth Factor), G-CSF (Granulocyte-Colony Stimulating Factor) und GM-CSF (Granulocyte Macrophage-Colony Stimulating Factor) (Rehman et al. 2003).

Diese Wachstumsfaktoren wirken den potenziell reversiblen Endothelveränderungen in vivo, wie zum Beispiel durch Anschwellen der Endothelien und somit der Lumenverengung bei ischämischen Vorgängen, entgegen (Leaf 1973, Urbich und Dimmeler 2004b). Zutreffender wird deshalb für diesen Zelltyp auch der Begriff "hämatopoetische Vorläuferzelle mit proangiogenem Potenzial“ genutzt (Case et al. 2007, Yoder et al. 2007).

\subsubsection{IEOCs}

Die zweite Gruppe der EPCs beschreibt die late Endothelial Outgrowth Cells, kurz IEOCs, da sie später, nach zwei bis drei Wochen in Kultur anwachsen (Lin et al. 2000, Moubarik et al. 2011, Murohara 2010, Wang et al. 2009, Yoder et al. 2007). Diese Gruppe von Zellen wird auch als Endothelial Colony Forming Cells - ECFCs (Yoder et al. 2007) bezeichnet.

IEOCs exprimieren nur Oberflächenmerkmale von endothelialen Zellen. Sie lassen sich ebenfalls aus der mononukleären Fraktion des Blutes isolieren, die Kultivierung gestaltet sich jedoch unterschiedlich zu der von eEOCs. Die Zellen werden in EBM-2 Medium auf Kollagen Typ 2-beschichteten Platten kultiviert (Moubarik et al. 2011, Wang et al. 2009). Ein sichtliches Zellwachstum ist erst nach zwei bis drei Wochen nachweisbar.

IEOCs, im Gegensatz zu eEOCs, sind phänotypisch den Endothelzellen ähnlicher (Lin et al. 2000), weisen mehr reife Oberflächenmerkmale auf und zeigen funktionell 
eine höhere Vaskulogeneseaktivität. Diese lässt sich in vitro eindeutig beobachten, bei In-vivo-Versuchsreihen zeigen die Zellen ein deutliches Inkorporationsverhalten in geschädigtes Endothel (Case et al. 2007, Xu 2007, Yoder et al. 2007). Ihr stärkeres proliferatives Verhalten in vitro markiert den größten Unterschied zu reifen Endothelzellen.

\subsection{EPCs beim iANV}

Die vasoprotektive Bedeutung von EPCs in ischämischen Modellen ist vor allem für die KHK erforscht. Die Datenlage für Nierenerkrankungen ist geringer. Erste Ergebnisse bezüglich der potenziellen Wirksamkeit von EPCs beim iANV wurden 2002 veröffentlicht. Yamamoto et al. konnten zeigen, dass die Applikation von reifen Endothelzellen nach beidseitiger renaler Ischämie das Auftreten eines akuten Nierenversagens verhindert (Yamamoto et al. 2002). Sie applizierten reife humane Endothelzellen (Human Umbilical Vein Endothelial Cells - HUVECs) und konnten diese in den Endothelschichten des peritubulären Gefäßsystems nachweisen. Dies deutete darauf hin, dass durch die strukturelle und funktionelle Erholung des Endothels auch die Nierenfunktion schneller wieder hergestellt werden konnte. Im gleichen Jahr konnten Brodsky et al. durch ihre Arbeit aufzeigen, dass die mikrovaskuläre Zelldysfunktion die mögliche Hauptursache für das No-ReflowPhänomen ist (Brodsky et al. 2002).

Diese Ergebnisse eröffneten eine neue therapeutische Strategie bezüglich des ischämisch bedingten akuten Nierenversagens: Es soll nach Therapiemöglichkeiten gesucht werden, die die renale Reperfusion nach einer Ischämie begünstigen. 


\section{6 eEOCs im murinen Modell des iANVs}

Das zuvor erwähnte Regenerationspotenzial von peritubulären Endothelzellen lässt sich durch die systemische Gabe von endothelialen Progenitorzellen (eEOCs) signifikant verbessern.

Den Wert dieser Progenitorzelltherapie im Rahmen des iANVs wurde im Jahr 2006 durch Patschan et al. beschrieben (Patschan et al. 2006a, Patschan et al. 2006b). Es konnte erstmals nachgewiesen werden, dass eEOCs nach passagerer renaler Ischämie vermehrt aus dem Knochenmark ausgeschwemmt werden und in der ischämisch geschädigten Niere ihre protektive Wirkung entfalten (Patschan et al. 2006a). Im Genauen führte eine 25-minütige einseitige renale Ischämie im murinen Modell zu signifikant erhöhter eEOC-Mobilisierung aus dem Knochenmark und zur Akkumulation und transienten Speicherung in der Milz. Bei ischämischer Präkonditionierung, (zweimalig 25 Minuten im Abstand von 7 Tagen) blieb die Akkumulation in der Milz aus. Ischämisch präkonditionierte Tiere zeigten im Vergleich zu nicht präkonditionierten Tieren (bei erneuter Ischämie von 25 Minuten) signifikant ausgeprägtere eEOC-Infiltrate in der medullopapillären Region der Niere. Wurden Zellen aus diesen Infiltraten isoliert und systemisch in postischämische Mäuse appliziert, blieb ein akutes Nierenversagen aus (Patschan et al. 2006a).

Die Mobilisation von eEOCs aus dem Knochenmark im Modell des iANVs wird unter anderem durch die Harnsäurekonzentration im Blut moduliert. Das Salz der Harnsäure, Natriumurat (Monosodium Urate - MSU), führt bei In-vitro- und In-vivoVersuchen über den TLR4 (Toll-Like Receptor 4) zur Exozytose von Weibel-PaladeKörperchen und somit zur eEOC-Mobilisierung (Kuo M C et al. 2008, Patschan D et al. 2007). Im Jahr 2010 konnten Patschan et al. zeigen, dass die Applikation von ex vivo entnommenden, syngenen, unbehandelten eEOCs (entweder $5 \times 10^{5}$ oder $1 \times 10^{6}$ ) bis zu einer Ischämiezeit von 35 Minuten im murinen Modell des iANVs das Auftreten eines ANVs verhindert (Patschan et al. 2010). Bei Überschreiten einer Ischämiezeit von 40 Minuten konnte ein ANV jedoch nicht mehr verhindert werden.

Dies führte zu der Aufgabenstellung, Einflussmöglichkeiten auf die Wirkweise und somit die nephroprotektiven Eigenschaften der eEOCs zu finden.

In derselben Arbeit präsentierten Patschan et al. die erste pharmakologische Möglichkeit, das nephroprotektive Potenzial der eEOCs zu verbessern: Eine Vorbehandlung von syngenen eEOCs in vitro mit dem Integrinrezeptoraktivator 8-pCPT-2'-O-Me-cAMP (8-O-cAMP) führt über eine $\beta 1$-Integrin Umverteilung an die zelluläre Oberfläche zu einer verstärkten In-vivo-Migration in die Niere, dem sogenannten Postischemic Cellular Homing, und einer größeren funktionellen Kompetenz der Zellen (Patschan et al. 2010). Dadurch konnte in jedem Fall nachgewiesen werden, dass eine gezielte pharmakologische Vorbehandlung von syngenen eEOCs in vitro, das nephroprotektive Potenzial im murinen Modell des iANVs verbessern kann.

Aufbauend auf dieser Erkenntnis konnten 2012 sowohl das Hormon Melatonin (Patschan et al. 2012a) als auch 2013 der Wachstumsfaktor Angiopoetin-1 
(Patschan et al. 2013b) und das Bone Morphogenetic Protein 5 (BMP-5) (Patschan et al. 2013c) als neue Agonisten der eEOCs im murinen Modell des iANVs identifiziert werden. Angiopoetin-2 wurde als dosisabhängiger Modulator der postischämischen Nierenfunktion identifiziert (Patschan et al. 2013a).

Eine detaillierte Darstellung der Wirkweise der benannten Mediatoren soll an dieser Stelle nicht erfolgen.

Die hier vorliegende Arbeit zielte darauf ab, weitere stimulierende pharmakologische Substanzen zu finden, die den nephroprotektiven Effekt von eEOCs begünstigen, um somit das therapeutische Potenzial beim iANV weiter zu stärken. 


\subsection{Peroxisomen und PPARs}

Säugetier-Peroxisomen sind subzelluläre Organellen von 0,1-0,5 $\mu \mathrm{m}$ Größe, die unter anderem Enzyme für den Fettstoffwechsel und für den Abbau reaktiver Sauertoffspezies (ROS) beinhalten. Die höchste Dichte findet sich in der Leber und der Niere. In enger funktioneller Beziehung zu den Mitochondrien bilden Peroxisomen durch $\beta$-Oxidation von Fettsäuren Energie in Form von ATP. Die Peroxisomen dienen dem Abbau von sehr langkettigen Fettsäuren (Very Long Chain Fatty Acids - VLCFAs) von mehr als 22 Kohlenstoffatomen zur weiteren Metabolisierung in den Mitochondrien. Im Rahmen der peroxisomalen $\beta$-Oxidation ensteht Wasserstoffperoxid, eine ROS. Deshalb befindet sich in der peroxisomalen Matrix, neben weiteren ROS-abbauenden Enzymen, das Enzym Katalase, welches das aggressive Wasserstoffperoxid zu Wasser und Sauerstoff umwandelt (Schmidt, Lang, Heckmann 2010). Mit Hilfe der antioxidativen Schutzenzyme kann der Parenchymschädigung durch die vermehrte ROS-Bildung bei Reperfusion postischämischer Gewebe entgegen gewirkt werden.

Die Abkürzung PPAR steht für Peroxisome Proliferator-Activated Receptor, zu deutsch „Peroxisom-Proliferator-aktivierter Rezeptor". Dieser Ausdruck entstand, weil die Aktivierung dieser intrazellulären Rezeptoren über sogenannte „PeroxisomProliferatoren" zur mengen- und größenmäßigen Zunahme von Peroxisomen führt.

PPARs gehören zur Steroidrezeptor-Familie und wirken intrazellulär am Zellkern als Transkriptionsfaktoren (Brown und Plutzky 2007). Alle PPARs entfalten ihre Effekte nach Aktivierung durch spezifische Liganden / Agonisten, durch Heterodimer-Bildung mit dem ebenfalls aktivierten Retinoid-X-Rezeptor / Retinsäure-X-Rezeptor (RXR) (DiRenzo et al. 1997, Latruffe et al. 2001, Rakhshandehroo et al. 2010) an einer speziellen DNA-Sequenz, dem PPAR Response Element - PPRE. Eine PPARAktivierung nimmt dementsprechend über die Transkription bestimmter Gene auf „ihre Ziele“ Einfluss.

Diese Genprodukte sind vorwiegend an der Adipogenese, Lipidmetabolisierung, Glukosehomöostase und Insulinsensitivität, an Zellproliferation und -differenzierung sowie an Immun- und Entzündungsreaktionen beteiligt. 


\subsubsection{PPAR-Subtypen}

Bis jetzt sind drei eng verwandte Subtypen identifiziert: PPAR $\alpha, P P A R \beta / \delta$ und PPARY.

PPARa kommt vorwiegend in Hepatozyten, in der Nierenrinde und vereinzelt auch in Kardiomyozyten, Skelettmuskelzellen und Enterozyten vor (Braissant et al. 1996). PPARa zeigt positive Einflüsse auf den Fettstoffwechsel und hat unter anderem eine antiinflammatorische Wirkung (Arakawa et al. 2005, Brown und Plutzky 2007, Frederiksen et al. 2004, Nakaya et al. 2011). Im Kapitel 2.7.2 wird eingehend über PPARa berichtet.

PPARy kommt vor allem in Adipozyten, in kleiner Zahl auch in Skelettmuskelzellen, Hepatozyten, in Mesangienzellen der Niere, in der Harnblase, den Brustdrüsen, dem Darm und immunkompetenten Zellen, wie Makrophagen, B- und T-Lymphozyten vor. PPARy moduliert grundlegend den Energiebedarfs-Metabolismus durch Steigerung der Insulinsensitivität, der Glukoseaufnahme und Adipozyten-Differenzierung (Yki-Jarvinen 2004) und ist an Entzündungsprozessen beteiligt. Eine Mutation an der Ligandenbindungsstelle von PPARy führt zu einem Syndrom mit der Trias aus Insulinresistenz, Diabetes mellitus und Hypertension. Die selektive PPARYAgonisten-Stoffklasse der Glitazone, oder Thiazolidindione, werden zur Behandlung des Typ-2 Diabetes verwendet, da sie die Glukoseaufnahme aus dem Blut fördern (Berger et al. 2005). Unerwünschte Nebenwirkungen wie Gewichtszunahme, Wasserretention und periphere Ödeme sind zu verzeichnen. Ein weiterer Agonist ist das 15dPGJ2 (Cyclopentenon-15desoxy-Prostaglandin J2), ein Prostaglandin D2Derivat (PGD2). Zusammenfassend lässt sich die antiinflammatorische Wirkung von PPARy durch die Verringerung der Freisetzung von funktionsfähigen Zytokinen aus, und verringerten Expression der induzierbaren Stockstoffmonooxid Synthase (inducible Nitric Oxide Synthase - iNOS) durch Makrophagen, der möglichen Apoptoseinduktion derselben und der verringerten Freisetzung von MatrixMetalloproteinasen aus Monozyten beschreiben.

PPAR $\beta / \delta$, in aktuellerer Literatur häufig nur noch als PPAR $\delta$ bezeichnet, kommt in kleiner Zahl ubiquitär vor. Dies könnte ein Ausdruck der potenziell fundamentalen Rolle dieses Rezeptors in der zellulären Biologie darstellen. PPAR $\beta / \delta$ erhöht den Energieverbrauch und moduliert Gene des allgemeinen Metabolismus, vor allem die der $\beta$-Oxidation und der adaptiven Thermogenese. Eine Überexpression von PPAR $\beta / \delta$ kann zu Gewichtsverlust und Schutz vor Dyslipidämie nach hochkalorischer und fettreicher Diät führen (Wang et al. 2003). Selektive PPARß/סAgonisten sind zur Zeit nicht in klinischer Erprobung oder Einsatz, aber Bezafibrat, ein unselektiver Agonist an allen PPAR-Rezeptoren, hat potenziell positive Einflüsse auf den Stoffwechsel: Die durch PPARy verursachte Gewichtszunahme scheint durch PPAR $\beta / \delta$ kompensiert zu werden (Dressel et al. 2003, Tenenbaum und Fisman 2012). 


\subsubsection{PPARa}

In dieser Arbeit wurden die Effekte von PPARa-vorbehandelten eEOCs auf die postischämische Nierenfunktion im murinen Modell des iANVs erforscht.

Es hat sich gezeigt, dass PPARa der Hauptregulator der Aktivierung und Proliferation von Peroxisomen darstellt (Vasko 2016).

Wie bereits zuvor erwähnt, wird PPARa vorwiegend in Hepatozyten, in der Nierenrinde und vereinzelt auch in Kardiomyozyten, Skelettmuskelzellen und Enterozyten exprimiert (Braissant et al. 1996). Dies sind alles Zellen von Organen mit einer hohen Rate an mitochondrialem und katabolem Fettsäuremetabolismus ( $\beta$-Oxidation). Ebenso wird dieser Rezeptor sowohl auf undifferenzierten Monozyten, als auch auf reifen Makrophagen exprimiert. Dies markiert einen Unterschied zu PPARy, der nur auf reifen Makrophagen vorkommt.

In der Niere wird PPARa vorwiegend in den Endothelzellen der proximalen Tubuli, den medullären Anteilen der dicken aufsteigenden Schenkel der Henle-Schleife und in weitaus geringerer Rate in den Mesangiumzellen der Glomeruli exprimiert (Guan et al. 1997, Ruan et al. 2003). PPARy wird vor allem im Sammelrohr, aber auch in den Mesangiumzellen exprimiert. Die Verteilung lässt Rückschlüsse auf ihre Bedeutung im Wasser- und Natriumhaushalt sowie bei der Regulation des Blutdruckes vermuten.

PPARa wird pharmakologisch durch die Substanzklasse der Fibrate aktiviert (Issemann und Green 1990) und zeigt positive Einflüsse auf den Fettstoffwechsel, weshalb die Fibrate in der Therapie von dyslipidämischen Patienten eingesetzt werden. Weitere Agonisten sind das Leukotrien B4 (LTB4), mehrfach ungesättigte Fettsäuren, deren Derivate, die Eikosanoide (Wardle 2004), wie zum Beispiel das Prostazyklin $\left(\mathrm{PGI}_{2}\right.$ ) (Chen et al. 2009) und weitere. Die Agonisierung durch Fibrate und andere Liganden hat pleiotrope Effekte. Sie kann zusätzlich zu den Liganden / Agonisten durch Koexpressoren und Korepressoren moduliert werden. Koexpressor ist zum Beispiel das CREB-Bindeprotein (CAMP Response Element-binding Protein, kurz CBP, oder p300), das durch Histon-Acetyl-Transferase-Aktivität (HAT) zur Chromatindekondensation und Heterodimerisierung von PPARa mit RXR führt. Korepressor ist zum Beispiel das NCoR (Nuclear Receptor Corepressor-1), welches durch verstärkte Wechselwirkung mit SUMOylierten PPARas zu einer verringerten Transkriptionsaktivität führt (Pourcet et al. 2010).

\subsubsection{Wirkweise}

\subsection{Fettsäuremetabolismus}

Die Effekte von PPARa auf den Lipidmetabolismus sind vielfältig und sollen an dieser Stelle nur zusammenfassend erörtert werden.

Die PPARa-Aktivierung führt intrazellulär zur vermehrten Bereitstellung von Fettsäure-Transportproteinen sowie diversen Enzymen, unter anderem der der ß-Oxidation (Dreyer et al. 1992, Gulick et al. 1994, Muerhoff et al. 1992, Tugwood et 
al. 1992) und welchen, die das Wiederaustreten der Fettsäuren aus der Zelle verhindern (Martin et al. 1997). Durch die Induktion der $\beta$-Oxidation wird grundsätzlich die Todesrate der Zellen durch Energiebereitstellung in Form von ATP aus $\mathrm{FADH}_{2}, \mathrm{NADH}+\mathrm{H}^{+}$und Acetyl-CoA verringert (Cheng et al. 2010). Extrazellulär hat die PPARa-Aktivierung zur Folge, dass die Lipoproteinlipase verstärkt aktiv ist, die die TGZ-Konzentration in den Very Low Density Lipoproteins (VLDLs) durch Hydrolyse verringert und die Fettsäuren so dem weiteren Stoffwechsel zur Verfügung stellt (Brown und Plutzky 2007, Schoonjans et al. 1996). Hinzukommend wird das HDL-Angebot erhöht (Vu-Dac et al. 1995, Vu-Dac et al. 1994) und die Cholesterinspeicher aus der Peripherie mobilisiert (Arakawa et al. 2005, Chinetti et al. 2001, Nakaya et al. 2011).

In der Zusammenschau erscheint PPARa als patenter Modulator des Fettsäurestoffwechsels, der zur Energiegewinnung beiträgt.

\subsection{Antiapoptotische und proangiogenetische Wirkung}

Verschiedene Signaltransduktionswege können die Apoptose erwirken. Für diese Arbeit von Belang sind das Zytokin TGF- $\beta$, der Tumornekrosefaktor alpha (TNF- $\alpha$ ) und allgemein die schädigende Wirkung der bereits beschriebenen ROS.

Das Zytokin TGF- $\beta$ aus der Familie der transformierenden Wachstumsfaktoren (Transforming Growth Factor - TGF) reguliert grundlegende Zellfunktionen in der Embryogenese und im adulten Organismus. Die Wirkweise ist stark von Art und Differenzierungsgrad der Zellen abhängig. Zusammengefasst reguliert TGF- $\beta$ die Proliferation, Differenzierung, Apoptose und Adhäsion von Zellen. Im Detail wirkt TGF- $\beta$ über die intrazellulären SMAD-Moleküle 2 und 3 durch Komplexbildung mit SMAD-4 proapoptotisch (Schuster und Krieglstein 2002). Die fibratbedingte PPARaAktivierung führt unter anderem zur Hemmung der TGF- $\beta$-Signalkaskade durch Suppression der TGF- $\beta 1$-, SMAD-3- und TGF- $\beta$-Rezeptor-2-Überexpression (Li et al. 2010) und soll so dem programmierten Zelltod entgegen wirken.

Hinzukommend führt die PPARa-Aktivierung zu einer verringerten Produktion von TNF- $\alpha$. Dies hat ebenfalls einen antiapoptotischen Effekt (Chen et al. 2009, Gilde et al. 2003). Das Zytokin TNF- $\alpha$ ist bei lokalen und systemischen Entzündungsreaktionen beteiligt und hat Einfluss auf die Aktivität verschiedener Immunzellen, auf die Zellproliferation und -differenzierung sowie auf apoptotische Vorgänge und das Migrationsverhalten von neutrophilen Granulozyten.

Die Proliferation und Differenzierung von Peroxisomen wird bekanntermaßen durch PPARa maßgeblich geregelt, wodurch die Agonisierung des Rezeptortypes indirekt zu einer erhöhten funktionellen Kompetenz gegenüber hoher Konzentrationen von ROS führt. Durch die Aktivierung der peroxisomalen antioxidativen Enzyme Superoxiddismutase, Gluthathionperoxidase und des Schlüsselenzyms Katalase werden die proapoptotischen ROS abgebaut (Vasko 2016). 


\subsection{Entzündungshemmende Wirkung}

PPARa ist vorwiegend als Modulator im Fettsäurestoffwechsel bekannt, jedoch scheint die antiinflammatorische Komponente seiner Wirkweise von größerer Bedeutung zu sein, als bisher angenommen. Im Rahmen des I/R-Modells wird die entzündungsfördernde Wirkung der aus Zellmembranen freigesetzten Eikosanoide durch die Zunahme von Eikosanoiden-abbauenden Leberenzymen gehemmt. Auf zellulärer Ebene wirkt die PPARa-Aktivierung, überwiegend auf die Wechselwirkungen zwischen Leukozyten, Makrophagen, Monozyten und Endothelzellen: Die Freisetzung von Protein-hydrolysierenden MatrixMetalloproteinasen (MMPs) aus Monozyten und Makrophagen wird gehemmt (Shu et al. 2000). Zusätzlich können Makrophagen, bei PPARa-Aktivierung und gleichzeitigem Vorliegen von entzündungsbedingt erhöhten TNF- $\alpha$ - und INFYKonzentrationen, durch das Interferieren mit dem NF-KB survival pathway (Nuclear Factor "kappa-light-chain-enhancer" of activated B-cells) (Chinetti et al. 1998) apoptotisch werden. Hinzukommend produzieren die Endothelzellen weniger TNF- $\alpha$ und die Expression von proinflammatorischen Zytokinen und Adhäsionsmolekülen (ICAM-1 und VCAM-1), mit konsekutiv geringerer Rekrutierung von neutrophilen Granulozyten, führt zu einer kleineren Entzündungsreaktion im (peritubulären) Interstitium (Delerive et al. 1999). Ebenso hat die Aktivierung dieses RezeptorSubtypes Einfluss auf die Lipid-Homöostase des gesamten MakrophagenMonozyten-Systems (MMS), einem Teil des mononukleär-phagozytierenden Systems (MPS).

Die verstärkte Bildung der eNOS und folglicher Stickstoffmonooxid-Freisetzung aus Endothelzellen hat vasoprotektiven Charakter (Wardle 2004). Allgemeinhin ist bekannt, dass Stickstoffmonooxid zur Vasodilatation beiträgt und somit zu einer vermehrten Perfusion führen kann.

Die Bildung von IL-6 und Tissue Factor (TF, Gewebethromboplastin, Faktor 3) auf drei Zelltypen, namentlich auf Endothelzellen, glatten Muskelzellen und Makrophagen, wird gehemmt. Zusätzlich wird die durch Thrombin und oxigeniertes LDL induzierte Expression von Endothelin-1 gehemmt (Gilde et al. 2003). Die Aktivierung und somit entzündungsfördernde Wirkung von sogenannten VSMCs (Vascular Smooth Muscle Cells) durch IL-1 induzierte Produktion von IL-6 und Prostaglandinen wird gehemmt und durch reduzierte Expression der COX-2 moduliert.

Zusammengefasst führt die Aktivierung dieses Rezeptortypes zu weniger Rekrutierung von Leukozyten und deren Adhäsion an Endothelzellen, Zytokinproduktion und -freisetzung (IL-2, IL-6, TNF- $\alpha$ und INFy) und hat Einfluss auf das Überleben und die Funktion von Makrophagen und des gesamten MakrophagenMonozyten-Systems. 


\subsubsection{Klinische Studien und Auswirkung der PPARa-Aktivierung auf renale Pathologien}

Die in Kapitel 2.7.2 ausführlich dargestellten Effekte können in klinischen Studien reproduziert werden.

Neuere Studien schaffen einen Zusammenhang zwischen PPARa-Aktivierung und dem Auftreten von Hypertension, metabolischen Störungen, kardiovaskulären Krankheiten, Atherosklerose und entzündungsbedingtem ANV (Robinson und Grieve 2009).

Durch Agonisierung von PPARa kann dessen entzündungshemmende Wirkung durch Senkung der Plasmakonzentration von IL-2, IL-6, TNF- $\alpha$ und INFY bei Patienten mit Atherosklerose (Gilde et al. 2003) und niedrigerem CRP bei Patienten mit kardiovaskulären Erkrankungen (Zambon et al. 2006) nachvollzogen werden.

Den grundsätzlich protektiven Nutzen von PPARa zeigen nicht nur Studien der Aktivierung, sondern auch Untersuchungen mit PPARa-knock-out-Mäusen. Diese weisen eine deutlich höhere Albuminkonzentration im Urin und in den proximalen Tubuluszellen im warmen I/R-Modell auf (Chen et al. 2009). Daraus lässt sich schlussfolgern, dass das Vorliegen von PPARa und dessen Aktivierung zu einer leichteren Albuminabsorption und -abbau in diesem Nephronsegment führt (Calkin et al. 2006, Liao et al. 2010).

Die Auswirkungen auf die Nierenfunktion wurde für die PPARa-Aktivierung vor allem in Modellen des chronischen Schadens, wie zum Beispiel im Rahmen von Studien bezüglich der diabetischen Nephropathie erforscht. Hier wurde die Albuminurie als Marker des chronischen renalen Schadens verwendet.

Tierexperimentelle und klinische Studien zeigen den Nutzen in der Therapie der diabetischen Nephropathie mit Fibraten: Typ-2-diabetogene Mäuse zeigen bei Fibrattherapie eine niedrigere Albuminkonzentration im Urin und eine bessere also geringere mesangiale Zellexpansion (Park et al. 2006).

In diesem Diabetesmodell konnte auch der TGF- $\beta$ induzierte Mesangiumzellschaden verringert werden: Die fibratinduzierte PPARa-Aktivierung hat zur Folge, dass die Glomerulusmatrix weniger proliferiert, da das ROS-induzierte Anschwellen der Mesangiumzellen abgeschwächt (Wilmer et al. 2002) und somit die Nierenfunktion, gemessen an der Albuminurie verbessert wird (Park et al. 2006).

Zugrunde liegt diesem Umstand die fibratbedingte Hemmung der TGF- $\beta$ Signalkaskade, im Detail durch Herunterregeln der TGF- $\beta 1$-, SMAD-3- und TGF- $\beta$ Rezeptor-2-Überexpression und verringerter Kollagen-4-Ablagerung in den Zellen (Li et al. 2010). 
Zwei große klinische Studien bezüglich der Wertigkeit von Fibraten auf das kardiovaskuläre Risiko von Typ-2-Diabetikern zeigten gute Ergebnisse:

Die FIELD-Studie (Fenofibrate Intervention and Event Lowering in Diabetes) zeigte vielversprechende Ergebnisse bezüglich der Prävention der Progression von diabetesinduzierten mikrovaskulären Folgeerkrankungen, wie zum Beispiel das Auftreten einer KHK, von nicht-tödlichen Myokardinfarkten oder Schlaganfällen (Keech et al. 2005, Scott et al. 2005, Scott et al. 2009).

Der Schaden durch chronisch erhöhte Blutzuckerwerte auf die Niere ist ebenso mikrovaskulärer Natur. Die Vermutung liegt dementsprechend nahe, dass auch die diabetische Nephropathie in inrer Progression verlangsamt bis aufgehalten werden könnte. Diese Annahme wird durch die Ergebnisse der ACCORD-Studie gestützt.

Die ACCORD-Studie (Action to Control Cardiovascular Risk in Diabetes) kam zwar zu keinem durchweg positiven Ergebnis, da das Risiko für kardiovaskuläre Folgeerkrankungen durch die Fibrattherapie nicht signifikant gesenkt werden konnte (Wierzbicki 2010), aber sie hat gezeigt, dass bei ausreichender Kontrolle des Blutglukosewertes die Mikroalbuminurie durch die Gabe von Fibraten signifikant gesenkt werden kann (Ismail-Beigi et al. 2010).

Allen In-vivo-Versuchsreihen und klinischen Studien ist eines gleich: Sie quantifizieren den renalen Schaden anhand der Konzentration von Albumin im Urin. $\mathrm{Da}$ die Mikroalbuminurie ein Marker renalen und vaskulären Schadens darstellt (Cerasola et al. 2010), erhärtet sich die Vermutung, dass durch die Therapie mit Fibraten, konsekutiv also die Agonisierung von PPARa, die morphologischen und funktionellen Nierenfunktionseinschränkungen verbessert werden könnten.

Akute Nierenschädigungen wie im Rahmen dieser Arbeit bildeten bis dato seltener die Grundlage einer solchen Fragestellung. Als Marker des akuten renalen Schadens wurde, wie auch in dieser Arbeit, die Kreatininkonzentration im Serum verwendet.

Grundsätzlich lässt sich festhalten, dass die PPARa-Aktivität durch einen Ischämie-Reperfusionsschaden, wie er beim iANV auftritt, verringert wird (LopezHernandez und Lopez-Novoa 2009, Sivarajah et al. 2002). Dies führt vor allem bei der Reperfusion und vermehrten Bildung von ROS zu erheblichen Konsequenzen.

Im Rahmen eines durch Cisplatin verursachten ANVs im Tiermodell können zwei Aussagen fest gehalten werden: Zum einen kann eine geringere PPAR $\alpha$-Expression und Transkriptionsaktivität sowie die Hemmung von Enzymen der $\beta$-Oxidation bei Vorliegen des ANVs nachgewiesen werden (Lopez-Hernandez und Lopez-Novoa 2009), zum anderen zeigen Studien eine Reduktion der Nierenschädigung durch PPARa-Aktivierung in diesen Modellen (Li et al. 2004, Portilla et al. 2000).

Für diese Arbeit von großem Interesse sind die Veröffentlichung von Chen et al., Patel et al. und Sivarajah et al., die zeigen konnten, dass mittels PPARa-Aktivierung durch direkte, systemische Applikation von Agonisten in ein Versuchstier eine durchweg verbesserte postischämische Nierenfunktion erreicht werden kann: Die 
Nierenfunktion von Wildtypmäusen im l/R-Modell wurde durch die direkte intraperitoneale Injektion der ungesättigten Docosahexaensäure (DHA) und Fenofibrat signifikant verbessert. Dies zeigte sich durch niedrigere Serumkreatininkonzentratioen (Chen et al. 2009, Patel et al. 2009). In-vitro-Versuche zeigen, dass durch die Applikation von Prostazyklin $\left(\mathrm{PGI}_{2}\right)$ der Zellschaden durch Apoptose begrenzt (geringere Anzahl an apoptotischen Zellen und Apoptose-Aktivität, gemessen an der Caspase-3 und -8 Aktivität) und die TNF-a-Überexpression verringert ist (Chen et al. 2009). Genauso führt die direkte Applikation von Clofibrat und Pirinixic-Säure (WY14643) bei Ratten zu einer signifikant geringeren Serumkreatininkonzentration (Sivarajah et al. 2002).

Allen Versuchen ist gemeinsam, dass in PPARa-knock-out-Mäusen keine signifikante Verbesserung der Nierenfunktion durch Verabreichen von Agonisten erreicht werden konnte. Somit liegt die Ursache der Verbesserung bei den durch PPAR a induzierten Genprodukten und nicht bei den pharmakologischen Agonisten.

Bis jetzt finden sich noch keine klinischen Studien auf die rein renale Auswirkung der Fibrattherapie bei akuten Nierenschädigungen, jedoch zeigen die Studien bezüglich chronischer Veränderungen erfreuliche Ergebnisse, die zur optimistischen Sichtweise auf den Nutzen der Fibrattherapie bei akuten Geschehen führen. 


\subsection{Erläuterung und gezielte Fragestellung}

Den größten Unterschied zwischen den zuvor beschriebenen Veröffentlichungen und der hier vorliegenden Arbeit markiert die Nutzung von nicht enddifferenzierten Vorläuferzellen.

In dieser Arbeit wurde nicht der gesamte, endogene PPARa-Pool durch systemische, direkte Applikation von Agonisten in das Versuchstier aktiviert, sondern der von angezüchteten endothelialen Vorläuferzellen. Somit wurde sich auf die Wirkweise von PPARa auf Endothelvorläuferzellen beschränkt und nicht alle möglichen Wirkmechanismen der PPARa-Aktivierung ausgenutzt. Es wurde davon ausgegangen, dass die PPARa-Agonisierung von eEOCs die gleichen Effekte zur Folge hat wie die von reifen Endothelzellen. Über diesen „indirekten“ Weg sollte die Nierenfunktion moduliert und nach Möglichkeit verbessert werden.

Grundannahme für diese Arbeit war die Vorstellung, eine bessere postischämische Nierenfunktion zu erhalten, wenn die bereits nachgewiesenen und reproduzierbaren nephroprotektiven Eigenschaften von eEOCs und die antiapoptotischen und antiinflammatorischen Effekte von PPARa kombiniert würden. Um dies zu erreichen, wurden die eEOCs vor der systemischen Applikation mit PPARa-Agonisten, den Fibraten inkubiert.

An dieser Stelle sei noch einmal erwähnt, dass im reperfundierten postischämischen Organ, neben dem vaskulären No-Reflow-Phänomen (Angriffspunkt der eEOCTherapie) eine ausgeprägte Entzündungsreaktion (Angriffspunkt der PPARaTherapie) abläuft, die unter anderem durch die hohe Konzentration von ROS unterhalten wird.

Wie in der Einleitung bereits erwähnt, gliedert sich diese Arbeit in zwei Versuchsreihen. Eine In-vivo-Tierversuchsreihe und drei In-vitro-Versuche.

Im Rahmen der In-vivo-Versuchsreihe wurde speziell analysiert, ob durch pharmakologische Aktivierung von PPARa, agonisiert durch Feno- und Clofibrat, eine Modulation der eEOC-vermittelten Nephroprotektion im murinen Modell beim iANV erzielt werden kann. Die Qualität der Behandlung, also die postischämische Nierenfunktion nach simuliertem iANV, wurde mittels Kreatininbestimmung im Serum ermittelt.

In der In-vitro-Versuchsreihe sollten die Auswirkungen auf zellulärer Ebene vertiefend analysiert werden. Um einen genaueren Eindruck der zellulären Konsequenzen einer Fibrat-Behandlung von eEOCs zu erhalten, wurden drei Parameter an kultivierten Zellen erhoben:

- Migrationsverhalten,

- Zellüberleben sowie

- Proangiogenität durch Freisetzung des Mediators VEGF (Vascular Endothelial Growth Factor - VEGF). 
Folgenden Fragen wurde in dieser Arbeit nachgegangen:

- Wird das nephroprotektive Potenzial von eEOCs durch eine Vorbehandlung mit Fibraten in vitro überhaupt beeinflusst und wenn ja, in welcher Weise?

- Kommt es zu funktionellen Veränderungen im murinen Modell des iANVs ?

- Wird das Migrationsverhalten der eEOCs beeinflusst und wenn ja, in welcher Weise?

- Wird das Überleben der eEOCs beeinflusst und wenn ja, in welcher Weise ?

- Wird die proangiogene Wirkung der eEOCs beeinflusst und wenn ja, in welcher Weise? 


\section{Material und Methoden}

\subsection{In-vivo-Tierversuchsreihe: Postischämische Nierenfunktion}

Bei der Datenerhebung handelte es sich um ein tierexperimentelles Verfahren. In allen In-vivo-Versuchen wurde mit 8 - 12 Wochen alten, männlichen C57BI/6NMäusen (Jackson Laboratory; Bar Harbor; USA) gearbeitet, die im universitären Tierstall gezüchtet wurden. Dort lebten die Tiere im zwölfstündlichen Tag-und-NachtRhythmus mit freiem Zugang zu Wasser und Futter.

Über die gewissenhafte Handhabung der Tiere und korrekte Ausführung der im Folgenden erläuterten Operationschritte überzeugte sich zudem noch der Tierschutzbeauftragte der Universitätsmedizin Göttingen Herr Professor Dr. rer. nat. H. Jarry persönlich.

\subsubsection{In-vivo-eEOC-Kultur}

Die Materialgewinnung von murinem Blut und Milz erfolgte im tierexperimentellen Operationsbereich der Universitätsklinik Göttingen. Die Zellkulturen, deren Isolation und Weiterverarbeitung erfolgte unter sterilen Bedingungen auf einer dafür ausgelegten Sterilbank im Labor der Arbeitsgruppe von Herrn Prof. D. Patschan. Das Vorgehen diente der Bereitstellung von syngenen eEOCs zur Applikation im Rahmen des In-vivo-Versuches.

\subsubsection{Materialgewinnung}

Die für die Kulturen benötigten murinen Zellen wurden aus Blut und Milz gewonnen.

Den Mäusen wurden zur Anästhesie 300-400 $\mu$ l eines Kombinationspräparates aus Ketamin und Xylazine der Firma SIGMA - ALDRICH $(10 \mathrm{ml}$ enthalten $800 \mathrm{mg}$ Ketamine $\mathrm{HCl}$ und $120 \mathrm{mg}$ Xylazine $\mathrm{HCl}$; Kat.-Nr.: K-113) in die Peritonealhöhle des rechten unteren Quadranten nach vorheriger Aspiration injiziert. Die Injektionslösung bestand aus $6,8 \mathrm{ml} 0,9 \% \mathrm{NaCl}$ und $520 \mu \mathrm{l}$ des Präparates.

Bis zum Eintreten einer tiefen Sedierung nach 10 bis 15 Minuten wurden die Mäuse in einen separaten und verdunkelten Käfig gesetzt.

Anschließend wurden die Mäuse rücklings auf einer Styroporplatte mit Klebestreifen an den Extremitäten und dem Schwanz fixiert. Der Operateur saß am Fußende. Das Fell am Bauch wurde mit einem Hautdesinfektionsmittel befeuchtet. Die Tiefe der Sedierung wurde durch Kneifen in den Schwanz kontrolliert.

Das Abdomen wurde mittels einer medianen Laparotomie beginnend auf Höhe der Blase, mit Schnittführung von kaudal nach kranial eröffnet und das Diaphragma dargestellt. 
Das Blut wurde mit einer 1-ml-Insulinspritze der Firma BD (Insulinspritze safetyglide; $1 \mathrm{ml}$; Kat.-Nr.: 305930) transdiaphragmal aus dem schlagenden Herzen gewonnen. Angestrebt wurde eine Menge von circa 400-500 $\mu$ l. Zur Gerinnungshemmung enthielt die Spitze einen Tropfen Heparin (Heparin-Natrium 25000; Firma RATIOPHARM; Kat.-Nr.: N21086.21-Z04). Anschließend wurde die Maus durch Durchtrennung des Diaphragmas getötet.

Nachfolgend wurde die Milz präpariert, in ein 15-ml-Röhrchen der Firma SARSTEDT $(15 \mathrm{ml}$; unsteril; Kat.-Nr.: 62.554.502) mit $2 \mathrm{ml}$ EBM-2-Medium (EBM-2-Medium; Endothelial Basal Medium-2; Firma LONZA; Kat.-Nr.: CC-3156) überführt und anschließend mit dem Spritzenkolben homogenisiert.

Homogenisierte Milz und Blut wurden auf Eis gekühlt ins Labor gebracht.

\subsubsection{2 eEOC-Kultur}

Unter sterilen Bedingungen wurden die homogenisierte Milz und das Vollblut in 50-ml-Röhrchen der Firma SARSTEDT (50 ml; steril; Art.-Nr.: 62.547.254) überführt und mit $4 \mathrm{ml}$ Biocoll-Lösung überschichtet (Biocoll-separation-solution der Firma BIOCHROM AG; Dichte 1,077 g/ml; Katalog Nr.: L6115).

Anschließend wurde bei $4{ }^{\circ} \mathrm{C}$ für 30 Minuten mit $1400 \mathrm{U} / \mathrm{min}$ ohne Bremse zentrifugiert (Zentrifuge der Firma Beckmann; Typ: G5-6R). Die hierbei abgetrennte mononukleäre Zellfraktion (Mononuclear Cells - MNCs) wurde mit einer 1-ml-Pipette der Firma EPPENDORF ab- und in ein neues 50-ml-Röhrchen umpipettiert. Die Zellen wurden danach in $10 \mathrm{ml}$ EBM-2-Medium resuspendiert.

Anschließend wurden die Zellen im Röhrchen bei $4{ }^{\circ} \mathrm{C}$ für 10 Minuten mit $1400 \mathrm{U} / \mathrm{min}$ mit Bremse zentrifugiert (Zentrifuge der Firma Beckmann; Typ: G5-6R), der Überstand abgenommen und die Zellen mit $2 \mathrm{ml}$ EBM-2-Medium resuspendiert. Dieser Vorgang wurde noch einmal wiederholt.

Eine Neubauerkammer diente zum Zählen der Zelldichte, welche auf $5 \times 10^{6} \mathrm{MNCs}$ in $2 \mathrm{ml}$ EBM-2-Medium reguliert wurde.

Abschließend wurden je $2 \mathrm{ml}$ der Zelllösung ( $5 \times 10^{6} \mathrm{MNCs}$ in $2 \mathrm{ml} \mathrm{EBM-2-Medium)}$ in jeweils eine Vertiefung einer mit Fibronectin (Firma SIGMA-ALDRICH; Kat.-Nr.: F0895-1MG) beschichteten 24-well-Platte (24 Well Cell Culture Plate; Firma GREINER BIO-ONE; steril; Kat.-Nr.: 662160) pipettiert und bei $37{ }^{\circ} \mathrm{C}$ und $5 \% \mathrm{CO}_{2}$ im Wärmeschrank der Firma W. KRANNICH (Wärmeschrank der Firma W. KRANNICH GmbH \& Co KG; Göttingen; Deutschland; Fabrikat: IR Sensor) inkubiert.

Die Zellen wurden für insgesamt $6-7$ Tage bis direkt vor der eigentlichen Operation inkubiert. Nach den ersten zwei Tagen wurden nichtadhärente Zellen verworfen und altes durch frisches EBM-2-Medium (2 ml) ersetzt. 


\subsubsection{Inkubation mit Fibraten}

Nach 6 - 7 Tagen Inkubation wurden die herangezüchteten Zellen mit der Stimulationslösung vorbehandelt.

Dazu wurden die Zellen von der Platte abgeschabt, samt Medium für 10 Minuten mit $1400 \mathrm{U} / \mathrm{min}$ zentrifugiert (Zentrifuge der Firma Beckmann; Typ: G5-6R). Anschließend wurde der Überstand abpipettiert und die Zellen mit PBS der Firma GIBCO (PBS; pH-Bereich 7,4 +/- 0,05; Kat.-Nr.: 10010-015) gewaschen. Nach abermaliger Zentrifugation und Verwerfen des Überstandes wurden die Zellen mit der jeweiligen Stimulationslösung, bestehend aus $2 \mathrm{ml}$ EBM-2-Medium und der jeweiligen Fibratlösung, bei $37^{\circ} \mathrm{C}$ für eine Stunde in einem 15-ml-Röhrchen inkubiert.

Zum Einsatz kam Fenofibrat der Firma SIGMA-ALDRICH (Konzentration: $100 \mathrm{mM}$; Kat.-Nr.: F6020) und Clofibrat der Firma SIGMA-ALDRICH (Konzentration: 4,7 M; Kat.-Nr.: C6643).

Die pulverförmigen Fibrate wurden zuerst mittels Dimethylsulfoxid $(250 \mathrm{ml}$ DMSO; Firma SERVA; Kat.-Nr.: 20385) gelöst und dann mit der Zelllösung zusammen geführt, sodass die Zellen in einer $50-\mu \mathrm{M}$-Fenofibratlösung und in einer 1-mM-Clofibratlösung inkubiert wurden.

Nach einer Stunde wurden die Zellen erneut für 10 Minuten mit $1400 \mathrm{U} / \mathrm{min}$ abzentrifugiert und so in EBM-2-Medium resuspendiert, dass sie in einer Konzentration von $5 \times 10^{5}$ eEOCs je $50 \mu \mathrm{l}$ EBM-2-Medium vorlagen.

Dann wurden die Zellen auf die Injektionsspritze (Insulinspritze safetyglide; Firma BD; 1 ml; Kat.-Nr.: 305930) aufgezogen.

\subsubsection{Zellmarkierung}

Die Zellmarkierung mittels Cell tracker ${ }^{\circledR}$ erfolgte grundsätzlich nach der Inkubation mit den Fibraten, aber vor der Resuspension auf $5 \times 10^{5}$ eEOCs je $50 \mu \mathrm{l}$ EBM-2Medium und Aufziehen auf die Injektionsspritze. 


\subsubsection{Tierexperimentelle Simulation des iANVs und eEOC-Injektion}

\subsubsection{Allgemeines zur Arbeit}

Im Versuch wurde ein beidseitiges, funktionelles, ischämisch bedingtes akutes Nierenversagen (iANV) simuliert. Dieses wurde durch 40-minütiges Abklemmen der linken renalen Hilusgefäße (Nierenarterie und -vene) bei simultaner Totalnephrektomie rechts induziert. Dem Schweregrad der Ausprägung des iANVs sollte durch die Injektion von vorbehandelten endothelialen Vorläuferzellen entgegen gewirkt werden. Die Qualität der Behandlung, also die postischämische Nierenfunktion nach simuliertem iANV, wurde mittels Kreatininbestimmung im Serum bestimmt.

Der Aufbau des murinen Modells beinhaltete grundsätzlich 2 Operationen im Abstand von 48 Stunden: In der ersten Operation wurde das iANV simuliert und die Zell- beziehungsweise die Kontrolllösung injiziert. Die zweite Operation beinhaltete die Gewinnung des Blutes sowie die Entnahme von linker Niere und der Lunge zur weiterführenden Aufarbeitung und Kontrolle eines etwaigen Therapieerfolges oder -misserfolges.

Der Versuch gliederte sich in fünf Gruppen mit jeweils fünf Tieren:

\section{Gruppe 1 - unbehandelte Kontrollen}

Sie diente als Kontrolle. Hier wurden lediglich das Blut und die Organe entnommen, eine Injektion blieb aus.

\section{Gruppe 2 - alleinige Ischämie}

Hier wurde nach der Simulation des iANVs isotone Kochsalzlösung injiziert.

\section{Gruppe 3 - unbehandelte Zellen}

Hier wurde nach der Simulation des iANVs unbehandelte eEOCs in der Konzentration von $5 \times 10^{5} / 50 \mu l$ injiziert.

\section{Gruppe 4 - Fenofibrat-vorbehandelte Zellen}

Hier wurde nach Simulation des iANVs mit $50 \mu \mathrm{M}$ Fenofibrat vorbehandelte eEOCs in der Konzentration von $5 \times 10^{5} / 50 \mu$ injiziert.

\section{Gruppe 5 - Clofibrat-vorbehandelte Zellen}

Hier wurde nach Simulation des iANVs mit $1 \mathrm{mM}$ Clofibrat vorbehandelte eEOCs in der Konzentration von $5 \times 10^{5} / 50 \mu$ injiziert. 


\subsubsection{Anästhesie}

Vorgegangen wurde auf gleiche Weise, wie bei der Gewinnung von Blut und Milz zur eEOC-Kultur (Kapitel 3.1.1.1).

Den Mäusen wurden 300-400 $\mu$ l eines Kombinationspräparates aus Ketamin und Xylazin der Firma SIGMA - ALDRICH $(10 \mathrm{ml}$ enthalten $800 \mathrm{mg}$ Ketamine $\mathrm{HCl}$ und $120 \mathrm{mg}$ Xylazine $\mathrm{HCl}$; Katalog Nr.: K-113) in die Peritonealhöhle des rechten unteren Quadranten nach vorheriger Aspiration injiziert. Die Injektionslösung bestand aus $6,8 \mathrm{ml} 0,9 \% \mathrm{NaCl}$ und $520 \mu \mathrm{l}$ des Präparates.

Bis zum Eintreten einer tiefen Sedierung nach 10 bis 15 Minuten wurden die Mäuse in einen verdunkelten separaten Käfig gesetzt. Zur Überprüfung der Sedationstiefe wurde mit einer Pinzette der Fuß oder Schwanz der Mäuse gekniffen und auf ein Zucken geachtet. Blieb diese Schmerzsymptomatik aus, wurde mit der Operation begonnen.

\subsubsection{Fixierung und OP-Vorbereitung}

Die Mäuse wurden rücklings auf einer Styroporplatte mit Klebestreifen an den Extremitäten und dem Schwanz fixiert. Das Fell am Bauch wurde mit einem Hautdesinfektionsmittel befeuchtet.

Die Mäuse auf der Styroporplatte wurden so ausgerichtet, dass der Operateur kaudal des Tieres saß und nach kranial blickte.

Die Sedationstiefe wurde noch einmal kontrolliert.

\subsubsection{Schnittführung und Darstellung des Operationsgebietes}

Das Operationsfeld wurde durch eine zweizeitige mediane Laparotomie eröffnet: Zuerst wurde das Fell und die Haut, dann die Muskulatur an der Linea alba eröffnet. Geschnitten wurde mit einer Schere (Schere der Firma FINE SCIENCE TOOLS; Kat.-Nr.: 14568-12). Der erste Schnitt eröffnete das Fell circa $2 \mathrm{~cm}$ in der Medianlinie aus Höhe der Blase nach kranial. Es wurde darauf geachtet, nicht bis zum Processus xiphoideus sterni zu schneiden. Der zweite Schnitt eröffnete die Muskulatur durch Auftrennen der Linea alba auf derselben Strecke. Beide Schichten wurden jeweils separat mit einer Naht der Firma ETHICON PROLENE (Faden: 6,0; Polypropylen; monofil; nicht resorbierbar; Kat.-Nr.: XN8706.P32) nach lateral aufgespannt und somit das Operationsgebiet dargestellt. Die Schnittränder wurden mit einer sterilen feuchten Kompresse abgedeckt. 


\subsubsection{Vorgehen an der linken Niere}

Zur Darstellung des linksseitigen retroperitonealen Raumes wurden die Darmschlingen mit angefeuchteten Wattestäbchen vorsichtig mobilisiert und nach rechts umgeschlagen. Zum Schutz vor Flüssigkeitsverlust und Verschmutzung wurden diese mit einer angefeuchteten sterilen Kompresse ummantelt. Mit Hilfe der Wattestäbchen wurde die linke Niere samt Hilusgefäßen dargestellt und stumpf präpariert. Es wurde darauf geachtet den linken Ureter nicht zu beschädigen. Das Peritoneum parietale wurde mit einer spitzen Pinzette kaudal der linken Hilusgefäße punktiert, damit die Gefäßklammer (Clip der Firma FINE SCIENCE TOOLS; 6 mm; Kat.-Nr.: 18055-03) diese auch von dorsal optimal abklemmen konnte. Unter ständiger Sichtkontrolle erfolgte das Vorschieben der Gefäßklammer und die anschließende Kompression der Gefäße. Der Zeitpunkt der Abklemmung wurde notiert. Die dunkle Farbveränderung der Niere diente als Kontrolle der Minderperfusion und somit korrekter Vorgehensweise.

\subsubsection{Vorgehen an der rechten Niere}

Die Darstellung der rechten Niere erfolgte gleichsam wie auf der linken Seite. Die Darmschlingen wurden auf die linke Seite verlagert. Die rechte Niere wurde stumpf aus ihrem Fettlager befreit und um ihre Hilusgefäße eine Nahtschlinge gelegt (Nahtmaterial der Firma PERMA-SHAR Sutures; Hu-Friedy; Faden: 4-0; Seidennahtmaterial; nicht resorbierbar; Kat.-Nr.: PSN683S). Sie diente als spätere Ligatur nach erfolgter Injektion der Zell- beziehungsweise Kontrollösung und musste weit medial in unmittelbarer Nähe zur Vena cava inferior positioniert werden.

\subsubsection{Ende der Ischämie, Injektion der Zellen und rechtsseitige Totalnephrektomie}

Nach 40 Minuten wurde nach erneuter visueller Kontrolle der andauernden Ischämie - die Farbe der linken Niere war weiterhin dunkelblau-schwarz - die Gefäßklammer links entfernt. Innerhalb eines Zeitintervalls von maximal 2 Minuten mussten Injektion und Ligatur an den rechten Hilusgefäßen erfolgen. Patschan et al. konnten 2010 zeigen, dass unbehandelte eEOCs das Auftreten eines iANVs in dem hier genutzten Modell nicht verhindern können (Patschan et al. 2010). Mit der Wahl von 40 Minuten sollte also das mögliche nephroprotektive Potenzial der Fibrat-Vorbehandlung von eEOCs im Verhältnis zu unbehandelten Zellen aufgezeigt werden.

Punktiert wurde die Vena renalis dextra lateral der Nahtschlinge mit Richtung der Injektionsnadel nach medial, zur Vena cava inferior hin. Dadurch wurde eine systemische Zellapplikation erreicht. Verabreicht wurde ein Bolus von $50 \mu \mathrm{l}$ mit einer Insulinspritze der Firma BD (Insulinspritze safetyglide; $1 \mathrm{ml}$; Kat.-Nr.: 305930). Je nachdem welche Versuchsgruppe operiert wurde, wurden entweder $50 \mu \mathrm{l}$ $0,9 \%$ ige-NaCl-Lösung der Firma BRAUN, oder $5 \times 10^{5}$ un- beziehungsweise vorbehandelte eEOCs suspendiert in $50 \mu \mathrm{l}$ EBM-2-Medium injiziert. 
Verifiziert wurde die richtige Injektionsstelle durch das sofortige Bluten aus dem Gefäß nach Entfernen der Kanüle. Die Nahtschlinge wurde schnellstmöglich geschlossen und die Ligatur durch Mehrfachknotung gesichert. Der vollständige Gefäßverschluss wurde kontrolliert. Abschließend wurde die rechte Niere nach Möglichkeit am Stück total resiziert. Das postoperative Ergebnis diente dem Zweck, dass die linke Niere die komplette Nierenfunktion alleine wahrnehmen musste. Da sie einer definierten Ischämiezeit unterzogen wurde, konnten die Auswirkungen von (vorbehandelten) eEOCs auf die vorgeschädigte Niere untersucht werden.

\subsubsection{Nahtverschluss und OP-Nachsorge}

Die Bauchhöhle wurde zweizeitig verschlossen: Zuerst erfolgte der Verschluss der abdominellen Muskulatur an der Linea alba mit fortlaufender Naht (Naht der Firma ETHICON PROLENE; Faden: 6,0; Polypropylen; monofil; nicht resorbierbar; Kat.-Nr.: XN8706.P32). Anschließend erfolgte der Verschluss des Bauchhaut und des Fells mit fortlaufender Naht (gleiches Nahtmaterial wie für die Muskulatur).

Nach der Operation wurde jede Maus mit einem feuchten Tuch gereinigt und auf einer beheizbaren Terrariumsplatte in einen neuen sauberen Käfig gelegt. Das Aufwachen der Mäuse wurde beobachtet und abgewartet. Die Mäuse erhielten postoperativ 0,5 I eines Trinkwassergemisches mit 0,3\% Metamizolanteil (Metamizol „Metapyrin®" der Firma SERUMWERK BERNBURG AG; Wirkstoff: MetamizolNatrium) zur Schmerzlinderung. 


\subsubsection{Materialgewinnung für die Auswertung}

\subsubsection{Blut- und Organentnahme}

Voruntersuchungen ergaben, dass 48 Stunden nach einer akuten Minderperfusion der Niere die Kreatininkonzentration im Serum ihr Maximum erreicht (Patschan et al. 2006a). Auf Grundlage dieser Erkenntnisse wurden Blut und die linke Niere zwei Tage nach der ersten Operation entnommen.

Die Anästhesie und Vorbereitungen gestalteten sich äquivalent zur ersten Operation. Nach medianer Schnittführung wurde der Bauchraum zusätzlich beidseits subcostal quer im Sinne von Entlastungsschnitten eröffnet. Zur Blutgewinnung wurde das schlagende Herz transdiaphragmal mit einer leeren 1-ml-Insulinspritze der Firma BD (Insulinspritze safetyglide; $1 \mathrm{ml}$; Kat.-Nr.: 305930) punktiert und unter langsamen Zug, um hämolytische Effekte zu vermeiden, aufgezogen. Es wurde ein Blutvolumen von 300-400 $\mathrm{ul}$ angestrebt. Das Blut wurde in Röhrchen der Firma EPPENDORF (SafeLock Tubes; 1,5 ml; Kat.-Nr.: 0030120.086) überführt. Anschließend wurde die Maus durch Durchtrennung des Diaphragmas getötet. Es folgte die Präparation von linker Niere und der Lungen. Die Organe wurden jeweils in zwei Hälften (ca. $0,5 \mathrm{~cm} \times 0,5 \mathrm{~cm}$ ) geteilt und für die histologische Beurteilung vorbereitet.

\subsubsection{Vorbereitung des Serums}

Das entnommene Vollblut (Kapitel 3.1.4.1) wurde zeitnah zur Entnahme für 10 - 15 Minuten bei $37{ }^{\circ} \mathrm{C}$ im Wasserbad erwärmt und danach bei Raumtemperatur für weitere $20-30$ Minuten stehen gelassen. Anschließend wurde für 5 Minuten mit $2000 \mathrm{U} / \mathrm{min}$ mit Bremse (Zentrifuge der Firma Labnet Internationals, Inc.; Model: Prism R; Kat.-Nr.: C2500-R-230V) zentrifugiert und das überstehende Serum in neue 1,5-ml-Eppendorfgefäße abpipettiert. Zur weiteren Diagnostik wurde das Serum bei $-20^{\circ} \mathrm{C}$ eingefroren.

\subsubsection{Organvorbereitung für die Histologie}

Die Organhälften für die konventionelle Durchlichtmikroskopie wurden in einer 4 \%igen-Formaldehydlösung gelagert und fixiert. Zur Herstellung dieser Lösung wurde 37 \%ige-Formaldehydlösung der Firma MERCK (Kat.-Nr.: 103999 2500) mit Phosphatpuffer der Firma GIBCO verdünnt („PBS“; pH-Bereich 7,4 +/- 0,05; Kat.-Nr.: 10010-015).

Die Organhälften für die immunhistochemische Beurteilung wurden jeweils für eine Stunde in einem 1,5-ml-Eppendorfgefäß gelagert, das mit der gleichen $4 \%$ igenFormaldehydlösung gefüllt war. Danach wurden die Organhälften in, mit $30 \%$ igerSaccharoselösung gefüllten, 1,5-ml-Eppendorfgefäßen für 12 bis optimaler weise 24 Stunden überführt und bei $5-7^{\circ} \mathrm{C}$ gelagert. Anschließend wurden sie in Plastikcups der Firma SAKURA (Cryomold Standard Disposible Vinyl Molds; Kat.-Nr.: 4557) umgelagert, mit Tissue-Tek-Medium (Firma SAKURA OCT; Katalog Nr.: 4583) ganzheitlich benetzt und bis auf Weiteres tief gefroren. 


\subsubsection{Bestimmung der Kreatininkonzentration im Mausserum}

Zur Beurteilung der filtrativen Nierenfunktion hat sich in der klinischen Praxis bis dato die Bestimmung des Retentionsparameters Kreatinin im Blutserum bewährt.

Kreatinin entsteht vorwiegend im Skelettmuskel zur Energiegewinnung bei der Reaktion von Kreatinphosphat und ADP zu ATP. Die Konzentration von Kreatinin im Serum ist abhängig vom Geschlecht, Alter, körperlichen Aktivität, Muskelmasse, Leberfunktion, Darmflora und der Nierenfunktion und liegt bei $0,66-1,09 \mathrm{mg} / \mathrm{dl}$ für Frauen und 0,84-1,44 mg/dl für Männer. Als harnpflichtiges Stoffwechselprodukt wird es mit einer relativ konstanten Ausscheidungsrate von 1,0 - 1,5 g in 24 Stunden filtriert und kaum, erst bei hohen Plasmakonzentrationen, leicht tubulär sezerniert und nicht resorbiert. Daher eignet es sich als Maß für die Bestimmung der glomerulären Filtrationsrate, der renalen Filterfunktion.

Bei der Beurteilung der Nierenfunktion anhand der Kreatininkonzentration ist es unabdingbar zu beachten, dass sich die Konzentration erst bei einer Einschränkung der Nierenfunktion von über $50 \%$ erhöht. Dieser sogenannte „Kreatinin-blinde Bereich" beschriebt das Nichtansteigen der Kreatininkonzentration bei schon eingetretener Nierenfunktionseinschränkung im Bereich zwischen $90-50 \mathrm{ml} / \mathrm{min}$ GFR.

Trotz oben beschriebener individueller Unterschiede hat sich die Bestimmung des Serumkreatinins als Screeningparameter durchgesetzt.

Das eingefrorene Serum (Kapitel 3.1.4.2) in den Röhrchen der Firma EPPENDORF (SafeLock Tubes; 1,5 ml; Kat.-Nr.: 0030120.086) wurde schonend bei Raumtemperatur aufgetaut.

\subsubsection{Testverfahren}

Zur Kreatininbestimmung diente das Kreatinin - Testverfahren „LT-SYS®“ der Firma LABOR UND TECHNIK EBERHARD LEHMANN (Creatinin-PAP; enzymatisch; flüssig; Bestellnummer: LT-CR 0101) und ein Photometer der Firma SCHIMADZU (Spectrophotometer UV-120-01).

Die Reagenzien wurden gebrauchsfertig geliefert:

- Reagenz 1: EHSPT $0,4 \mathrm{mmol} / \mathrm{l}$; Creatinase $\geq 10 \mathrm{kU} / \mathrm{l}$; Sarcosinoxidase $\geq 3,5 \mathrm{kU} / \mathrm{l} ;$ Ascorbinatoxidase $\geq 1 \mathrm{kU} / \mathrm{l}$

- Reagenz 2: 4-Aminoantipyrin 2,95 mmol//; Peroxidase $\geq 4 \mathrm{kU} / \mathrm{l}$; Creatininase $\geq 150 \mathrm{kU} / \mathrm{l}$

Es handelt sich hierbei um einen enzymatischen Farbtest nach der Trinder-Methode: Das Serumkreatinin reagiert in mehreren Schritten mit den Enzymen Kreatininase, Kreatinase und Sarkosinoxidase zu Wasserstoffperoxid. Dieses bildet im letzten Schritt, der sogenannten „Trinder-Reaktion“, mit 4-Aminoantipyrin und $\mathrm{N}$-Ethyl- $\mathrm{N}$-(3-Sulfopropyl)-3-methoxyaniline sodium salt ADPS einen rot-violetten Chinonimin-Farbstoff. 
Der Farbumschlag wurde photometrisch (Spectrophotometer der Firma SHIMADZU; Kat.-Nr.: UV-120-01) bei $550 \mathrm{~nm}$ und einer Schichtdicke von $1 \mathrm{~cm}$ gemessen und ist bis zu einer Konzentration von $30 \mathrm{mg} / \mathrm{dl}$ im Serum, dementsprechend $2650 \mu \mathrm{mol} / \mathrm{l}$, linear. Die untere Nachweisgrenze im Serum liegt bei 0,025 mg/dl.

Zur Vorbereitung wurden das Serum, die Reagenzien und Küvetten auf $37^{\circ} \mathrm{C}$ temperiert. Die Serumproben wurden in einem 1,5-ml-Eppendorf-Gefäß mit destilliertem Waser auf 1:5 bis 1:10 verdünnt. Um ein Zielvolumen von $50 \mu \mathrm{lu}$ erreichen, wurden $10 \mu \mathrm{l}$ Serum mit $40 \mu \mathrm{l}$ destilliertem Wasser auf $50 \mu \mathrm{l}$ aufgefüllt beziehungsweise $5 \mu \mathrm{l}$ Serum mit $45 \mu \mathrm{l}$ destilliertem Wasser. Insgesamt wurden drei Werte ermittelt: ein Leerwert, ein Standard und die Kreatininkonzentration der zu analysierende Probe (Analyse).

Pipettiert wurde nach folgendem Schema: Jede Küvette wurde jeweils mit $600 \mu \mathrm{l}$ Reagenz 1 befüllt. Dem Standard wurden $50 \mu \mathrm{l}$ Standardreagenz (Kreatinin $2,00 \mathrm{mg} / \mathrm{dl}$ ), der Analyse wurden $50 \mu \mathrm{l}$ des verdünnten Serums hinzu gegeben. Nach vorsichtigem Mischen wurden alle drei Küvetten bei $37^{\circ} \mathrm{C}$ für 3 Minuten inkubiert. Jeder Küvette wurden anschließend $200 \mu \mathrm{l}$ Reagenz 2 hinzugegeben und weiter temperiert. Die Extinktion $E_{1}$ jeder Küvette wurde nach 90 Sekunden bei $550 \mathrm{~nm}$ gemessen. Die Extinktion $E_{2}$ jeder Küvette wurde nach 210 Sekunden, beziehungsweise 120 Sekunden nach Messung von $E_{1}$, bei $550 \mathrm{~nm}$ gemessen.

Die Differenz berechnete sich wie folgt: $\Delta E=E_{2}-E_{1}$

Die Konzentration des Serumkreatinins errechnete sich aus dem Sollwert des Standards, multipliziert mit dem Quotienten aus der Differenz von $E_{2}$ und $E_{1}(\Delta E)$ des Analysates und $\Delta E$ des Standards.

$$
\text { Serumkreatinin }=\text { Sollwert }(\text { Standard }) \times \frac{\Delta E_{\text {Analyse }}}{\Delta E_{\text {Standard }}}
$$




\subsection{In-vitro-Versuchsreihe}

In der Versuchsreihe sollten die in vivo beobachteten Auswirkungen, der Feno- und Clofibrat-induzierten PPARa-Aktivierung auf die Wirkweise von syngenen eEOCs, durch In-vitro-Versuche auf zellulärer Ebene vertiefend analysiert werden.

Es wurden drei Parameter an kultivierten Zellen erhoben:

- Migrationsverhalten (Versuch 1),

- Zellüberleben (Versuch 2) sowie

- Freisetzung des proangiogenen Wachstumsfaktors VEGF (Versuch 3).

Jeder Versuch bestand aus zwei Teilen. Zuerst wurden orientierend die Effekte von Fenofibrat in der Konzentration von $50 \mu \mathrm{M}$ und Clofibrat in der Konzentration von $1 \mathrm{mM}$ auf die jeweiligen Parameter begutachtet. Hierfür wurden je Gruppe sechs Zellkulturen verwendet. Im Anschluss erfolgte die genauere Betrachtung der konzentrationsabhängigen (1, 5 und $10 \mu \mathrm{M})$ Effekte von Fenofibrat. Hierfür wurden, mit Ausnahme des dritten Versuches, je Gruppe drei Zellkulturen verwendet. In Versuch 3 Teil 2 wurde mit jeweils neun Ansätzen pro Zellkultur gearbeitet.

\subsubsection{Vorbereitung}

\subsubsection{In-vitro-eEOC-Kultur}

Zum Heranzüchten einer ausreichenden Anzahl von murinen eEOCs für die Versuche, wurden Zellen der Firma CELPROGEN® $(1.2 \times$ murine eEOCs; Kat.-Nr.: 66110-37) verwendet.

Die Ampulle, mit in flüssigem Stickstoff tiefgefrorenen Zellen, wurde ein bis zwei Minuten durch vorsichtiges Eintauchen in ein $37^{\circ} \mathrm{C}$ warmes Wasserbad aufgetaut und anschließend mit $70 \%$ igem Ethanol außen abgewischt. Unter der Sterilbank wurden die Zellen in ein 15-ml-Röhrchen der Firma SARSTEDT (15 ml; unsteril; Kat.Nr.: 62.554.502) überführt. Die Zellampulle wurde mit $500 \mu \mathrm{l}$ Celprogen Complete Growth Medium I (CCGMI; Firma CELPROGEN; Kat.-Nr.: M66110-37S) gespült und die Lösung ebenfalls in das Röhrchen überführt. Dieses wurde anschließend auf $10 \mathrm{ml}$ mit demselben Medium aufgefüllt.

Die Zellen wurden anschließend für 5 Minuten bei $1400 \mathrm{U} / \mathrm{min}$ zentrifugiert (Zentrifuge der Firma Labnet Internationals, Inc.; Model: Prism R; Kat.-Nr.: C2500-R230V), der Überstand verworfen und die Zellen erneut in $10 \mathrm{ml}$ des CCGMI-Mediums resuspendiert und in einer T75-Flasche der Firma CELPROGEN (Kat.-Nr.: E6611037-T75) für die Kultur ausplattiert. Die Flasche ist eigens dafür vom Hersteller mit unbekannter Beschaffenheit speziell beschichtet.

Die Zellen wurden für 24 Stunden bei $37{ }^{\circ} \mathrm{C}$ und $5 \% \mathrm{CO}_{2}$ im Wärmeschrank der Firma W. KRANNICH (Wärmeschrank der Firma W. KRANNICH GmbH \& Co KG; Göttingen; Deutschland; Fabrikat: IR Sensor) inkubiert. Laut Herstellerangaben sollen danach $75 \%$ der Zellen adhärent sein. Die übrigen $25 \%$ befänden sich dementsprechend noch in Lösung. 
Das CCGMI-Medium wurde durch frisches ersetzt. Dafür wurde der Überstand vorsichtig abpipettiert und für das weitere Vorgehen in ein 15-ml-Röhrchen der Firma SARSTEDT (15 ml; unsteril; Kat.-Nr.: 62.554.502) überführt. Die T75-Flasche wurde mit $5 \mathrm{ml}$ frischem CCGMI-Medium aufgefüllt. Das Überstand-Röhrchen, mit den restlichen $25 \%$ der Zellen, wurde für acht Minuten bei $1400 \mathrm{U} / \mathrm{min}$ zentrifugiert und das Zellpellet in die T75-Flasche mit $2 \mathrm{ml}$ CCGMI-Medium übernommen. Die so erstellte Kultur wurde täglich mit frischem Medium versorgt und die Zelldichte mit Hilfe eines Mikroskops geschätzt. Als die Zellen $65-75$ \%ige Zellkontakte aufwiesen wurden sie erst mit 5 - 10 ml PBS (PBS Phosphatpuffer; GIBCO; Kat.-Nr.: 10010-15)

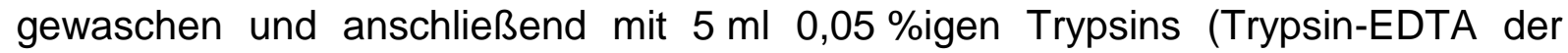
Firma GIBCO; Kat.-Nr.: 25300-054) durch zwei- bis dreiminütiges Schütteln und leichten Klopfens, bei $37^{\circ} \mathrm{C}$ von der Platte abgelöst. Das Ablösen der Zellen wurde mit einem Mikroskop verfolgt. Der Vorgang wurde mit $5 \mathrm{ml} \mathrm{CCGMI} \mathrm{gestoppt.}$

Die in CCGMI-Suspension befindlichen Zellen wurden zur Herstellung weiterer Kulturen verwendet. Dazu wurden sie in ein neues 15-ml-Röhrchen der Firma SARSTEDT überführt.

Um sicher zu gehen, dass genügend vitale Zellen in Kultur sind, wurde etwas Überstand abpipettiert, mit Trypanblau der Firma GIBCO (Kat.-Nr.: 15250-061) versetzt und die in Suspension befindlichen Zellen in einer Zählkammer unter dem Mikroskop gezählt. Da Trypanblau lediglich tote Zellen färbt, konnte die Anzahl der lebenden eEOCs einfach bestimmt werden.

Das Röhrchen wurde für acht Minuten bei $1400 \mathrm{U} / \mathrm{min}$ zentrifugiert (Zentrifuge der Firma Labnet Internationals, Inc.; Model: Prism R; Kat.-Nr.: C2500-R-230V). Ein Teil der ab zentrifugierten Zellen wurde für die Fibrat-Inkubation verwendet, der andere Teil so in T75-Flaschen mit CCGMI-Medium resuspendiert.

Die für die Fibrat-Inkubation vorgesehenen Zellen wurden auf einer mit Fibronectin der Firma SIGMA-ALDRICH (Kat.-Nr.: F0895-1MG) beschichteten 24-well-Platte der Firma GREINER BIO-ONE (24 Well Cell Culture Plate; steril; Kat.-Nr.: 662160) ausplattiert und bei $37^{\circ} \mathrm{C}$ und $5 \% \mathrm{CO}_{2}$ im Brutschrank (Wärmeschrank; Fabrikat: IR Sensor; Firma W. KRANNICH GmbH \& Co KG; Göttingen; Deutschland) ein bis drei Tage inkubiert.

Die Zellen wurden anschließend auf 6-well-Platten umkultiviert.

Die so kultivierten Platten dienten als Ausgangskulturen für die weiteren Versuche. 


\subsubsection{Inkubation mit Fibraten}

Jeder Ansatz (6-well-Platte) aller Versuchsgruppen wurde mit $350 \mu$ l Lösung für eine Stunde bei $37^{\circ} \mathrm{C}$ inkubiert. Danach endete die Inkubation durch Entfernung des Zellmediums.

Die Zellkulturen der Gruppe 1 - unbehandelte Kontrollen wurden in $350 \mu \mathrm{l}$ Celprogen Complete Growth Medium I (CCGMI; Firma CELPROGEN; Kat.-Nr.: M66110-37S) inkubiert. Sie diente als Kontrollgruppe und somit zur Abschätzung des Effektes der Fibrat-induzierten PPARa-Aktivierung.

Die jeweiligen Zellkulturen der Gruppe 2 - Fenofibrat-vorbehandelte Zellen wurden in $350 \mu \mathrm{l}$ Celprogen Complete Growth Medium I (CCGMI; Firma CELPROGEN; Kat.-Nr.: M66110-37S) mit einer Fenofibratkonzentration von 1, 5, 10 und $50 \mu \mathrm{M}$ inkubiert.

Hierfür wurde $1 \mu \mathrm{l}$ einer 100-mM-Fenofibratlösung mit unterschiedlichen Mengen Medium verdünnt. Für $50 \mu \mathrm{M}$ wurden $2000 \mu \mathrm{l}$ Medium, für $10 \mu \mathrm{M} 10000 \mu \mathrm{l}$ Medium, für $5 \mu \mathrm{M} 20000 \mu \mathrm{l}$ und für $1 \mu \mathrm{M} 100000 \mu \mathrm{l}$ Medium genutzt. Zum Einsatz kam Fenofibrat der Firma SIGMA-ALDRICH (Konzentration: $100 \mathrm{mM}$; Kat.-Nr.: F6020). Zur Herstellung der Fenofibratlösung wurde das pulverförmige Fenofibrat in Dimethylsulfoxid (250 ml DMSO; Firma SERVA; Kat.-Nr.: 20385) gelöst.

Die Zellkulturen der Gruppe 3 - Clofibrat-vorbehandelte Zellen wurden in $350 \mu \mathrm{l}$ Celprogen Complete Growth Medium I (CCGMI; Firma CELPROGEN; Kat.-Nr.: M66110-37S) mit einer Clofibratkonzentration von $1 \mathrm{mM}$ inkubiert.

Hierfür wurde $1 \mu \mathrm{l}$ Clofibrat in 4,7 ml Medium verdünnt. Zum Einsatz kam Clofibrat der Firma SIGMA-ALDRICH (Konzentration: 4,7 M; Kat.-Nr.: C6643). Zur Herstellung der Clofibratlösung wurde das pulverförmige Clofibrat in Dimethylsulfoxid $(250 \mathrm{ml}$ DMSO; Firma SERVA; Kat.-Nr.: 20385) gelöst. 


\subsubsection{Versuch 1: Migrationsverhalten}

Gemeinhin ist davon auszugehen, dass eine raschere Migration von Vorläuferzellen der endothelialen und auch mesenchymalen Zellreihe Ausdruck einer vermehrten Zellaktivierung und -kompetenz ist. In den Vorjahren von Patschan et al. bereits identifizierte Aktivatoren und Modulatoren der eEOC-Funktion wirken unter anderem genau über diesen Mechanismus (Patschan et al. 2010, Patschan et al. 2012a, Patschan et al. 2013a, Patschan et al. 2013b, Patschan et al. 2013c). Aus diesem Grund wurde analysiert, ob und falls ja, in welcher Weise Fibrate die Migration von eEOCs modulieren können.

Hierfür wurden mittels eines standardisierten Stempels (Stempel aus hauseigener Produktion nach Anweisung in den wissenschaftlichen Werkstätten der Universitätsmedizin Göttingen, kreisrunde Stempelfläche; Durchmesser äquivalent zu der einer Vertiefung einer 6-well-Platte) eine artifizielle Wundflächen in eEOC-Zellrasen induziert. In jede Vertiefung der 6-well-Kulturplatten wurde eine Wundfläche von $2 \mathrm{~mm}$ gestempelt. Die Wundflächen wurden zu den Zeitpunkten 0, 3 und 24 Stunden fotodokumentiert.

Die Stimulationskonzentrationen lagen, wie oben erwähnt, für Fenofibrat bei 1, 5, 10 und $50 \mu \mathrm{M}$ und für Clofibrat bei $1 \mathrm{mM}$.

Die Quantifizierung der Wundflächengröße erfolgte computergestützt (prozentuale Reduktion der Pixelanzahl der zellfreien Fläche in \%).

Das Ausmaß der Migration wurde über die prozentuale Reduktion der Wundflächengröße nach 24 Stunden ermittelt. 


\subsubsection{Versuch 2: Zellüberleben}

Zur Analyse des Zellüberlebens wurde ein Test eingesetzt, der tote Zellen mittels Annexin-V-Markierung demaskiert.

FITC-Annexin V bindet Phosphatidylserin (PS) von Zellmembranen apoptotischer und nekrotischer Zellen. PS befindet sich an der zellinneren Membranseite und bindet FITC-Annexin V dementsprechend nur, wenn FITC-Annexin V entweder in die Zellen eindringen kann, oder PS Kontakt zum extrazellulären Milieu hat. Als einer der ersten Vorgänge im Rahmen der Apoptose wird PS in das äußere Blatt der Zellmembran transloziert und bietet somit, durch die Anfärbung mit FITC-Annexin V, die Möglichkeit apoptotische Zellen in der frühen Phase zu identifizieren. Die PSUmlagerung hat zur Folge, dass über eine Rezeptorbindung an Makrophagen die apoptotischen Zellen phagozytiert und abgebaut werden (Schmidt, Lang, Heckmann 2010).

Die Zellintegrität ist sowohl bei nekrotischen als auch bei spät-apoptotischen Zellen unter anderem auf Grund durchlässiger Zellmembranen gestört. Somit werden auch diese durch FITC-Annexin V angefärbt. Zur weiteren Differenzierung wurden die Zellen deshalb zusätzlich mit Propidiumiodid (PI) angefärbt, welches nur in nekrotische und spät-apoptotische Zellen, also mit durchlässiger Membran, eindringt.

Die unterschiedliche Anfärbbarkeit weist die Zellen ihren Stadien zu:

- Stadium I: lebendig

- Stadium II: früh-apoptotisch

- Stadium III: spät-apoptotisch
FITC-Annexin $V$ negativ, PI negativ

FITC-Annexin $V$ positiv, PI negativ

FITC-Annexin $V$ positiv, PI positiv

Somit kann durch den Test zum einen durch zeitliches Aufzeichnen und Beobachtung der Zellen beim Durchlauf der charakteristischen Stadien I bis III auf das Vorliegen einer Apoptose geschlossen werden, zum anderen können lebende Zellen von früh-apoptotischen und nekrotischen beziehungsweise spät-apoptotischen unterschieden werden.

Im Rahmen dieser Arbeit wurden Zellen im Stadium I (lebendig) und II (früh-apoptotisch) als lebendige Zellen, von denen im Stadium III tot (spät-apoptotisch und nekrotisch) unterschieden.

Die Quantifizierung erfolgte mittels Durchflusszytometrie. Die Auswertung des Zellüberlebens erfolgte anhand der prozentualen Reduktion (\%) der toten Zellen (Stadium III) im Vergleich zur Kontrollgruppe. 


\subsubsection{Testverfahren}

Zum Einsatz kam das FITC Annexin $V$ Apoptosis Detection Kit 1 der Firma BD (BD Pharmingen ${ }^{\mathrm{TM}}$; Kat.-Nr.: 556547) und zur durchflusszytometrischen Auswertung ein FACS-Analysegerät (FacsCalibur; Firma BD).

Die Reagenzien wurden größtenteils gebrauchsfertig geliefert:

- FITC Annexin V (0,5 ml; Kat.-Nr.: 51-65874X)

- FITC Annexin V Puffer (50 ml; Kat.-Nr.: 51-66121E; 10-fach konzentriert), bestehend aus $0.1 \mathrm{M} \mathrm{HEPES} / \mathrm{NaOH}(\mathrm{pH} 7,4) ; 1,4 \mathrm{M} \mathrm{NaCl} ; 25 \mathrm{mM}$

- Propidiumiodid-Lösung (2 ml; Kat.-Nr.: 51-66211E)

\subsection{Verwendete Zellen}

Die Apoptoserate wurde anhand derselben Zellen bestimmt, die auch für das Migrationsverhalten fotografiert wurden. Dies waren die in vitro gezüchteten murinen eEOCs der Firma CELPROGEN® (1.2 × murine eEOCs; Kat.-Nr.: 66110-37). Der Vorgang wurde in Kapitel 3.2.1.1 beschrieben.

Zuerst wurden die Zellkultur in den 6-well-Platten zweimal mit PBS der Firma GIBCO (PBS; pH-Bereich 7,4 +/- 0,05; Kat.-Nr.: 10010-015) gewaschen, von der Kulturplatte mit $5 \mathrm{ml} \mathrm{0,05}$ \%igen Trypsins (Trypsin-EDTA der Firma GIBCO; Kat.-Nr.: 136861-8) abgelöst und danach in der Konzentration von $1 \times 10^{6}$ Zellen $/ \mathrm{ml}$ in verdünnter Pufferlösung resuspendiert.

\subsection{Vorbereitung der Pufferlösung}

Der FITC-Annexin V Puffer wurde vor dem Einsatz im Verhältnis von 1:9 mit destilliertem Wasser verdünnt.

\subsection{Färbungsvorgang und Auswertung}

$100 \mu \mathrm{l}$ der Suspension $\left(1 \times 10^{5}\right.$ Zellen) wurden anschließend in ein $5 \mathrm{ml}$ FACSRöhrchen ( $5 \mathrm{ml}$ tube; Firma SARSTEDT; $75 \times 12$ mm; Kat.-Nr.: 55.476) überführt und zusammen mit $5 \mu \mathrm{I}$ FITC-Annexin V und $5 \mu \mathrm{II}$ für 15 Minuten bei Raumtemperatur im Dunkeln inkubiert. Zum Schluss wurde in jedes FACS-Röhrchen $400 \mu$ verdünnte Pufferlösung hinzugegeben. Die Analyse mit Hilfe der Durchflusszytometrie (FacsCalibur; Firma BD) erfolgte innerhalb der nächsten Stunde. 


\subsubsection{Versuch 3: Proangiogenität}

Wie im Kapitel 2 „Stand der Wissenschaft" mehrfach beschrieben, kann VEGF, als endothelialer proangiogener Mediator, im Zellmedium bei statt gefundenem Zellwachstums nachgewiesen werden und wird von eEOCs sezerniert (Rehman et al. 2003).

Die Konzentration von VEGF im Überstand gilt als Maß für den proangiogenen Effekt der eEOCs.

ELISA steht als Akronym für die Bezeichnung Enzyme-Linked Immuno Sorbent Assay und dient klassischerweise zur Detektion bestimmter Antigene.

Eine Antigen ( $A G$ )-enthaltende Probe wird mit einer Antikörper (AK)-enthaltenden Probe inkubiert. Dadurch bildet sich ein AG-AK-Komplex. Gleiches wird mit einer Kontrollprobe gemacht. Hier bildet sich kein Komplex. Zu beiden Proben wird nun ein Markerenzym hinzugegeben, welches durch eine Farbreaktion den AG-AK-Komplex demaskiert und im Verhältnis zu Kontrollprobe quantitativ messbar macht. Die Farbreaktion ist proportional zur Konzentration der AGs. Zur Auswertung wurden die Ergebnisse der Standardproben auf doppelt-logarithmischem Papier aufgetragen und eine Standardgerade ermittelt. Auf der x-Achse wurde die VEGF-Konzentration, auf der y-Achse die Absorption aufgetragen. Anhand der Standardgeraden können die Konzentrationen unbekannter Proben abgeschätzt werden.

Das ELISA-Verfahren kann durch Enzym- und Bindungspartner-Austausch für andere Fragestellungen modifiziert werden. Der Mechanismus der Komplexreaktion aus Antigen und Antikörper bleibt gleich.

In dieser Arbeit wurde die VEGF-Konzentration im Nährmedium von eEOCs ermitttelt.

\subsubsection{Allgemeines zum Testverfahren}

Zum quantitativen Nachweis von VEGF im Zellmedium wurde der RayBio $\Theta$ Mouse VEGF ELISA-Test (RayBio® Mouse VEGF ELISA Kit; RAYBIOTECH, INC.; Kat.-Nr.: ELM-VEGF-001), ein enzymgekoppelter Absorptionstest benutzt. Zur Bestimmung der Absorption diente ein ELISA-Mikrotiter-Platten-Reader (Teca Spectra; Photometer der Firma TECAN).

Die Materialien wurden weitestgehend gebrauchsfertig geliefert:

- Reagenz A: 96-well-Platte, beschichtet mit dem AK (anti-mouse VEGF)

- Reagenz B: $25 \mathrm{ml}$ Pufferkonzentrat (20-fach konzentriert) zum Waschen

- Reagenz C: „Standards“, bestehend aus 2 Fläschchen und rekombinanten murinen VEGFs

- Reagenz D: $30 \mathrm{ml}$ 0,09 \% Natriumazid Lösung, zur Verdünnung von Standard und Serum-, Plasmaprobe (nicht für den Test verwendet)

- Reagenz E: $15 \mathrm{ml}$ Pufferkonzentrat (5-fach konzentriert), zur Verdünnung von Standard und Zellmedium-Überstand

- Reagenz F: Biotyniliertes anti-mouse VEGF (murine VEGF-AKs) 
- Reagenz G: $200 \mu$ l HRP-konjugiertes Streptavidin (160-fach konzentriert)

- Reagenz H: TMB-Reagenz (TMB in Pufferlösung)

- Reagenz I: $8 \mathrm{ml}$ Schwefelsäure (0,2 M), als „Stopp-Reagenz“

Zusätzliche Materialien und Reagenzien, die zur Durchführung benötigt wurden, finden sich im Anhang in der Material- und Substanzliste. Der Testaufbau bestand aus der Absorptionsbestimmung von acht Standardlösungen, die zur Ermittlung einer Standardgeraden dienten sowie der Absorptionsbestimmung der sechs Ansätze einer jeden Gruppe (A, B, C).

Insgesamt wurden dementsprechend für achtzehn Proben die Konzentration von VEGF in $\mathrm{pg} / \mathrm{ml}$ über die Absorption und Abschätzung an der Standardgeraden ermittelt.

Alle Reaktionsschritte wurden bei Zimmertemperatur $\left(18-25^{\circ} \mathrm{C}\right)$ durchgeführt.

\subsubsection{Vorbereitung der Reagenzien}

Grundsätzlich wurden die Proben und Standards mit dem dafür vorgesehenen Reagenz E verdünnt. Reagenz E wurde anfänglich 5-mal mit destilliertem Wasser verdünnt. Im folgenden Text wird mit "Reagenz E“ das verdünnte Reagenz E beschrieben.

\subsection{Vorbereitung der Standardlösungen}

Alle Standards wurden doppelt hergestellt und gemessen.

Zur Herstellung einer $25 \mathrm{ng} / \mathrm{ml}$-Standardlösung wurde das Pulver (murines rekombinantes VEGF) der zwei Reagenz-C-Fläschchen in jeweils $400 \mu \mathrm{l}$ der Reagenz E aufgelöst und verdünnt. $40 \mu \mathrm{l}$ dieser Lösung wurden in ein neues Behältnis überführt und erneut mit dem Reagenz E, diesmal $960 \mu$ l, verdünnt.

Dadurch wurde eine Ausgangslösung mit 1.000 pg VEGF / 1 ml Lösung geschaffen, die als Ausgangsreagenz einer Verdünnungsserie zur Herstellung der acht Standardlösungen diente.

Zur Herstellung der Standards wurden sieben Behältnisse mit $300 \mu \mathrm{l}$ Reagenz E befüllt. Aus der Ausgangslösung wurden $200 \mu \mathrm{l}$ in Behältnis eins pipettiert und sorgfältig gemischt. Danach wurden $200 \mu$ laus Behältnis eins in das zweite pipettiert und gemischt. Dieser Vorgang wurde bis Behältnis sechs weitergeführt. Behältnis sieben blieb als Leerwert unangetastet.

Durch diese Verdünnungsserie wurden sieben in ihrer VEGF-Konzentration absteigende Behältnisse geschaffen. 
Die VEGF-Konzentrationen beliefen sich auf:

$\begin{array}{lrl}\text { Ausgangslösung: } & 1000,0 & \mathrm{pg} / \mathrm{ml} \\ \text { Behältnis eins: } & 400,0 & \mathrm{pg} / \mathrm{ml} \\ \text { Behältnis zwei: } & 160,0 & \mathrm{pg} / \mathrm{ml} \\ \text { Behältnis drei: } & 64,0 & \mathrm{pg} / \mathrm{ml} \\ \text { Behältnis vier: } & 25,6 & \mathrm{pg} / \mathrm{ml} \\ \text { Behältnis fünf: } & 10,2 & \mathrm{pg} / \mathrm{ml} \\ \text { Behältnis sechs: } & 4,1 & \mathrm{pg} / \mathrm{ml} \\ \text { Behältnis sieben: } & 0,0 & \mathrm{pg} / \mathrm{ml}\end{array}$

(Reagenz E, gilt als Standard Null / Leerwert)

\subsection{Vorbereitung der Waschlösung}

Zur Herstellung der Waschlösung wurden $20 \mathrm{ml}$ des Pufferkonzentrates (Reagenz B) in $400 \mathrm{ml}$ destilliertem Wasser verdünnt.

\subsection{Vorbereitung der Antikörper-Detektionslösung}

$100 \mu \mathrm{l}$ Reagenz E wurden in ein Fläschchen des Reagenz F pipettiert, um ein Detektionskonzentrat zu erhalten. Dieses wurde durch vorsichtiges Auf- und Abpipettieren durchmischt und anschließend zur Herstellung der Detektionslösung 80-fach mit Reagenz E verdünnt.

\subsection{Vorbereitung der Streptavidinlösung}

Zur Herstellung der benötigten Lösung wurde das HRP-Streptavidinkonzentrat (Reagenz G) 8000-fach mit Reagenz E verdünnt.

\subsection{Waschvorgang}

Im Testverfahren wurde die VEGF-Mikroplatte dreimal gewaschen. Dieser Vorgang beinhaltete das Verwerfen der Lösungen in den Vertiefungen und das anschließende 4-malige Auf- und Abpipettieren mit $300 \mu \mathrm{l}$ Waschlösung (verdünntes Reagenz B). Hierzu wurde eine Multikanalpipette der Firma EPPENDORF (Multipette® plus; EPPENDORF; Kat.-Nr.: 4981 000.019) benutzt. Danach wurde alle Restflüssigkeit abpipettiert, die Platte umgedreht und mit Zellstofftüchern trocken getupft. 


\subsubsection{Testverfahren}

Es wurden folgende Schritte durchgeführt:

1. Je $100 \mu$ l eines jeden Standards (Reagenz C) $(2 \times 8=16)$ und der Proben (Gruppe 1, 2, 3 mit jeweils 6 Proben $=18$ ) wurde in die Vertiefungen der 96-well-VEGF-Mikroplatte (Reagenz A) pipettiert. Dadurch bindet das VEGF an die an den Platten festen AKs. Diese wurde dann für 2,5 Stunden bei Raumtemperatur oder über Nacht bei $4{ }^{\circ} \mathrm{C}$ und leichtem Schwenken (rotierender Plattformschüttler Rotamax 120; Firma Heidolph; Kat.-Nr.: 544-41200-00) abgedeckt inkubiert.

2. Anschließend wurden die Lösungen aus jeder Vertiefung abpipettiert und die

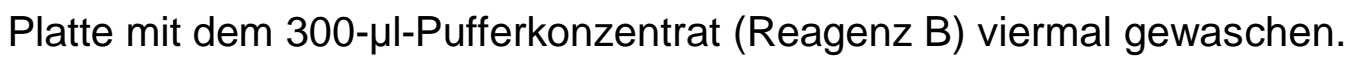

3. Je $100 \mu \mathrm{l}$ der Antikörper-Detektionslösung (biotyniliertes anti-mouse VEGF, murine VEGF-AKs, Reagenz F) wurde in die Vertiefungen pipettiert und für eine Stunde bei Raumtemperatur und leichtem Schwenken inkubiert.

4. Zweiter Waschvorgang (Reagenz B) zur Ablösung der nicht gebundenen zweiten AKs (Reagenz F).

5. Je $100 \mu \mathrm{l}$ der Streptavidinlösung (Reagenz G) wurde in die Vertiefungen pipettiert und für 45 Minuten bei Raumtemperatur und leichtem Schwenken inkubiert.

6. Waschvorgang (Reagenz B)

7. Starten der Farbreaktion: Je $100 \mu \mathrm{l}$ der TMB-Reagenz (Reagenz H) wurde in die Vertiefungen pipettiert und für 30 Minuten bei Raumtemperatur ohne Schwenken im Dunkeln inkubiert.

Die Intensität des Farbumschlages ist proportional zur VEGF-Konzentration.

8. Stoppen der Farbreaktion: Anschließend wurde $50 \mu \mathrm{l}$ der Stopplösung (Reagenz I) in jede Vertiefung pipettiert.

Die VEGF-Konzentration der Proben auf der Mikroplatte wurde unmittelbar nach Schritt 8 mit Hilfe des Photometers (ELISA-Mikrotiter-Platten-Reader Teca Spectra; Firma TECAN) bei $450 \mathrm{~nm}$ gemessen.

Die Extinktion einer jeden Lösung (Standards, Proben) errechnete sich aus der Differenz von gemessener Extinktion bei $450 \mathrm{~nm}$ und der durchschnittlichen optischen Dichte des Leerwertes $(=0 \mathrm{pg} / \mathrm{ml}$ VEGF $=$ verdünntes Reagenz $\mathrm{E})$.

Zur Auswertung wurden die Ergebnisse auf doppelt-logarithmischem Papier aufgetragen und eine Standardgerade durch die Ergebnisse / Punkte der ermittelten Standards gezogen. Auf der x-Achse wurde die VEGF-Konzentration, auf der $y$-Achse die Absorption aufgetragen. Anhand dieser Standardgeraden wurde die VEGF-Konzentration in $\mathrm{pg} / \mathrm{ml}$ im Überstand einer jeden Zellkultur anhand ihrer Absorption bestimmt. 


\subsection{Statistische Auswertung}

Zur Beurteilung von eventuellen statistisch signifikanten Unterschieden zwischen den Tieren der verschiedenen Gruppen diente der Mann-Whitney-U-Test. Unterschiede in der In-vitro-Versuchsreihe, also in der prozentualen Zellmigration, den prozentualen Anteilen toter zu lebendiger Zellen und der Freisetzung von VEGF, wurden mittels t-Test analysiert.

Ein signifikanter Unterschied wurde bei einem $p$-Wert von $<0,05$ angenommen. 


\subsection{Tabellarische Zusammenfassung verwendeter Materialien und Substanzen}

\begin{tabular}{|c|c|c|c|}
\hline Gerät & Firma & Katalognummer & Verwendung \\
\hline Schere klein & $\begin{array}{c}\text { FINE SCIENCE } \\
\text { TOOLS }\end{array}$ & $14568-12$ & $\begin{array}{c}\text { Operation } \\
\text { (Tierexperiment) }\end{array}$ \\
\hline Schere groß & $\begin{array}{c}\text { FINE SCIENCE } \\
\text { TOOLS }\end{array}$ & $14502-14$ & $\begin{array}{c}\text { Operation } \\
\text { (Tierexperiment) }\end{array}$ \\
\hline $\begin{array}{c}\text { Pinzette klein } \\
\text { Stahl, } 10 \mathrm{~cm}, 0,8 \mathrm{~mm}\end{array}$ & $\begin{array}{c}\text { FINE SCIENCE } \\
\text { TOOLS }\end{array}$ & $11050-10$ & $\begin{array}{c}\text { Operation } \\
\text { (Tierexperiment) }\end{array}$ \\
\hline Pinzette groß & $\begin{array}{c}\text { FINE SCIENCE } \\
\text { TOOLS }\end{array}$ & $11008-15$ & $\begin{array}{c}\text { Operation } \\
\text { (Tierexperiment) }\end{array}$ \\
\hline $\begin{array}{l}\text { Pinzette chirurgisch } \\
\text { slim }\end{array}$ & $\begin{array}{c}\text { FINE SCIENCE } \\
\text { TOOLS }\end{array}$ & $11023-14$ & $\begin{array}{c}\text { Operation } \\
\text { (Tierexperiment) }\end{array}$ \\
\hline $\begin{array}{l}\text { Nadelhalter Matthieu } \\
\qquad 14 \mathrm{~cm}\end{array}$ & $\begin{array}{c}\text { FINE SCIENCE } \\
\text { TOOLS }\end{array}$ & $12510-14$ & $\begin{array}{c}\text { Operation } \\
\text { (Tierexperiment) }\end{array}$ \\
\hline Clipapplikator & $\begin{array}{c}\text { FINE SCIENCE } \\
\text { TOOLS }\end{array}$ & $18057-14$ & $\begin{array}{c}\text { Operation } \\
\text { (Tierexperiment) }\end{array}$ \\
\hline
\end{tabular}




\begin{tabular}{|c|c|c|c|}
\hline Gerät & Firma & Katalognummer & Verwendung \\
\hline $\begin{array}{l}\text { Clip } \\
6 \mathrm{~mm}\end{array}$ & $\begin{array}{c}\text { FINE SCIENCE } \\
\text { TOOLS }\end{array}$ & $18055-03$ & $\begin{array}{c}\text { Operation } \\
\text { (Tierexperiment) }\end{array}$ \\
\hline Instrumentenbox & $\begin{array}{c}\text { FINE SCIENCE } \\
\text { TOOLS }\end{array}$ & $20311-21$ & $\begin{array}{c}\text { Operation } \\
\text { (Tierexperiment) }\end{array}$ \\
\hline Nahtmaterial & $\begin{array}{c}\text { PERMA-SHAR } \\
\text { Hu-Friedy }\end{array}$ & PSN683S & $\begin{array}{c}\text { Operation } \\
\text { (Tierexperiment) }\end{array}$ \\
\hline Nahtmaterial & ETHICON PROLENE & XN8706.P32 & $\begin{array}{c}\text { Operation } \\
\text { (Tierexperiment) }\end{array}$ \\
\hline $\begin{array}{c}\text { Insulinspritze } \\
\text { safetyglide } \\
1 \mathrm{ml}\end{array}$ & BD & 305930 & $\begin{array}{c}\text { Operation } \\
\text { (Tierexperiment) }\end{array}$ \\
\hline $\begin{array}{c}\text { Pipette } \\
(0,5-10 \mu l)\end{array}$ & EPPENDORF & 3120000020 & Laborarbeiten \\
\hline $\begin{array}{c}\text { Pipette } \\
(10-100 \mu l)\end{array}$ & EPPENDORF & 3120000046 & Laborarbeiten \\
\hline
\end{tabular}




\begin{tabular}{|c|c|c|c|}
\hline Gerät & Firma & Katalognummer & Verwendung \\
\hline $\begin{array}{c}\text { Pipette } \\
(100-1000 \mu \mathrm{l})\end{array}$ & EPPENDORF & 3120000062 & Laborarbeiten \\
\hline Multipette $\AA^{\circledR}$ plus & EPPENDORF & 4981000.019 & Laborarbeiten \\
\hline $\begin{array}{c}\text { Pipettierspitzen } \\
\text { für } 0,5-10 \mu \text { l-Pipette }\end{array}$ & EPPENDORF & 0030000811 & Laborarbeiten \\
\hline $\begin{array}{c}\text { Pipettierspitzen } \\
\text { für } 10-100 \mu \text { l-Pipette }\end{array}$ & EPPENDORF & 0030000889 & Laborarbeiten \\
\hline $\begin{array}{l}\text { Pipettierspitzen } \\
\text { für } 100-1000 \mu \mathrm{l}- \\
\text { Pipette }\end{array}$ & EPPENDORF & 0030000927 & Laborarbeiten \\
\hline 1,5-ml-Röhrchen & EPPENDORF & 0030120.086 & Laborarbeiten \\
\hline 15-ml-Röhrchen & SARSTEDT & 62.554 .502 & EPC-Kultur \\
\hline
\end{tabular}




\begin{tabular}{|c|c|c|c|}
\hline Gerät & Firma & Katalognummer & Verwendung \\
\hline 50-ml-Röhrchen & SARSTEDT & 62.547. 254 & EPC-Kultur \\
\hline 5-ml-Röhrchen & SARSTEDT & 55.476 & FACS Analyse \\
\hline $\begin{array}{l}\text { Zentrifuge } \\
\text { (G5-6R) }\end{array}$ & BECKMANN & & Zellisolation \\
\hline Zentrifuge Prism R & $\begin{array}{c}\text { LABNET } \\
\text { INTERNATIONALS }\end{array}$ & C2500-R-230V & $\begin{array}{c}\text { Laborarbeiten } \\
\text { (Kreatininbestimmung) }\end{array}$ \\
\hline $\begin{array}{l}\text { Wärmeschrank } \\
\text { (IR Sensor) }\end{array}$ & $\begin{array}{l}\text { W. KRANNICH GmbH } \\
\text { \& Co KG, Göttingen, } \\
\text { Deutschland }\end{array}$ & & Laborarbeiten \\
\hline Spectrophotometer & SHIMADZU & UV-120-01 & Kreatininbestimmung \\
\hline T75-Flasche & CELPROGEN & E66110-37-T75 & EPC-Kultur \\
\hline
\end{tabular}




\begin{tabular}{|c|c|c|c|}
\hline Gerät & Firma & Katalognummer & Verwendung \\
\hline 24-well-Platte & GREINER BIO-ONE & 662160 & EPC-Kultur \\
\hline 6-well-Platte & GREINER BIO-ONE & 657160 & EPC-Kultur \\
\hline Stempel & hauseigene Produktion & & $\begin{array}{l}\text { In-vitro-Versuch 1: } \\
\text { Migrationsverhalten }\end{array}$ \\
\hline $\begin{array}{c}\text { Photometer / ELISA- } \\
\text { Micro-Titer-Platten- } \\
\text { Reader } \\
\text { TECA SPECTRA }\end{array}$ & TECAN & & ELISA-Auswertung \\
\hline FACSCalibur & Becton Dickinson (BD) & & Durchflusszytometrie \\
\hline Rotamax 120 & Heidolph & $544-41200-00$ & Laborarbeiten \\
\hline $\begin{array}{c}\text { Cryomold Standard } \\
\text { Molds }\end{array}$ & SAKURA & 4557 & $\begin{array}{c}\text { Vorbereitung der } \\
\text { Organschnitte }\end{array}$ \\
\hline
\end{tabular}

Tabelle 1: Liste der verwendeten Werkzeuge und Geräte. 


\begin{tabular}{|c|c|c|c|}
\hline Substanz & Firma & Katalognummer & Verwendung \\
\hline Ketamine / Xylazine & SIGMA-ALDRICH & $\mathrm{K}-113$ & $\begin{array}{c}\text { Narkose } \\
\text { (Tierexperiment) }\end{array}$ \\
\hline Metamizol-Natrium & $\begin{array}{l}\text { SERUMWERK } \\
\text { BERNBURG AG }\end{array}$ & & $\begin{array}{c}\text { Postoperative } \\
\text { Schmerzlinderung }\end{array}$ \\
\hline Heparin & RATIOPHARM & N21086.21-Z04 & Zellisolation \\
\hline EBM-2-Medium & LONZA & CC-3156 & Verschiedenes \\
\hline Biocoll & BIOCHROM AG & L-6115 & $\begin{array}{c}\text { Dichtetrennung der } \\
\text { EPCs aus Vollblut una } \\
\text { Milz }\end{array}$ \\
\hline Fibronectin & SIGMA-ALDRICH & F0895 - 1MG & EPC-Kultur \\
\hline Formalin & MERCK & 1039992500 & Fixierung der Organe \\
\hline PBS (Phosphatpuffer) & GIBCO & $10010-015$ & Waschen, verdünnen \\
\hline
\end{tabular}




\begin{tabular}{|c|c|c|c|}
\hline Substanz & Firma & Katalognummer & Verwendung \\
\hline Tissue Tek O.C.T. & SAKURA & 4583 & $\begin{array}{l}\text { Fixierung der Organe } \\
\text { für Kryoschnitte }\end{array}$ \\
\hline $0,9 \% \mathrm{NaCl}$ & BRAUN & & Verschiedenes \\
\hline Clofibrat & SIGMA-ALDRICH & C6643 & EPC-Inkubation \\
\hline Fenofibrat & SIGMA-ALDRICH & F6020 & EPC-Inkubation \\
\hline DMSO & SERVA & 20385 & Lösungsmittel \\
\hline Murine EPCs & CELPROGEN & $66110-37$ & $\begin{array}{c}\text { EPC-Kultur für In-vitro- } \\
\text { Versuche }\end{array}$ \\
\hline CCGMI Medium & CELPROGEN & M66110-37S & $\begin{array}{c}\text { Zellkulturen, In-vitro- } \\
\text { Versuche }\end{array}$ \\
\hline Trypsin-EDTA & GIBCO & $136861-8$ & $\begin{array}{l}\text { Lösen der Zellen aus } \\
\text { der T75-Flasche }\end{array}$ \\
\hline
\end{tabular}




\begin{tabular}{|c|c|c|c|}
\hline Substanz & Firma & Katalognummer & Verwendung \\
\hline Trypanblau & GIBCO & $15250-61$ & $\begin{array}{c}\text { Färben abgestorbener } \\
\text { Zellen }\end{array}$ \\
\hline $\begin{array}{c}\text { RayBio® Mouse VEGF } \\
\text { ELISA Kit }\end{array}$ & RAYBIOTECH, INC. & ELM-VEGF-001 & $\begin{array}{c}\text { In-vitro-Versuch 3: } \\
\text { VEGF-ELISA }\end{array}$ \\
\hline $\begin{array}{c}\text { FITC Annexin V } \\
\text { Apoptosis Detection Kit }\end{array}$ & BD PHARMINGEN ${ }^{\mathrm{TM}}$ & 556547 & $\begin{array}{c}\text { In-vitro-Versuch 2: } \\
\text { Apoptose-Bestimmung }\end{array}$ \\
\hline
\end{tabular}

Tabelle 2: Liste der verwendeten Substanzen. 


\section{Ergebnisse}

\subsection{In-vivo-Tierversuchsreihe: Postischämische Nierenfunktion}

Im Versuch wurde ein beidseitiges, funktionelles, ischämisch bedingtes akutes Nierenversagen (iANV) simuliert. Dieses wurde durch 40-minütiges Abklemmen der linken renalen Hilusgefäße bei simultaner Totalnephrektomie rechts induziert. Dem Schweregrad der Ausprägung des iANVs sollte durch die Injektion von vorbehandelten endothelialen Vorläuferzellen entgegengewirkt werden. Die Qualität der Behandlung, also die postischämische Nierenfunktion nach simuliertem iANV, wurde mittels Kreatininbestimmung im Serum bestimmt.

Im Folgenden werden die Gruppen kurz vorgestellt sowie die Ergebnisse tabellarisch und graphisch zusammengefasst.

\subsubsection{Gruppe 1 - unbehandelte Kontrollen}

Gruppe 1 konstituierte sich aus unbehandelten Kontrolltieren. Diesen fünf Mäusen wurden lediglich Blut und die Nieren entnommen.

Die Kreatininkonzentration im Serum lag im Mittel (MW) bei 0,10 mg / dl, bei einer Standardabweichung (SD) von 0,00.

\subsubsection{Gruppe 2 - alleinige Ischämie}

Den fünf Mäusen der Gruppe 2 wurde für 40 Minuten die linke Nierenarterie okkludiert. Gegen Ende der Ischämiezeit wurden zunächst $50 \mu \mathrm{N} \mathrm{NaCl}$ in die rechte Nierenvene injiziert, das Organ wurde anschließend resiziert.

Die Kreatininkonzentration im Serum lag im Mittel (MW) bei 0,16 mg / dl, bei einer Standardabweichung (SD) von 0,00.

\subsubsection{Gruppe 3 - unbehandelte Zellen}

Das experimentelle Prozedere in dieser sowie den folgenden Gruppen entsprach dem Vorgehen der Gruppe 2, anstelle von $\mathrm{NaCl}$ wurden jedoch entweder unbehandelte oder Fibrat-vorbehandelte Zellen appliziert. Die Tiere der aktuellen Gruppe erhielten unbehandelte Zellen.

Die Kreatininkonzentration im Serum lag im Mittel (MW) bei 0,17 mg / dl, bei einer Standardabweichung (SD) von 0,02. 


\subsubsection{Gruppe 4 - Fenofibrat-vorbehandelte Zellen}

Den Mäusen der Gruppe 4 wurden Fenofibrat-vorbehandelte eEOCs appliziert. Die Fenofibratkonzentration lag bei $50 \mu \mathrm{M}$.

Die Kreatininkonzentration im Serum lag im Mittel (MW) bei $0,15 \mathrm{mg} / \mathrm{dl}$, bei einer Standardabweichung (SD) von 0,02.

\subsubsection{Gruppe 5 - Clofibrat-vorbehandelte Zellen}

Den Mäusen der Gruppe 5 wurden Clofibrat-vorbehandelte eEOCs appliziert. Die Clofibratkonzentration lag bei $1 \mathrm{mM}$.

Die Kreatininkonzentration im Serum lag im Mittel (MW) bei 0,22 $\mathrm{mg} / \mathrm{dl}$, bei einer Standardabweichung (SD) von 0,06. 


\subsubsection{Zusammenfassung und Deutung}

In Tabelle 3 werden die Ergebnisse der Kreatininkonzentration im Mausserum in $\mathrm{mg} / \mathrm{dl}$ zusammengefasst. Abbildung 1 zeigt die Ergebnisse graphisch aufarbeitet.

\begin{tabular}{|c|c|c|c|c|c|}
\hline \multirow[b]{2}{*}{ Maus } & \multicolumn{5}{|c|}{ Kreatininkonzentration im Serum (mg / dl) } \\
\hline & $\begin{array}{c}\text { Gruppe } 1 \text { - } \\
\text { unbehandelte } \\
\text { Kontrollen }\end{array}$ & $\begin{array}{c}\text { Gruppe 2- } \\
\text { alleinige } \\
\text { Ischämie }\end{array}$ & $\begin{array}{c}\text { Gruppe } 3 \text { - } \\
\text { unbehandelte } \\
\text { Zellen }\end{array}$ & $\begin{array}{c}\text { Gruppe } 4 \text { - } \\
50 \mu \mathrm{M} F- \\
\text { vorbehandelte } \\
\text { Zellen }\end{array}$ & $\begin{array}{c}\text { Gruppe } 5 \text { - } \\
1 \mathrm{mM} \text { CF- } \\
\text { vorbehandelte } \\
\text { Zellen }\end{array}$ \\
\hline 1 & 0,1 & 0,16 & 0,16 & 0,16 & 0,22 \\
\hline 2 & 0,1 & 0,16 & 0,16 & 0,16 & 0,20 \\
\hline 3 & 0,1 & 0,16 & 0,18 & 0,13 & 0,23 \\
\hline 4 & 0,1 & 0,16 & 0,16 & 0,13 & 0,13 \\
\hline 5 & 0,1 & 0,16 & 0,20 & 0,16 & 0,30 \\
\hline MW & 0,1 & 0,16 & 0,17 & 0,15 & 0,22 \\
\hline SD & 0,00 & 0,00 & 0,02 & 0,02 & 0,06 \\
\hline $\begin{array}{c}M W \pm \\
\text { SD }\end{array}$ & $0,10 \pm 0$ & $0,16 \pm 0$ & $0,17 \pm 0,02$ & $0,15 \pm 0,02$ & $0,22 \pm 0,06$ \\
\hline
\end{tabular}






Abbildung 1: Ergebnisse der postischämischen Nierenfunktion: Kreatininkonzentration im Serum in $\mathrm{mg} / \mathrm{dl}$. Ergebnisse als MW \pm SD. ${ }^{*}=\mathrm{p}<0,05$.

Die Ergebnisse lassen sich wie folgt deuten:

Nach alleiniger Ischämie kam es zu einer deutlichen Verschlechterung der Nierenfunktion. Das Ergebnis ist statistisch signifikant.

- Alleinige Ischämie: $0,16 \pm 0 \mathrm{mg} / \mathrm{dl}$ vs. unbehandelte Kontrollen: $0,10 \pm 0 \mathrm{mg} / \mathrm{dl}, \mathrm{p}=0,01$

Die Applikation von unbehandelten eEOCs führte bei gewähltem Versuchsaufbau erwartungsgemäß zu keiner Verbesserung der Nierenfunktion (Patschan et al. 2010). Das Ergebnis ist statistisch nicht signifikant.

- Unbehandelte Zellen: 0,17 $\pm 0,02 \mathrm{mg} / \mathrm{dl}$ vs. alleinige Ischämie: $0,16 \pm 0 \mathrm{mg} / \mathrm{dl}, \mathrm{p}=0,35$

Die Fibrat-Vorbehandlung der eEOCs verbesserte die Funktion nicht. Unter Fenofibrat kam es zu einer leichten Verbesserung der Nierenfunktion. Unter Clofibrat kam es zu einer Verschlechterung der Nierenfunktion. Beide Ergebnisse sind statistisch nicht signifikant.

- $\quad 50-\mu M-F e n o f i b r a t: 0,15 \pm 0,02$ mg / dl vs. unbehandelte Zellen:

$0,17 \pm 0,02 \mathrm{mg} / \mathrm{dl}, \mathrm{p}=0,12$

- 1-mM-Cofibrat: 0,22 $\pm 0,06 \mathrm{mg} / \mathrm{dl}$ vs. unbehandelte Zellen:

$0,17 \pm 0,02 \mathrm{mg} / \mathrm{dl}, \mathrm{p}=0,17$ 


\subsection{In-vitro-Versuchsreihe}

Um einen genaueren Eindruck der zellulären Konsequenzen einer Fibrat-Behandlung von eEOCs zu erhalten, wurden die folgenden drei Parameter an kultivierten Zellen erhoben:

- Migrationsverhalten (Versuch 1),

- Zellüberleben (Versuch 2) sowie

- Proangiogener Effekt der Zellen über die Freisetzung des Wachstumsfaktors VEGF (Versuch 3).

Wie bereits beschrieben, bestand der Versuch aus zwei Teilen. Zuerst wurden orientierend die Effekte von Fenofibrat in der Konzentration von $50 \mu \mathrm{M}$ und Clofibrat in der Konzentration von $1 \mathrm{mM}$ auf die jeweiligen Parameter begutachtet. Hierfür wurden je Gruppe sechs Zellkulturen verwendet. Im Anschluss erfolgte die genauere Betrachtung der konzentrationsabhängigen (1,5 und $10 \mu \mathrm{M}$ ) Effekte von Fenofibrat. Hierfür wurden, mit Ausnahme des dritten Versuches, je Gruppe drei Zellkulturen verwendet. In Versuch 3 Teil 2 wurde mit jeweils neun Ansätzen pro Zellkultur gearbeitet.

\subsubsection{Versuch 1: Migrationsverhalten}

Zur Analyse der fibratbedingten Modulation der Migration von eEOCs wurde mittels eines standardisierten Stempels eine artifizielle Wundfläche in ein eEOC-Zellrasen induziert. Die Wundfläche wurde zu unterschiedlichen Zeitpunkten $(0,3$ und 24 Stunden) fotografiert. Das Ausmaß der Migration wurde über die prozentuale Reduktion der Wundflächengröße nach 24 Stunden ermittelt.

Im Folgenden werden die Gruppen kurz vorgestellt sowie die Ergebnisse tabellarisch und graphisch zusammengefasst.

\subsubsection{Teil 1: Orientierung}

\subsection{Gruppe 1 - unbehandelte Kontrollen}

Die sechs Zellkulturen der Gruppe 1 wurden ohne spezielles Medium inkubiert. Sie dienten als Kontrollgruppe und somit zur Abschätzung des Effektes der Fibratinduzierten PPARa-Aktivierung auf das Migrationsverhalten.

Nach 24 Stunden lag die mittlere Größe der weiterhin freien Wundfläche bei $62,57 \pm 11,52 \%$ (MW $\pm \mathrm{SD}$ ) der Ausgangsfläche. Das entspricht einer mittleren Reduktion der Wundfläche um 37,43 $\pm 11,52 \%$ (MW \pm SD). 


\subsection{Gruppe 2 - Fenofibrat-vorbehandelte Zellen}

Die fün Zellkulturen der Gruppe 2 wurden mit Fenofibrat in der Konzentration von $50 \mu \mathrm{M}$ inkubiert. Es sollte die Fibrat-induzierte Modulation auf das Migrationsverhalten der eEOCs untersucht werden.

Nach 24 Stunden lag die mittlere Größe der weiterhin freien Wundfläche bei $62,12 \pm 10,66 \%$ (MW $\pm S D$ ) der Ausgangsfläche. Das entspricht einer mittleren Reduktion der Wundfläche um 37,88 $\pm 10,66 \%$ (MW \pm SD).

\subsection{Gruppe 3 - Clofibrat-vorbehandelte Zellen}

Die sechs Zellkulturen der Gruppe 3 wurden mit Clofibrat in der Konzentration von $1 \mathrm{mM}$ inkubiert. Es sollte die Fibrat-induzierte Modulation auf das Migrationsverhalten der eEOCs untersucht werden.

Die prozentuale Auswertung war bei der mit Clofibrat behandelten Zellpopulation nicht möglich, da sich nach 24 Stunden eine komplette Desintegration des Zellverbandes von den Kulturplattenböden zeigte.

\subsubsection{Teil 2: konzentrationsabhängige Effekte von Fenofibrat}

\subsection{Gruppe 1 - unbehandelte Kontrollen}

Die drei Zellkulturen der Gruppe 1 wurden ohne spezielles Medium inkubiert. Sie dienten als Kontrollgruppe und somit zur Abschätzung des Effektes der Fibratinduzierten PPARa-Aktivierung auf das Migrationsverhalten.

Nach 24 Stunden lag die mittlere Größe der weiterhin freien Wundfläche bei $32,34 \pm 28,94 \%(M W \pm S D)$ der Ausgangsfläche. Das entspricht einer mittleren Reduktion der Wundfläche um 67,36 $\pm 28,94 \%$ (MW $\pm S D$ ).

\subsection{Gruppe 2 - Fenofibrat-vorbehandelte Zellen}

Die drei Zellkulturen der Gruppe 2 wurden mit Fenofibrat in unterschiedlichen Konzentration von 1, 5 und $10 \mu \mathrm{M}$ inkubiert. Es sollte die Fibrat-induzierte Modulation auf das Migrationsverhalten der eEOCs untersucht werden.

Nach 24 Stunden lag die Größe der weiterhin freien Wundfläche bei MW \pm SD \% der Ausgangsfläche:

- Fenofibrat $1 \mu \mathrm{M}$ : $23,7 \pm 35,27 \%$

- Fenofibrat $5 \mu \mathrm{M}$ : $8,94 \pm 0,59 \%$

- Fenofibrat $10 \mu \mathrm{M}$ : $13,79 \pm 14,63 \%$

Das entspricht einer mittleren Reduktion der Wundfläche um MW \pm SD \%:

- Fenofibrat $1 \mu \mathrm{M}: \quad 76,3 \pm 35,27 \%$

- Fenofibrat $5 \mu \mathrm{M}$ : $91,06 \pm 0,59 \%$

- Fenofibrat $10 \mu \mathrm{M}$ : $86,21 \pm 14,63 \%$ 


\subsubsection{Fotodokumentation}

Exemplarisch seien auf den folgenden Seiten die Fotos der Gruppe 1 unbehandelte Kontrollen und Gruppe $2-50-\mu \mathrm{M}$-Fenofibrat-vorbehandelte Zellen des ersten Teils (Orientierung) aufgeführt. Die Beschriftung der Abbildungen erfolgt nach dem Schema X.Y., wobei $X$ die Nummer der Gruppe und $Y$ die Nummer des Ansatzes darstellt. Ergebnisse gerundet auf zwei Stellen hinter dem Komma.

\subsection{Gruppe 1 - unbehandelte Kontrollen}

\begin{tabular}{|c|c|c|c|}
\hline Zeit in h & $0 \mathrm{~h}$ & $3 \mathrm{~h}$ & $24 \mathrm{~h}$ \\
\hline & & & \\
& & \\
\hline $\begin{array}{c}\text { Reduktion } \\
\text { nach 24 h } \\
\text { um \% }\end{array}$
\end{tabular}

Abbildung 2: Fotos Gruppe 1 - unbehandelte Kontrollen, Ansatz 1

\begin{tabular}{|c|c|c|c|}
\hline Zeit in h & Oh & $3 \mathrm{~h}$ & $24 \mathrm{~h}$ \\
\hline & & & \\
& & & \\
\hline $\begin{array}{c}\text { Reduktion } \\
\text { nach 24 h } \\
\text { um \% }\end{array}$ & 34,94 \\
\hline
\end{tabular}

Abbildung 3: Fotos Gruppe 1 - unbehandelte Kontrollen, Ansatz 2 


\begin{tabular}{|c|c|c|c|}
\hline Zeit in h & Oh & $3 \mathrm{~h}$ & $24 \mathrm{~h}$ \\
\hline & & & \\
& & & \\
\hline $\begin{array}{c}\text { Reduktion } \\
\text { nach 24 } \mathrm{h} \\
\text { um \% }\end{array}$
\end{tabular}

Abbildung 4: Fotos Gruppe 1 - unbehandelte Kontrollen, Ansatz 3

\begin{tabular}{|l|l|l|l|}
\hline Zeit in h & Oh & $3 \mathrm{~h}$ & $24 \mathrm{~h}$ \\
\hline & & & \\
& & & \\
& & & \\
\hline $\begin{array}{c}\text { Reduktion } \\
\text { nach 24 } \mathrm{h} \\
\text { um \% }\end{array}$ & 27,8 \\
\hline
\end{tabular}

Abbildung 5: Fotos Gruppe 1 - unbehandelte Kontrollen, Ansatz 4

\begin{tabular}{|c|c|c|c|}
\hline Zeit in h & Oh & $3 \mathrm{~h}$ & $24 \mathrm{~h}$ \\
\hline & & & \\
& & & \\
\hline $\begin{array}{c}\text { Reduktion } \\
\text { nach 24 h } \\
\text { um \% }\end{array}$ & 40,59 \\
\hline
\end{tabular}

Abbildung 6: Fotos Gruppe 1 - unbehandelte Kontrollen, Ansatz 5 


\begin{tabular}{|c|c|c|c|}
\hline Zeit in $\mathrm{h}$ & $\mathrm{Oh}$ & $3 \mathrm{~h}$ & $24 \mathrm{~h}$ \\
\hline & & & \\
& & & \\
\hline $\begin{array}{c}\text { Reduktion } \\
\text { nach 24 } \mathrm{h} \\
\text { um \% }\end{array}$ & 22,52 \\
\hline
\end{tabular}

Abbildung 7: Fotos Gruppe 1 - unbehandelte Kontrollen, Ansatz 6

\subsection{Gruppe 2 - 50- $\mu \mathrm{M}$-Fenofibrat-vorbehandelte Zellen}

\begin{tabular}{|c|c|c|c|}
\hline Zeit in $\mathrm{h}$ & $\mathrm{Oh}$ & $3 \mathrm{~h}$ & $24 \mathrm{~h}$ \\
\hline Abbildung & & & 2 \\
& & & \\
& & & \\
\hline $\begin{array}{c}\text { Reduktion } \\
\text { nach 24 } \mathrm{h} \\
\text { um \% }\end{array}$ & 22,06 & \\
\hline
\end{tabular}

Abbildung 8: Fotos Gruppe 2 - $50 \mu$ M Fenofibrat-vorbehandelte Zellen, Ansatz 1

\begin{tabular}{|c|c|c|c|}
\hline Zeit in $\mathrm{h}$ & $0 \mathrm{~h}$ & $3 \mathrm{~h}$ & $24 \mathrm{~h}$ \\
\hline Abbildung & & & \\
\hline $\begin{array}{c}\text { Reduktion } \\
\text { nach } 24 \text { h } \\
\text { um \% }\end{array}$ & & \multicolumn{2}{|l|}{44,88} \\
\hline
\end{tabular}

Abbildung 9: Fotos Gruppe 2 - $50 \mu$ M Fenofibrat-vorbehandelte Zellen, Ansatz 2 


\begin{tabular}{|c|c|c|c|}
\hline Zeit in $\mathrm{h}$ & $\mathrm{Oh}$ & $3 \mathrm{~h}$ & $24 \mathrm{~h}$ \\
\hline Abbildung & & & \\
\hline $\begin{array}{c}\text { Reduktion } \\
\text { nach } 24 \text { h } \\
\text { um } \%\end{array}$ & & \multicolumn{2}{|l|}{39,85} \\
\hline
\end{tabular}

Abbildung 10: Fotos Gruppe 2 - $50 \mu \mathrm{M}$ Fenofibrat-vorbehandelte Zellen, Ansatz 3

\begin{tabular}{|c|c|c|c|}
\hline Zeit in $\mathrm{h}$ & $0 \mathrm{~h}$ & $3 \mathrm{~h}$ & $24 \mathrm{~h}$ \\
\hline Abbildung & & & \\
\hline $\begin{array}{c}\text { Reduktion } \\
\text { nach } 24 \text { h } \\
\text { um \% }\end{array}$ & & 45,44 & \\
\hline
\end{tabular}

\begin{tabular}{|c|c|c|c|}
\hline Zeit in $\mathrm{h}$ & $\mathrm{Oh}$ & $3 \mathrm{~h}$ & $24 \mathrm{~h}$ \\
\hline Abbildung & & & \\
\hline $\begin{array}{c}\text { Reduktion } \\
\text { nach } 24 \text { h } \\
\text { um \% }\end{array}$ & & \multicolumn{2}{|l|}{33,16} \\
\hline
\end{tabular}

Abbildung 12: Fotos Gruppe 2 - 50 MM Fenofibrat-vorbehandelte Zellen, Ansatz 5 


\subsubsection{Zusammenfassung und Deutung}

Tabelle 4 fasst die Ergebnisse des ersten Teils zusammen, Abbildung 14 stellt die Ergebnisse graphisch dar. Tabelle 5 fasst die Ergebnisse des zweiten Teils zusammen, Abbildung 15 stellt die Ergebnisse graphisch dar. In Tabelle und Abbildung 15 erfolgt die Gruppennummerierung wie folgt: Gruppe 1 - unbehandelte Kontrollen, Gruppe 2 - 1- $\mathrm{MM}$-Fenofibrat-vorbehandelte Zellen, Gruppe 3 5- $\mu \mathrm{M}$-Fenofibrat-vorbehandelte Zellen, Gruppe $4-10-\mu \mathrm{M}$-Fenofibrat-vorbehandelte Zellen.

\begin{tabular}{|c|c|c|c|}
\hline \multicolumn{4}{|c|}{ Reduktion der Wundfläche nach 24 Stunden um \% } \\
\hline Zellkultur & $\begin{array}{c}\text { Gruppe 1- } \\
\text { unbehandelte Kontrollen }\end{array}$ & 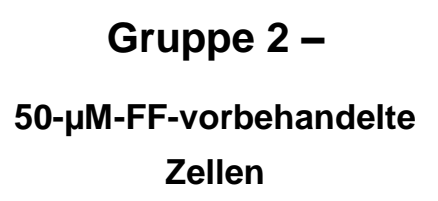 & $\begin{array}{c}\text { Gruppe 3- } \\
\text { 1-mM-CF-vorbehandelte } \\
\text { Zellen }\end{array}$ \\
\hline 1 & 54,22 & 22,06 & l \\
\hline 2 & 34,94 & 48,88 & I \\
\hline 3 & 44,53 & 39,85 & I \\
\hline 4 & 27,8 & 45,44 & I \\
\hline 5 & 40,49 & 33,16 & I \\
\hline 6 & 22,52 & / & I \\
\hline MW & 37,43 & 37,88 & I \\
\hline SD & 11,52 & 10,66 & I \\
\hline MW \pm SD & $37,43 \pm 11,52$ & $37,88 \pm 10,66$ & I \\
\hline
\end{tabular}

Tabelle 4: Ergebnisse der Wundflächenreduktion in \% (Versuch 1: Migrationsverhalten, Teil 1). Ergebnisse gerundet auf zwei Stellen hinter dem Komma und als MW \pm SD. 


\begin{tabular}{|c|c|c|c|c|}
\hline \multicolumn{5}{|c|}{ Reduktion der Wundfläche nach 24 Stunden um \% } \\
\hline Zellkultur & $\begin{array}{c}\text { Gruppe } 1 \text { - } \\
\text { unbehandelte } \\
\text { Kontrollen }\end{array}$ & 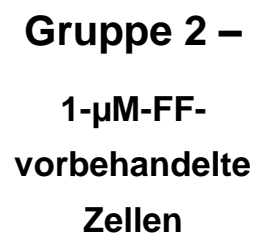 & $\begin{array}{c}\text { Gruppe } 3 \text { - } \\
5-\mu M-F F- \\
\text { vorbehandelte } \\
\text { Zellen }\end{array}$ & 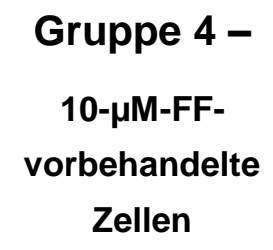 \\
\hline 1 & 84,50 & 35,6 & 90,99 & 94,93 \\
\hline 2 & 33,95 & 97,87 & 90,5 & 69,32 \\
\hline 3 & 83,63 & 95,43 & 91,68 & 94,37 \\
\hline MW & 67,36 & 76,3 & 91,06 & 86,21 \\
\hline SD & 28,94 & 35,27 & 0,59 & 14,63 \\
\hline $\mathbf{M W} \pm \mathrm{SD}$ & $67,36 \pm 28,94$ & $76,3 \pm 35,27$ & $91,06 \pm 0,59$ & $86,21 \pm 14,63$ \\
\hline
\end{tabular}




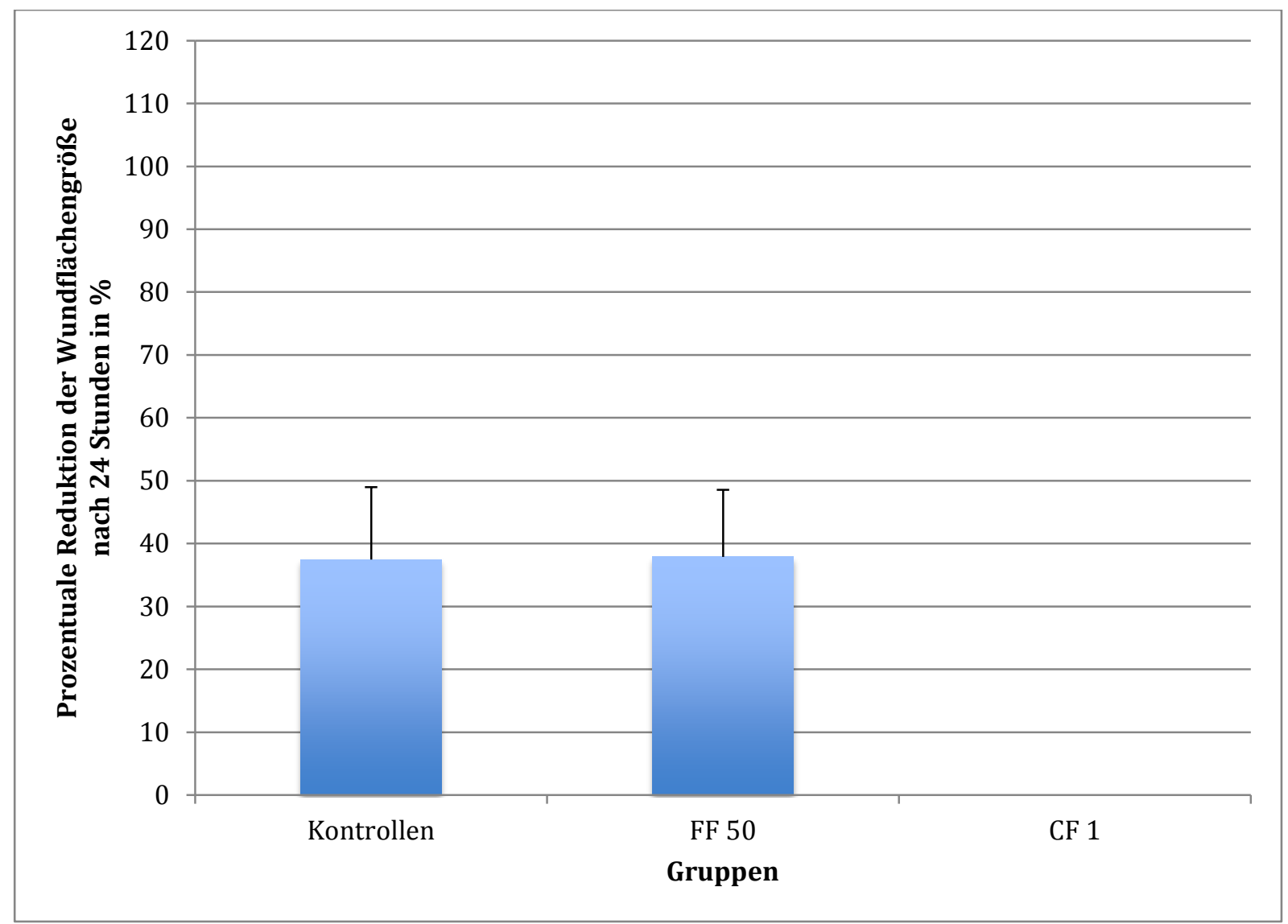

Abbildung 13: Prozentuale Reduktion der Wundflächengröße nach 24 Stunden in \% (Versuch 1: Migrationsverhalten, Teil 1).

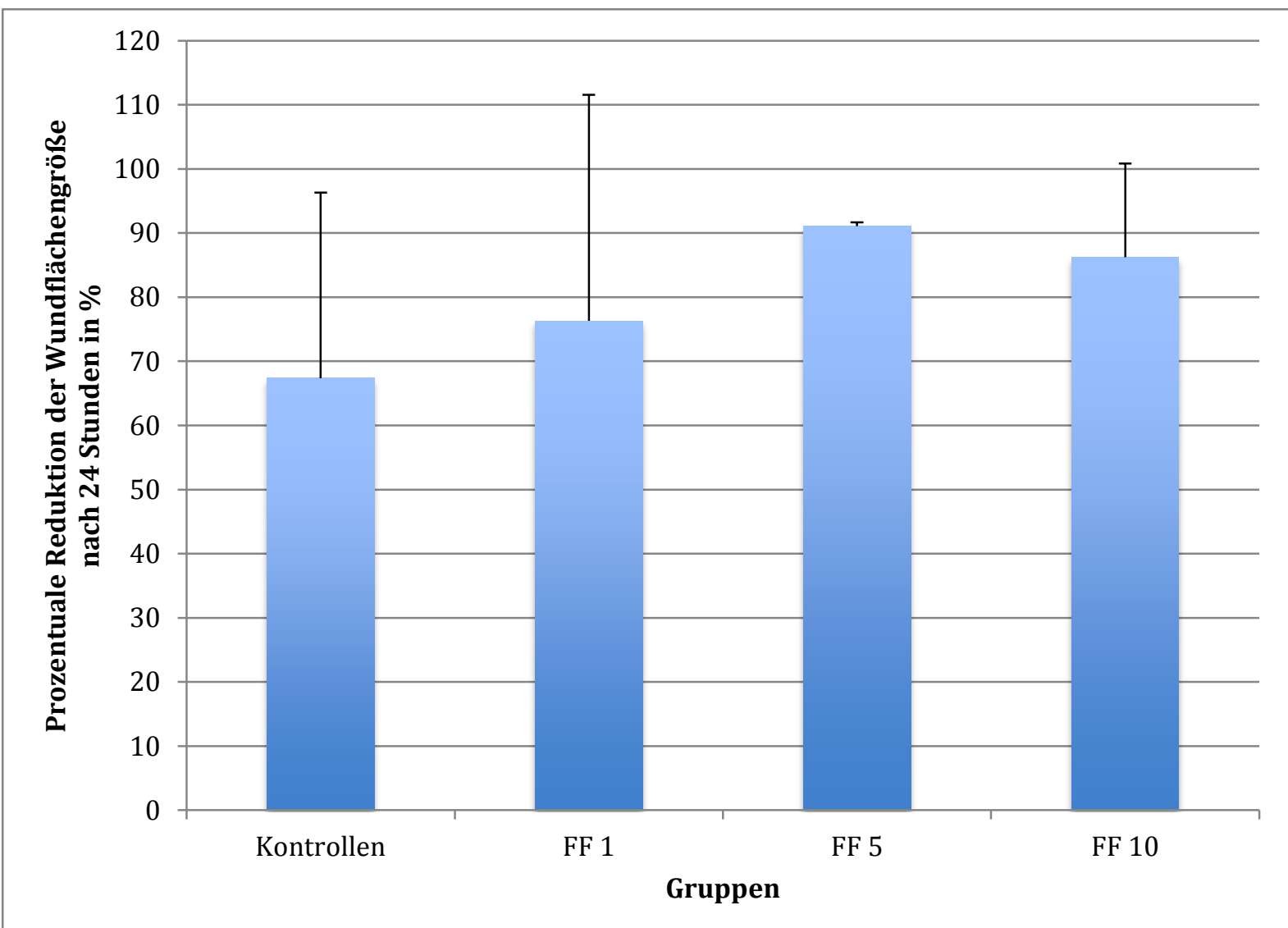

Abbildung 14: Prozentuale Reduktion der Wundflächengröße nach 24 Stunden in \% (Versuch 1: Migrationsverhalten, Teil 2). 
Die Ergebnisse lassen sich wie folgt deuten:

Unter dem Einfluss von Fenofibrat kam es zu Veränderungen der Wundflächengröße, wenn auch durchweg nicht in signifikantem Ausmaß. Fenofibrat steigerte das Migrationsverhalten der kultivierten Zellen in vitro. Kleine und mittlere Konzentrationen $(1,5,10 \mu \mathrm{M})$ steigerten das Migrationsverhalten im Verhältnis mehr, als Fenofibrat in hoher Konzentration von $50 \mu \mathrm{M}$.

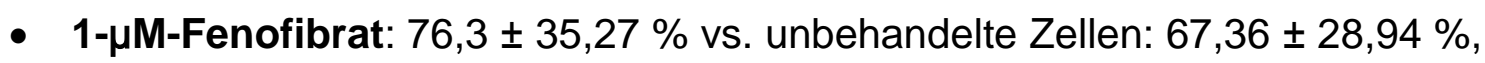
$p=0,75$


$p=0,22$

- 10- $\mu \mathrm{M}$-Fenofibrat: $86,21 \pm 14,63 \%$ vs. unbehandelte Zellen:

$67,36 \pm 28,94 \%, p=0,37$

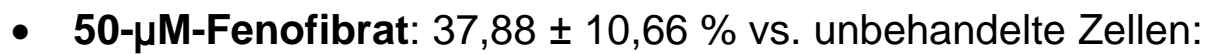

$37,43 \pm 11,52 \%, p=0,95$

Unter dem Einfluss von 1-mM-Clofibrat hingegen zeigte sich nach 24 Stunden eine komplette Desintegration des Zellverbandes von den Kulturplattenböden. Daher war einen prozentuale Auswertung nicht möglich. 


\subsubsection{Versuch 2: Zellüberleben}

Zur Analyse des Zellüberlebens wurde ein Test eingesetzt, der tote Zellen (Stadium III: spät-apoptotisch und nekrotisch) mittels Annexin-V-Markierung und Anfärbung mit Propidiumiodid (PI) demaskiert. Die Quantifizierung erfolgte mittels Durchflusszytometrie. Die Werte entsprechen dem prozentualen Vorliegen von toten Zellen im Verhältnis zur Gesamtzellzahl.

Im Folgenden werden die Gruppen kurz vorgestellt sowie die Ergebnisse tabellarisch und graphisch zusammengefasst.

\subsubsection{Teil 1: Orientierung}

\subsection{Gruppe 1 - unbehandelte Kontrollen}

Die vier Zellkulturen der Gruppe 1 wurden ohne spezielles Medium inkubiert. Sie diente als Kontrollgruppe und somit zur Abschätzung des Effektes der Fibrat-induzierten PPARa-Aktivierung auf das Überleben der eEOCs.

Die Rate von toten zu lebendigen Zellen lag im Mittel (MW) bei 7,18\%, die Standardabweichung (SD) betrug 1,06.

\subsection{Gruppe 2 - Fenofibrat-vorbehandelte Zellen}

Die sechs Zellkulturen der Gruppe 2 wurden mit einer Fenofibratkonzentration von $50 \mu \mathrm{M}$ inkubiert. Es sollte die Fibrat-induzierte Modulation auf das Überleben der eEOCs untersucht werden.

Die Rate von toten zu lebendigen Zellen lag im Mittel (MW) bei $12,54 \%$, die Standardabweichung (SD) betrug 2,89. Dies entspricht einer mittleren Steigerung der toten Zellen um $74,58 \pm 40,2 \%$.

\subsection{Gruppe 3 - Clofibrat-vorbehandelte Zellen}

Die sechs Zellkulturen der Gruppe 3 wurden mit einer Clofibratkonzentration von $1 \mathrm{mM}$ inkubiert. Es sollte die Fibrat-induzierte Modulation auf das Überleben der eEOCs untersucht werden.

Die Rate von toten zu lebendigen Zellen lag im Mittel (MW) bei 7,11\%, die Standardabweichung (SD) betrug 1,01. Dies entspricht einer mittleren Reduktion der toten Zellen um $0,93 \pm 14,07 \%$. 


\subsubsection{Teil 2: konzentrationsabhängige Effekte von Fenofibrat}

\subsection{Gruppe 1 - unbehandelte Kontrollen}

Die drei Zellkulturen der Gruppe 1 wurden ohne spezielles Medium inkubiert. Sie diente als Kontrollgruppe und somit zur Abschätzung des Effektes der Fibrat-induzierten PPARa-Aktivierung auf das Überleben der eEOCs.

Die Rate von toten zu lebendigen Zellen lag im Mittel (MW) bei 60,33\%, die Standardabweichung (SD) betrug 6,51.

\subsubsection{Gruppe 2 - Fenofibrat-vorbehandelte Zellen}

Die drei Zellkulturen der Gruppe 2 wurden mit Fenofibrat in unterschiedlichen Konzentrationen von 1, 5 und $10 \mu \mathrm{M}$ inkubiert. Es sollte die Fibrat-induzierte Modulation auf das Überleben der eEOCs untersucht werden.

Die mittlere Rate von toten zu lebendigen Zellen (MW) \pm Standardabweichung (SD) lag für folgende Konzentrationen bei:

- Fenofibrat $1 \mu \mathrm{M}$ : $19 \pm 5,57 \%$

- Fenofibrat $5 \mu \mathrm{M}$ : $13 \pm 1 \%$

- Fenofibrat $10 \mu \mathrm{M}$ : 15,67 $\pm 2,08 \%$

Dies entspricht einer mittleren Reduktion der toten Zellen um MW \pm SD \%:

- Fenofibrat $1 \mu \mathrm{M}$ : $68,33 \pm 9,28 \%$

- Fenofibrat $5 \mu \mathrm{M}$ : 78,33 $\pm 1,67 \%$

- Fenofibrat $10 \mu \mathrm{M}$ : 78,89 $\pm 3,47 \%$ 


\subsubsection{Zusammenfassung und Deutung}

Tabelle 6 fasst die Ergebnisse des ersten Teils zusammen, Abbildung 16 stellt die Ergebnisse des ersten Teils graphisch dar. Tabelle 7 fasst die Ergebnisse des zweiten Teils zusammen, Abbildung 17 stellt die Ergebnisse des zweiten Teils graphisch dar. In Tabelle und Abbildung 17 erfolgt die Gruppennummerierung wie folgt: Gruppe 1 - unbehandelte Kontrollen, Gruppe 2 - 1- $\mu \mathrm{M}$-Fenofibratvorbehandelte Zellen, Gruppe 3 - 5- $\mu \mathrm{M}$-Fenofibrat-vorbehandelte Zellen, Gruppe 4 $10-\mu \mathrm{M}$-Fenofibrat-vorbehandelte Zellen.

\begin{tabular}{|c|c|c|c|}
\hline \multicolumn{4}{|c|}{ Tote Zellen im Verhältnis zur Gesamtzellzahl in \% } \\
\hline Zellkultur & $\begin{array}{l}\text { Gruppe 1- } \\
\text { unbehandelte } \\
\text { Kontrollen }\end{array}$ & $\begin{array}{c}\text { Gruppe } 2 \text { - } \\
50-\mu M-F F- \\
\text { vorbehandelte Zellen }\end{array}$ & $\begin{array}{c}\text { Gruppe } 3 \text { - } \\
\text { 1-mM-CF- } \\
\text { vorbehandelte Zellen }\end{array}$ \\
\hline 1 & 8,22 & 11,76 & 6,41 \\
\hline 2 & 6,26 & 9,07 & 6,54 \\
\hline 3 & 7,97 & 10,09 & 6,43 \\
\hline 4 & 6,28 & 13,02 & 8,90 \\
\hline 5 & I & 14,29 & 7,75 \\
\hline 6 & / & 16,98 & 6,65 \\
\hline MW & 7,18 & 12,54 & 7,11 \\
\hline SD & 1,06 & 2,89 & 1,01 \\
\hline$M W \pm S D$ & $7,18 \pm 1,06$ & $12,54 \pm 2,89$ & $7,11 \pm 1,01$ \\
\hline
\end{tabular}




\begin{tabular}{|c|c|c|c|c|}
\hline \multicolumn{5}{|c|}{ Tote Zellen im Verhältnis zur Gesamtzellzahl in \% } \\
\hline Zellkultur & $\begin{array}{c}\text { Gruppe } 1 \text { - } \\
\text { unbehandelte } \\
\text { Kontrollen }\end{array}$ & 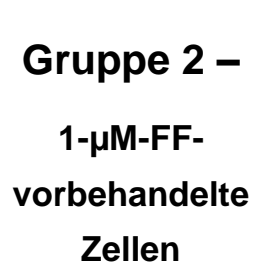 &  &  \\
\hline 1 & 60 & 14 & 14 & 14 \\
\hline 2 & 54 & 25 & 13 & 15 \\
\hline 3 & 67 & 18 & 12 & 18 \\
\hline MW & 60,33 & 19 & 13 & 15,67 \\
\hline SD & 6,51 & 5,57 & 1 & 2,08 \\
\hline$M W \pm S D$ & $60,33 \pm 6,51$ & $19 \pm 5,57$ & $13 \pm 1$ & $15,67 \pm 2,08$ \\
\hline
\end{tabular}

Tabelle 7: Ergebnisse des prozentualen Anteils toter Zellen an der Gesamtzellzahl in \% (Versuch 2: Zellüberleben, Teil 2). Ergebnisse gerundet auf zwei Stellen hinter dem Komma und als MW \pm SD. 




Abbildung 15: Prozentualer Anteil toter Zellen an der Gesamtzellzahl in \% (Versuch 2: Zellüberleben, Teil 1). ${ }^{*}=p<0,05$.

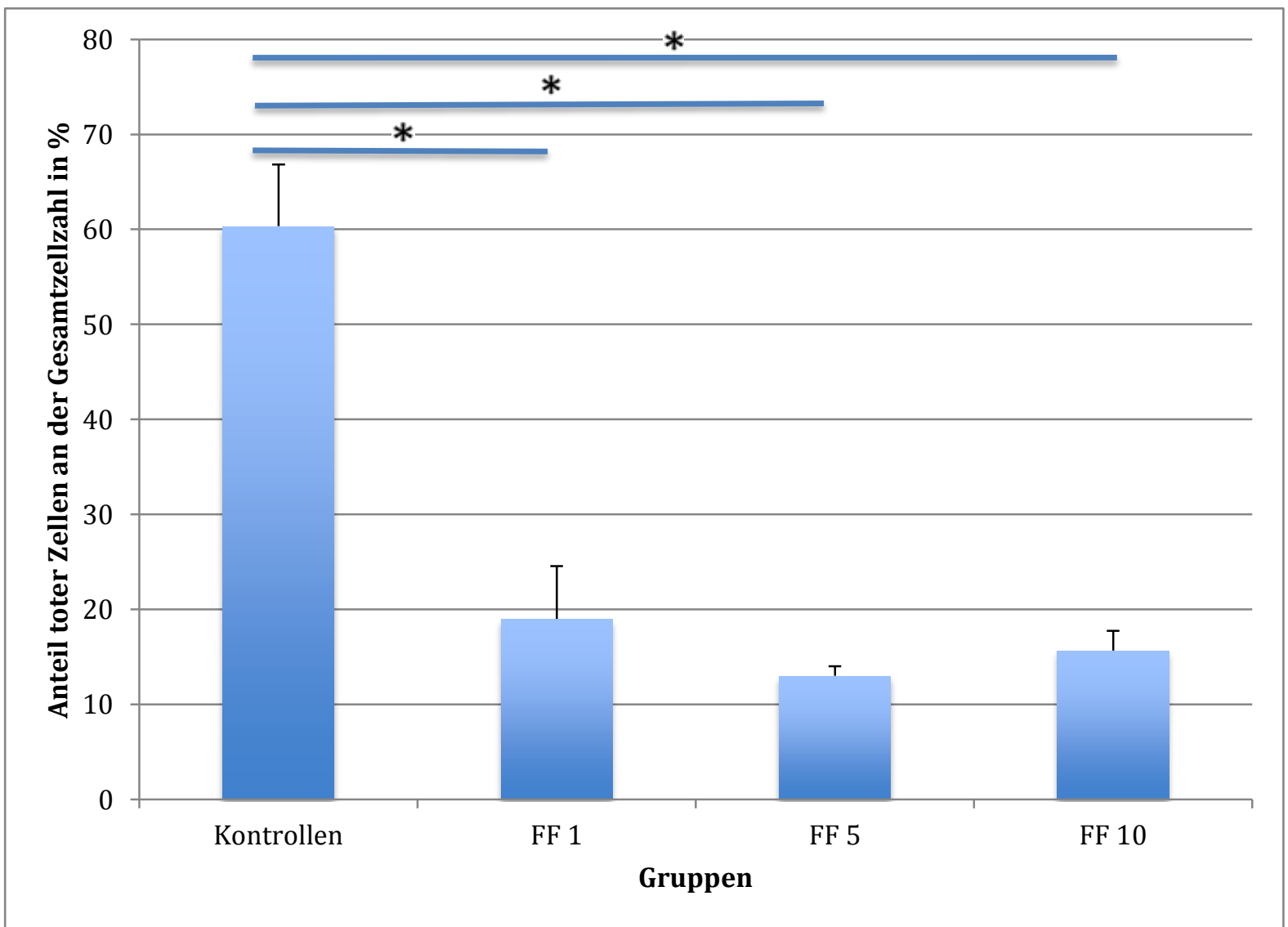

Abbildung 16: Prozentualer Anteil toter Zellen an der Gesamtzellzahl in \% (Versuch 2: Zellüberleben, Teil 2). * $=p<0,05$ 
Die Ergebnisse lassen sich wie folgt deuten:

Durch die Inkubation mit Fenofibrat kam es konzentrationsabhängig zu einer heterogenen Modulation des Zellüberlebens. In kleinen und mittleren Konzentrationen $(1,5,10 \mu \mathrm{M})$ zeigte sich das Zellüberleben anhand prozentual weniger toter Zellen erhöht. In hoher Konzentration $(50 \mu \mathrm{M})$ zeigte sich jedoch ein geringeres Zellüberleben. Die Ergebnisse sind statistisch signifikant.

- 1- $\mu$ M-Fenofibrat: $19 \pm 5,57 \%$ vs. unbehandelte Kontrollen: 60,33 $\pm 6,51 \%$, $p=0,001$

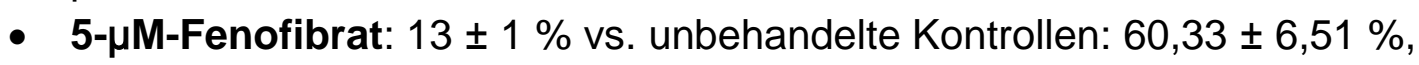
$p=0,0002$

- 10- $\mu \mathrm{M}$-Fenofibrat: $15,67 \pm 2,08 \%$ vs. unbehandelte Kontrollen: $60,33 \pm 6,51 \%, p=0,0003$

- 50 - $\mu$ M-Fenofibrat: $12,54 \pm 2,89 \%$ vs. unbehandelte Kontrollen: $7,18 \pm 1,06 \%, p=0,008$

Die Inkubation mit Clofibrat in der Konzentration von $1 \mathrm{mM}$ hatte nur einen sehr kleinen positiven Einfluss auf das Überleben, welches sich auf weniger als $1 \%$ toter Zellen im Verhältnis zur Kontrollgruppe beläuft.

- 1-mM-Clofibrat: 7,11 $\pm 1,01 \%$ vs. unbehandelte Kontrollen 7,18 $\pm 1,06 \%$, $p=0,92$

Bezogen auf die Anzahl toter Zellen zur Ausgangszellzahl bedeutet das:

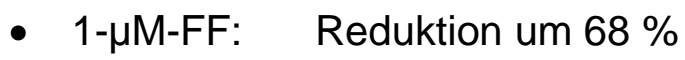





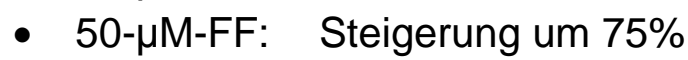

- 1-mM-CF: Reduktion um $<1 \%$ 


\subsubsection{Versuch 3: Proangiogenität}

VEGF kann als endothelialer, proangiogener Mediator im Zellmedium bei stattgefundenem Zellwachstums nachgewiesen werden und wird von eEOCs sezerniert (Rehman et al. 2003). Die Konzentration von VEGF im Überstand gilt daher als Maß für den proangiogenen Effekt der eEOCs. Zur Bestimmung der VEGF-Konzentration wurde ein ELISA-Verfahren genutzt.

Im Folgenden werden die Gruppen kurz vorgestellt sowie die Ergebnisse tabellarisch und graphisch zusammengefasst.

\subsubsection{Teil 1: Orientierung}

\subsection{Gruppe 1 - unbehandelte Kontrollen}

Die sechs Zellkulturen der Gruppe 1 wurden für eine Stunde bei $37^{\circ} \mathrm{C}$ in $350 \mu \mathrm{l}$ Celprogen Complete Growth Medium I (CCGMI; Firma CELPROGEN; Kat.-Nr.: M66110-37S) inkubiert. Sie diente als Kontrollgruppe und somit zur Abschätzung des Effektes der Fibrat-induzierten PPARa-Aktivierung auf die Sekretion von VEGF durch die eEOCs.

Die VEGF-Konzentration im Überstand lag im Mittel (MW) bei $201 \mathrm{pg} / \mathrm{ml}$, bei einer Standardabweichung (SD) von 14.

\subsection{Gruppe 2 - Fenofibrat-vorbehandelte Zellen}

Die sechs Zellkulturen der Gruppe 2 wurden für eine Stunde bei $37^{\circ} \mathrm{C}$ in $350 \mu \mathrm{l}$ Celprogen Complete Growth Medium I (CCGMI; Firma CELPROGEN; Kat.-Nr.: M66110-37S) mit einer Fenofibratkonzentration von $50 \mu \mathrm{M}$ inkubiert. Es sollte die Fibrat-induzierte Modulation der VEGF-Sekretion durch die eEOCs untersucht werden.

Die VEGF-Konzentration im Überstand lag im Mittel (MW) bei $164 \mathrm{pg} / \mathrm{ml}$, bei einer Standardabweichung (SD) von 16.

\subsection{Gruppe 3 - Clofibrat-vorbehandelte Zellen}

Die sechs Zellkulturen der Gruppe 3 wurden für eine Stunde bei $37^{\circ} \mathrm{C}$ in $350 \mu \mathrm{l}$ Celprogen Complete Growth Medium I (CCGMI; Firma CELPROGEN; Kat.-Nr.: M66110-37S) mit einer Clofibratkonzentration von $1 \mathrm{mM}$ inkubiert. Es sollte die Fibrat-induzierte Modulation der VEGF-Sekretion durch die eEOCs untersucht werden.

Die VEGF-Konzentration im Überstand lag im Mittel (MW) bei $108 \mathrm{pg} / \mathrm{ml}$, bei einer Standardabweichung (SD) von 43. 


\subsubsection{Teil 2: konzentrationsabhängige Effekte von Fenofibrat}

\subsection{Gruppe 1 - unbehandelte Kontrollen}

Die neun Zellkulturen der Gruppe 1 wurden für eine Stunde bei $37^{\circ} \mathrm{C}$ in $350 \mu \mathrm{l}$ Celprogen Complete Growth Medium I (CCGMI; Firma CELPROGEN; Kat.-Nr.: M66110-37S) inkubiert. Sie diente als Kontrollgruppe und somit zur Abschätzung des Effektes der Fibrat-induzierten PPARa-Aktivierung auf die Sekretion von VEGF durch die eEOCs.

Die VEGF-Konzentration im Überstand lag im Mittel (MW) bei $170 \mathrm{pg} / \mathrm{ml}$, bei einer Standardabweichung (SD) von 18.

\subsection{Gruppe 2 - Fenofibrat-vorbehandelte Zellen}

Die neun Zellkulturen der Gruppe 2 wurden für eine Stunde bei $37^{\circ} \mathrm{C}$ in $350 \mu \mathrm{l}$ Celprogen Complete Growth Medium I (CCGMI; Firma CELPROGEN; Kat.-Nr.: M66110-37S) mit Fenofibrat in unterschiedlichen Konzentration von 1, 5 und $10 \mu \mathrm{M}$ inkubiert. Es sollte die Fibrat-induzierte Modulation der VEGF-Sekretion durch die eEOCs untersucht werden.

Die mittlere Konzentration von VEGF $(\mathrm{MW}) \pm$ Standardabweichung $(\mathrm{SD})$ lag für folgende Konzentrationen bei:

- Fenofibrat $1 \mu \mathrm{M}: 142 \pm 16 \mathrm{pg} / \mathrm{ml}$

- Fenofibrat $5 \mu \mathrm{M}$ : $148 \pm 18 \mathrm{pg} / \mathrm{ml}$

- Fenofibrat $10 \mu \mathrm{M}$ : $313 \pm 24 \mathrm{pg} / \mathrm{ml}$ 


\subsubsection{Zusammenfassung und Deutung}

Tabelle 8 fasst die Ergebnisse des ersten Teils zusammen, Abbildung 18 stellt die Ergebnisse graphisch dar. Tabelle 9 fasst die Ergebnisse des zweiten Teils zusammen, Abbildung 19 stellt die Ergebnisse graphisch dar. In Tabelle 9 und Abbildung 19 erfolgt die Gruppennummerierung wie folgt: Gruppe 1 - unbehandelte

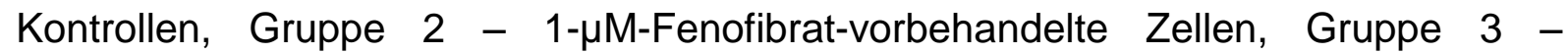
5- $\mu \mathrm{M}$-Fenofibrat-vorbehandelte Zellen, Gruppe 4 - 10- $\mu \mathrm{M}$-Fenofibrat-vorbehandelte Zellen.

\begin{tabular}{|c|c|c|c|}
\hline \multicolumn{4}{|c|}{ VEGF-Konzentration in pg / $\mathrm{ml}$ im Überstand } \\
\hline Zellkultur & $\begin{array}{l}\text { Gruppe 1- } \\
\text { unbehandelte } \\
\text { Kontrollen }\end{array}$ & $\begin{array}{c}\text { Gruppe } 2 \text { - } \\
50-\mu M-F F- \\
\text { vorbehandelte Zellen }\end{array}$ & $\begin{array}{c}\text { Gruppe } 3 \text { - } \\
\text { 1-mM-CF- } \\
\text { vorbehandelte Zellen }\end{array}$ \\
\hline 1 & 211 & 175 & 23 \\
\hline 2 & 192 & 180 & 122 \\
\hline 3 & 194 & 173 & 115 \\
\hline 4 & 225 & 148 & 117 \\
\hline 5 & 192 & 167 & 132 \\
\hline 6 & 190 & 140 & 139 \\
\hline MW & 201 & 164 & 108 \\
\hline SD & 14 & 16 & 43 \\
\hline$M W \pm S D$ & $201 \pm 14$ & $164 \pm 16$ & $108 \pm 43$ \\
\hline
\end{tabular}

Tabelle 8: Ergebnisse der VEGF-Konzentration im Überstand in pg / ml (Versuch 3: Proangiogener Effekt, Teil 1). Ergebnisse gerundet ohne Kommastellen und als MW \pm SD. 


\begin{tabular}{|c|c|c|c|c|}
\hline \multicolumn{5}{|c|}{ VEGF-Konzentration in pg / ml im Überstand } \\
\hline Zellkultur & $\begin{array}{c}\text { Gruppe } 1 \text { - } \\
\text { unbehandelte } \\
\text { Kontrollen }\end{array}$ & 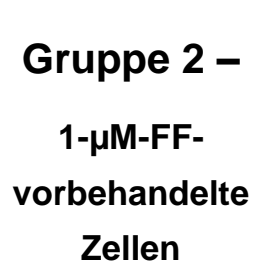 & $\begin{array}{c}\text { Gruppe } 3 \text { - } \\
5-\mu M-F F- \\
\text { vorbehandelte } \\
\text { Zellen }\end{array}$ & 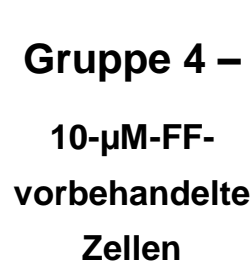 \\
\hline 1 & 193 & 176 & 75 & 295 \\
\hline 2 & 180 & 225 & 77 & 276 \\
\hline 3 & 249 & 132 & 208 & 411 \\
\hline 4 & 149 & 51 & 195 & 261 \\
\hline 5 & 72 & 115 & 163 & 297 \\
\hline 6 & 101 & 176 & 186 & 228 \\
\hline 7 & 219 & 147 & 117 & 388 \\
\hline 8 & 194 & 157 & 101 & 421 \\
\hline 9 & 174 & 100 & 216 & 241 \\
\hline MW & 170 & 142 & 148 & 313 \\
\hline SD & 18 & 16 & 18 & 24 \\
\hline$M W \pm S D$ & $170 \pm 18$ & $142 \pm 16$ & $148 \pm 18$ & $313 \pm 24$ \\
\hline
\end{tabular}

Tabelle 9: Ergebnisse der VEGF-Konzentration im Überstand in $\mathrm{pg} / \mathrm{ml}$ (Versuch 3: Proangiogener Effekt, Teil 2). Ergebnisse gerundet ohne Kommastellen und als MW \pm SD. 


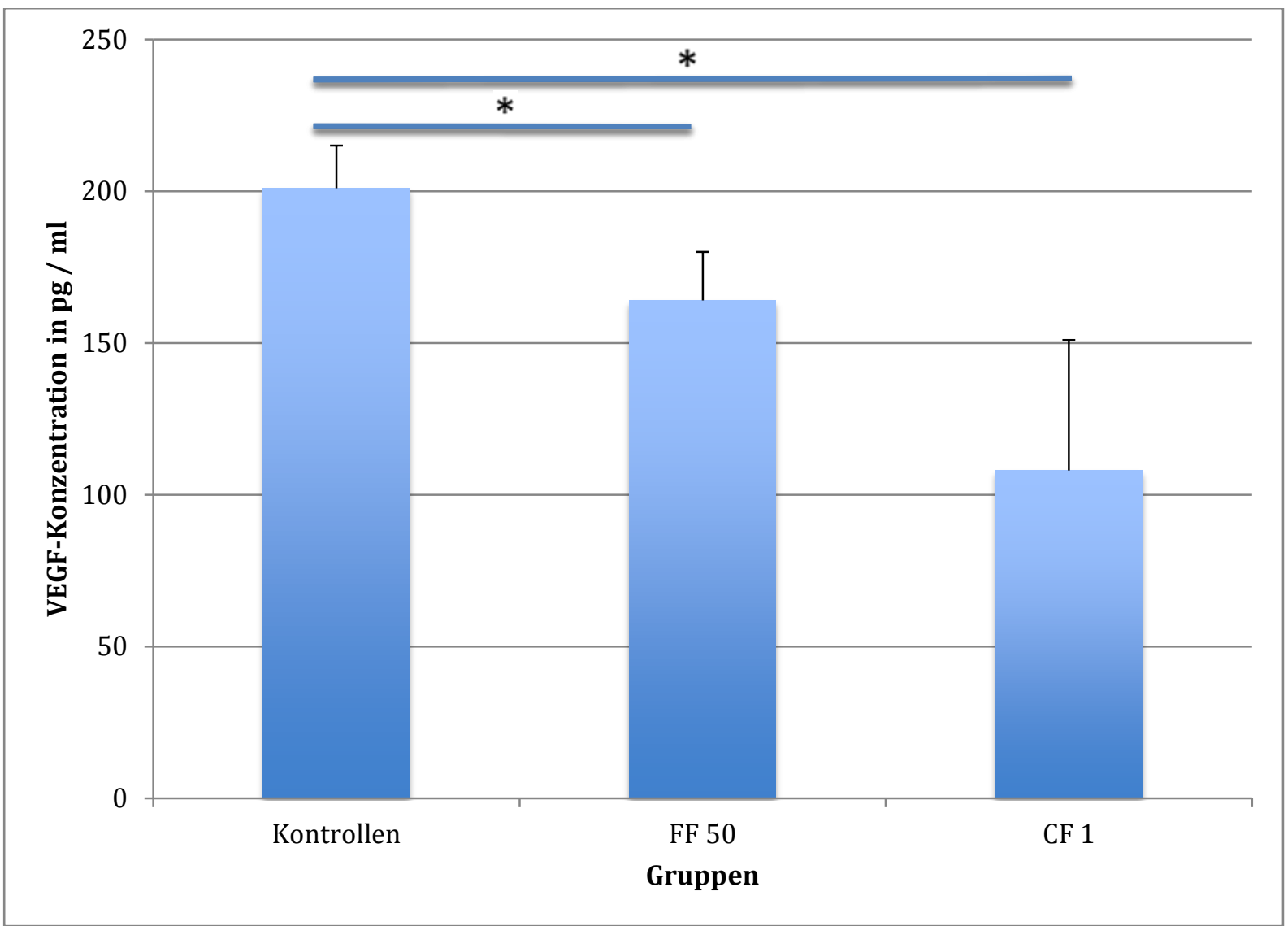

Abbildung 17: Ergebnisse der VEGF-Konzentration im Überstand in pg / ml (Versuch 3: Proangiogener Effekt, Teil 1). * $=p<0,05$.

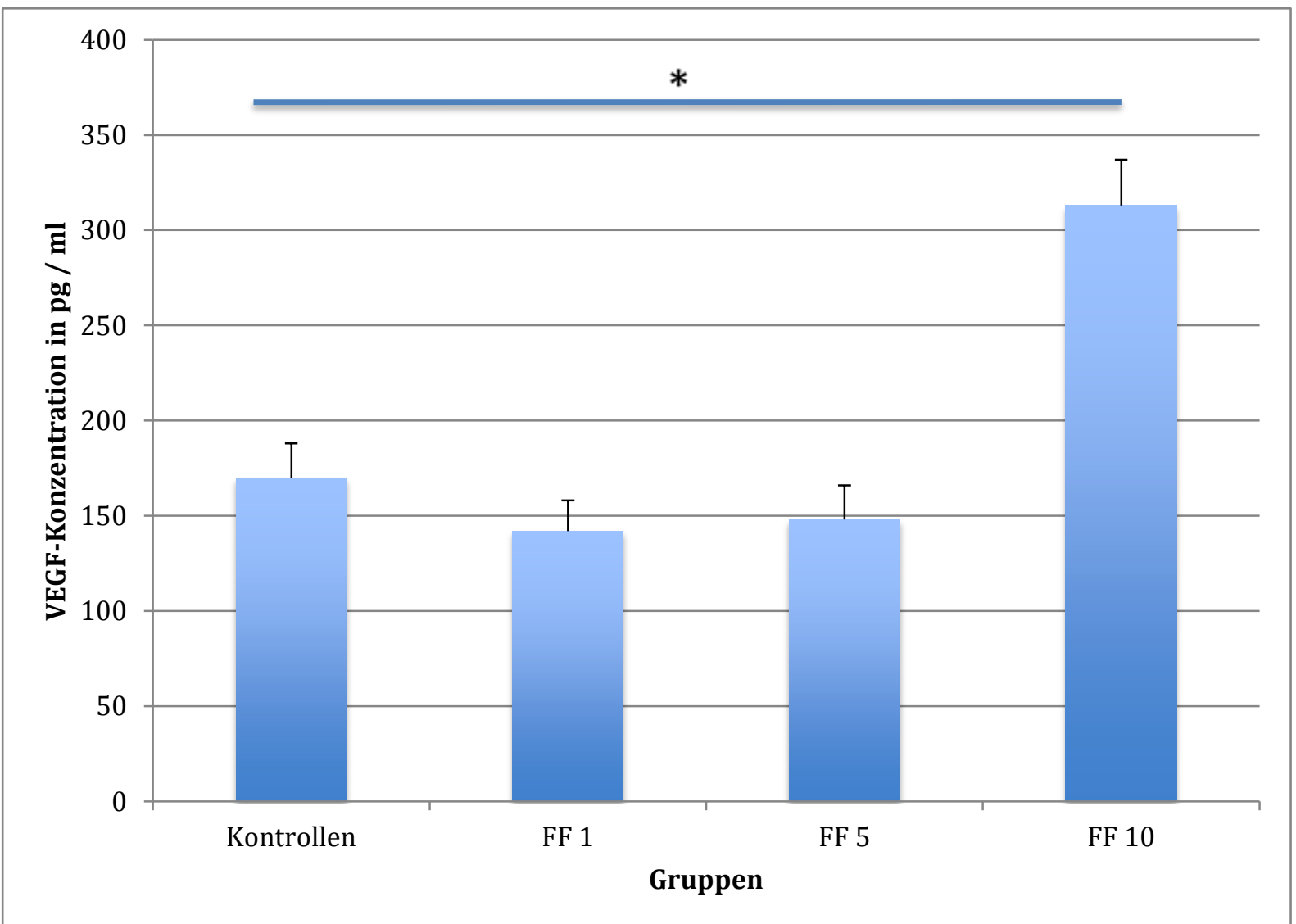

Abbildung 18: Ergebnisse der VEGF-Konzentration im Überstand in pg / ml (Versuch 3: Proangiogener Effekt, Teil 2). * $=p<0,05$. 
Die Ergebnisse lassen sich wie folgt deuten:

Über die Konzentration von VEGF im Überstand lässt sich der proangiogene Effekt der eEOCs bestimmen.

Durch die Inkubation mit Fenofibrat kam es konzentrationsabhängig zu einer heterogenen Modulation der proangiogenen Aktivität. In kleinen Konzentrationen $(1,5 \mu \mathrm{M})$, wie auch signifikant in hoher Konzentration $(50 \mu \mathrm{M})$ verschlechterte es die Funktionsweise der eEOCs. In mittlerer Konzentration von $10 \mu \mathrm{M}$ steigerte es die proangiogene Aktivität der Zellen in signifikantem Ausmaß.

- 1- $\mu$ M-Fenofibrat: $142 \pm 16$ vs. unbehandelte Kontrollen: $170 \pm 18, p=0,28$



- 10- $\mu$ M-Fenofibrat: $313 \pm 24$ vs. unbehandelte Kontrollen: $170 \pm 18, p=0,0003$

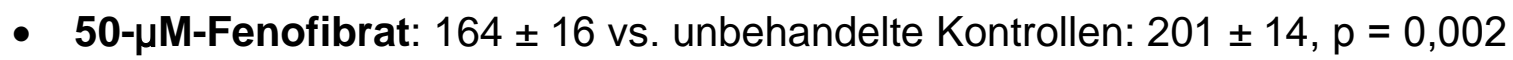

Durch die Inkubation mit $1 \mathrm{mM}$ Clofibrat kam es zu einer signifikant geringeren VEGF-Konzentration im Überstand.

- 1-mM-Clofibrat: $108 \pm 46$ vs. unbehandelte Kontrollen: $201 \pm 14, p=0,0005$ 


\section{Diskussion}

\subsection{Eigene Ergebnisse}

Die in der vorliegenden Arbeit dargestellten Versuche wurden im Rahmen eines Forschungsprojektes zur Untersuchung der therapeutischen Wertigkeit endothelialer Vorläuferzellen beim ischämisch bedingten akuten Nierenversagen durchgeführt.

Speziell wurde analysiert, ob durch pharmakologische Aktivierung von PPARa eine Modulation der eEOC-vermittelten Nephroprotektion beim iANV erzielt werden kann.

Die Experimente umfassten eine In-vivo-Tierversuchsreihe sowie drei In-vitroVersuche.

Im Rahmen der In-vivo-Experimente wurde der Effekt von PPARa, agonisiert durch Feno- und Clofibrat, auf die postischämische Nierenfunktion von eEOC-behandelten C57BI/6N-Mäusen untersucht.

Zu diesem Zweck wurde ein iANV durch 40-minütiges Abklemmen der linken renalen Hilusgefäße bei simultaner Totalnephrektomie rechts induziert.

Ausgenommen der Kontrolltiere (Gruppe 1) wurde mit der Reperfusion ein Bolus von $50 \mu \mathrm{l}$ intravasal appliziert. Die Versuchstiere erhielten je nach Gruppe physiologische Kochsalzlösung (Gruppe 2), $5 \times 10^{5}$ unbehandelte eEOCs/50 $\mu \mathrm{l}$ (Gruppe 3), $5 \times 10^{5}$ mit $50-\mu \mathrm{M}$-Fenofibrat vorbehandelte eEOCs /50 $\mu \mathrm{l}$ (Gruppe 4), oder $5 \times 10^{5}$ mit 1-mM-Clofibrat vorbehandelte eEOCs / $50 \mu l$ (Gruppe 5).

Die Qualität der Behandlung, also die postischämische Nierenfunktion nach simuliertem iANV, wurde mittels Kreatininbestimmung im Serum bestimmt.

Folgende Ergebnisse wurden erhoben:

\section{Postischämische Nierenfunktion (Serumkreatinin)}

- Nach alleiniger Ischämie kam es zu einer deutlichen Verschlechterung der Nierenfunktion. Das Ergebnis ist statistisch signifikant.

- Die Applikation von unbehandelten eEOCs führte bei gewähltem Versuchsaufbau einer 40-minütigen Ischämiezeit erwartungsgemäß zu keiner Verbesserung der Nierenfunktion (Patschan et al. 2010).

- Die Vorbehandlung der eEOCs mit den PPARa-Agonisten Feno- und Clofibrat in vitro verbesserte die In-vivo-Funktionsweise nicht. Unter Fenofibrat kam es zwar rein rechnerisch zu einer Verbesserung der Nierenfunktion, diese aber in so geringem und statistisch nicht signifikantem Ausmaß, dass dieses Ergebnis nicht als Nephroprotektion gedeutet wird. Unter Clofibrat kam es zu einer Verschlechterung der Nierenfunktion. 
Zur Analyse der zellulären Auswirkungen der Fibratbehandlung auf die eEOCs wurden verschiedene In-vitro-Versuche durchgeführt.

Dazu diente die Bestimmung des zellulären Migrationsverhaltens (Versuch 1: Computergestützte Bestimmung der prozentualen Reduktion einer zellfreien Wundfläche), des Zellüberlebens (Versuch 2: Durchflusszytometrische Bestimmung des Vorliegens toter Zellen im Verhältnis zur Gesamtzellzahl mittels Annexin-V-Markierung und PI-Anfärbung) und der Analyse proangiogener Effekte über die Freisetzung des Wachstumsfaktors VEGF (Versuch 3: ELISA-Verfahren zur Konzentrationsbestimmung von VEGF im Überstand einer Zellkultur in pg / $\mathrm{ml}$ ).

Folgende Ergebnisse wurden erhoben:

Migrationsverhalten

- Unter dem Einfluss von Fenofibrat kam es zu Veränderungen der Wundflächengröße, wenn auch durchweg nicht in signifikantem Ausmaß: Fenofibrat aktiviert das Verhalten hinsichtlich der Migration, vor allem in geringen $(1,5 \mu \mathrm{M})$ und mittleren $(10 \mu \mathrm{M})$ Konzentrationen. $50-\mu \mathrm{M}$-Fenofibrat steigert das Migrationsverhalten nur um 0,45 \%-Punkte im Verhältnis zur Kontrollgruppe und wird deshalb nicht als Steigerung gewertet.

- Unter dem Einfluss von Clofibrat (1 mM) hingegen zeigte sich nach 24 Stunden eine komplette Desintegration des Zellverbandes von den Kulturplattenböden. Daher war eine prozentuale Auswertung nicht möglich.

\section{Zellüberleben}

- In geringen $(1,5 \mu \mathrm{M})$ und mittleren $(10 \mu \mathrm{M})$ Konzentrationen aktiviert Fenofibrat vor allem das Verhalten hinsichtlich des Überlebens deutlich. Die Ergebnisse sind statistisch signifikant. In höherer Konzentration von $50 \mu \mathrm{M}$ verschlechtert es die Funktionsweise der eEOCs leicht.

- Unter dem Einfluss von Clofibrat (1 mM) zeigte sich nach 24 Stunden eine allenfalls minimale Reduktion von toten Zellen zur Kontrollgruppe von unter $1 \%$, sodass wir das Ergebnis als Zeichen dafür werten, dass Clofibrat in der Konzentration von $1 \mathrm{mM}$ keinen Einfluss auf das Überleben von eEOCs hat.

Proangiogener Effekt (VEGF-Konzentration)

- In geringen Konzentrationen $(1,5 \mu \mathrm{M})$, wie auch signifikant in hoher Konzentration $(50 \mu \mathrm{M})$ verschlechtert Fenofibrat die proangiogene Aktivität der eEOCs. Im Kontrast dazu steigert Fenofibrat in mittlerer Konzentration von $10 \mu \mathrm{M}$ die proangiogene Aktivität der Zellen in signifikantem Ausmaß.

- Unter dem Einfluss von 1-mM-Clofibrat zeigt sich eine signifikant geringere proangiogene Aktivität. 
Tabelle 10 fasst die Ergebnisse aller Versuche orientierend zusammen.

Ein "+ " steht für ein positives Ergebnis bei der statistischen Auswertung des jeweiligen Parameters (z.B. stärkeres Migrationsverhalten bezogen auf die Kontrollgruppe in vitro). Ein "- " steht dementsprechend für ein negatives Ergebnis (z.B. verringertes Migrationsverhalten bezogen auf die Kontrollgruppe in vitro). Statistisch signifikante Ergebnisse $(p<0,05)$ sind mit einem " " gekennzeichnet. Farblich hinterlegte Kästchen dienen der Deutung. Versuchsgebundene Maßnahmen, die zu einer Stimulation nephroprotektiver Effekte führten, sind grün hinterlegt. Nephrodeletäre Maßnahmen im Rahmen der Versuche sind rot hinterlegt.

\begin{tabular}{|c|c|c|c|c|}
\hline & In-vivo- & \multicolumn{3}{|c|}{ In-vitro-Versuchsreihe } \\
\hline Pharmakon & $\begin{array}{l}\text { Serum- } \\
\text { kreatinin }\end{array}$ & $\begin{array}{l}\text { Versuch } 1 \text { - } \\
\text { Migrations- } \\
\text { verhalten }\end{array}$ & $\begin{array}{c}\text { Versuch } 2 \text { - } \\
\text { Zellüberleben }\end{array}$ & $\begin{array}{c}\text { Versuch } 3 \text { - } \\
\text { Proangio- } \\
\text { gener Effekt }\end{array}$ \\
\hline $\mathrm{FF} 1 \mu \mathrm{M}$ & & + & $+^{*}$ & - \\
\hline FF $5 \mu \mathrm{M}$ & & + & $+^{*}$ & - \\
\hline $\mathrm{FF} 10 \mu \mathrm{M}$ & & + & $+^{*}$ & $+^{*}$ \\
\hline $\mathrm{FF} 50 \mu \mathrm{M}$ & + & + & $-*$ & -* \\
\hline $\mathrm{CF} 1 \mathrm{mM}$ & - & / & + & $-^{*}$ \\
\hline
\end{tabular}

Tabelle 10: Zusammenfassung aller Versuche. 
Die im Rahmen dieser Dissertation beschriebenen Ergebnisse wurden bereits

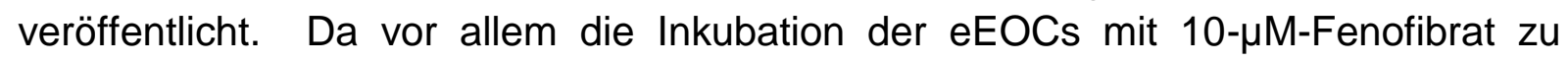
positiven Ergebnissen führte, wurde ein In-vivo-Tierversuch mit 10- $\mu \mathrm{M}$-Fenofibrat, der nicht Bestandteil dieser Arbeit war, den hier beschriebenen Versuchen angestellt. Jedoch zeigte sich auch hier keine Stimulation der In-vivo-Nephroprotektion von eEOCs (Patschan et al. 2014). 


\subsection{Einordung in den Gesamtkontext}

Grundannahme für diese Arbeit war die Vorstellung eine verbesserte postischämische Nierenfunktion zu erhalten, wenn die bereits nachgewiesenen und reproduzierbaren, nephroprotektiven Eigenschaften von eEOCs und die antientzündliche und antiapoptotische Komponente von PPAR $\alpha$ kombiniert würden.

Um dies zu erreichen, wurden die eEOCs vor der systemischen Applikation mit den PPARa-Agonisten Feno- und Clofibrat inkubiert.

Damit sollte an zwei Schlüsselpunkten der Pathogenese des iANVs angesetzt werden:

- Die eEOCs sollten vor allem durch die vermehrte VEGF-Sekretion der mikrovaskulären Zellschwellung (No-Reflow-Phänomen) entgegen wirken und somit zu einer besseren Reperfusion der Endstrombahn führen.

- Die PPARa-Aktivierung sollte die Resistenz der eEOCs gegen das postischämische, ROS-reiche und somit proapoptotische und proinflammatorische Milieu stärken und so zu weniger Zelltod führen.

Durch weniger Zellschwellung, somit bessere Reperfusion, eine geringere Entzündungsreaktion und weniger Zelltod, sollte die postischämische Nierenfunktion verbessert werden.

Die für die vorliegende Arbeit wichtigen Punkte seien hier noch einmal kurz zusammengefasst:

Die Pathophysiologie des iANVs wird durch das Ischämie-Reperfusions-Modell beschrieben und ist durch folgende drei Prozesse gekennzeichnet: direkter tubulärer Zellschaden, anhaltende mikrovaskuläre Zellschwellung und interstitielle Entzündungsreaktion (Brady und Singer 1995, Goligorsky und DiBona 1993, Kellerman et al. 1990, Molitoris 1991, Molitoris et al. 1992, Racusen et al. 1991, Spencer et al. 1991). Bei der Pathogenese muss besonderes Augenmerk auf die im reperfundierten postischämischen Organ weiterhin anhaltende mikrovaskuläre Zirkulationsstörung und die ausgeprägte Entzündungsreaktion, unter anderem aufgrund der hohen Konzentration schädlicher ROS, gelegt werden. Die mikrovaskuläre Zirkulationsstörung wird durch die verminderte Reperfusion der Endstrombahn auf Grund oszillierender Endothelschwellung kleiner peritubulärer Arteriolen und Kapillaren (Microsvascular Endothelial Cell Dysfunction - ED) bedingt und führt zu einem prolongierten Verlauf des iANVs (Brodsky et al. 2002, Goligorsky 2005, Leaf 1973, Patschan et al. 2012b, Yamamoto et al. 2002).

Dieses No-Reflow-Phänomen beschränkt das Regenerationspotenzial der vaskulären und in der Folge auch der tubulären Endothelzellen und ist Angriffspunkt der Therapie mit eEOCs. Die systemische Gabe dieser Zellen nämlich, führt zu einer signifikant besseren postischämischen Nierenfunktion durch weniger Microsvascular Endothelial Cell Dysfunction (Patschan et al. 2006a, b), vor allem durch vermehrte VEGF-Sekretion (Rehman et al. 2003). 
Anhand weiterer Veröffentlichungen konnte gezeigt werden, dass eine gezielte pharmakologische Vorbehandlung von syngenen eEOCs in vitro, das nephroprotektive Potenzial im murinen Modell des iANVs noch weiter verbessern kann (Patschan et al. 2010, Patschan et al. 2012a, Patschan et al. 2013a, b, c). Eine detaillierte Darstellung findet sich in Kapitel 2.6.

Zur Verbesserung der eEOC-Funktion wurden in dieser Arbeit die Auswirkungen der PPARa-Aktivierung durch Fibratvorinkubation evaluiert. Dadurch sollte die funktionelle Kompetenz der Zellen, durch Schaffung einer höheren Resistenz gegenüber den schlechten Bedingungen im postischämischen Organ gesteigert werden. Die Mechanismen dahinter wurden in Kapitel 2.7.2 detailliert beschrieben. Die für die vorliegende Arbeit wichtigen Punkte seien hier kurz dargestellt:

Wie bereits mehrfach erwähnt, werden bei der Reperfusion der Niere vermehrt schädigende ROS gebildet, die die ohnehin schon ablaufende Entzündungsreaktion weiter unterhalten. PPAR $\alpha$ ist maßgeblich an der Proliferation von Peroxisomen beteiligt und führt darüber indirekt zur Erhöhung der antioxidativen Schutzmechanismen. Durch die Aktivierung der peroxisomalen antioxidativen Enzyme Superoxiddismutase, Gluthathionperoxidase und des Schlüsselenzyms Katalase nämlich, werden die proapoptotischen und proinflammatorischen ROS, vor allem das Wasserstoffperoxid, abgebaut (Vasko 2016).

Die Induktion der peroxisomalen $\beta$-Oxidation stellt Energie in Form von ATP bereit, was zur Sicherung der Zellfunktionen beiträgt und die zelluläre Todesrate verringern kann (Cheng et al. 2010).

Eine PPARa-bedingte Induktion der eNOS auf Endothelzellen (Wardle 2004) sowie eine geringere Konzentration von TNF- $\alpha$ wirken vasoprotektiv. Allgemeinhin ist bekannt, dass Stickstoffmonooxid zur Vasodilatation beiträgt und somit zu einer besseren Perfusion führen kann.

Die geringere Sekretion proinflammatorischer Zytokine (z. B. IL-6, TNF- $\alpha$, TGF- $\beta$ ) durch die Endothelzellen und eine verminderte Expression von Adhäsionsmolekülen (z. B. ICAM-1, VCAM-1) auf denselben, mit konsekutiv weniger Rekrutierung von neutrophilen Granulozyten, führt zu einer besseren kapillären Durchblutung und einer weniger stark ausgeprägten Entzündungsreaktion im Interstitium (Delerive et al. 1999).

Hinzukommend wird die Rate von apoptotischen endothelialen Zellen allgemein durch Hemmung der TGF- $\beta$-Signalkaskade und verringerter TNF- $\alpha$-Produktion kleiner (Chen et al. 2009, Gilde et al. 2003, Li et al. 2010). Da es im Rahmen des iANVs vor allem die tubulären Endothelzellen sind, die typischerweise absterben, erklärt dies vielleicht den fehlenden positiven Effekt auf die postischämische Nierenfunktion in vivo durch PPARa-bedingte Apoptosehemmung der eEOCs. Möglicherweise spielt aber die Apoptose auch bei letzterer Zellart eine Rolle. 
Vorangegangene Arbeiten bezüglich der direkten, systemischen PPARa-Aktivierung im I/R-Modell des iANVs zeigten prorenale Ergebnisse anhand signifikant geringerer Serumkreatininkonzentrationen (Chen et al. 2009, Patel et al. 2009, Sivarajah et al. 2002).

In dieser Arbeit wurde nicht der komplette endogene PPARa-Pool durch direkte, systemische Applikation von Agonisten in das Versuchstier aktiviert, sondern der von angezüchteten endothelialen Vorläuferzellen. Somit wurde sich auf die Wirkweise von PPARa auf Endothelvorläuferzellen beschränkt und nicht alle möglichen Wirkmechanismen der PPARa-Aktivierung ausgenutzt. Außerdem wurde davon ausgegangen, dass die PPARa-Agonisierung von eEOCs die gleichen Effekte zeigt, wie die von reifen Endothelzellen.

Grundsätzlich charakterisieren folgende Ergebnisse die gesteigerte nephroprotektive Wirkung der Zelltherapie mit eEOCs:

- Eine geringere Serumkreatininkonzentration im Tierversuch,

- ein verstärktes Migrationsverhalten von endothelialen Stamm- und reifen Zellen,

- eine erhöhte Überlebensrate der eEOCs und

- eine erhöhte Produktion und Sekretion des proangiogenen Wachstumsfaktors VEGF.

Die Überprüfung dieser Mechanismen war Bestandteil der vorliegenden Arbeit:

Die postischämische Nierenfunktion wurde mittels Serumkreatininkonzentration bestimmt (In-vivo-Tierversuchsreihe, Kapitel 3.1). Das Migrationsverhalten wurde bildmorphologisch begutachtet (In-vitro-Versuch 1, Kapitel 3.2.2). Das Zellüberleben wurde anhand der Rate toter Zellen mittels Annexin-V-Markierung und PI-Anfärbung bestimmt (In-vitro-Versuch 2, Kapitel 3.2.3). Der proangiogene Effekt wurde über die Konzentration von VEGF im Zellmedium mit Hilfe eines ELISA-Verfahrens bestimmt (In-vitro-Versuch 3, Kapitel 3.2.4). 
Überraschenderweise konnten die benannten theoretischen Überlegungen in dieser Arbeit nicht bestätigt werden.

Es zeigte sich vielmehr, dass die beiden Fibrate in den jeweiligen Konzentrationen das nephroprotektive Potenzial der syngenen eEOCs im murinen Modell des iANVs nicht verbessern. Für $50-\mu \mathrm{M}$-Fenofibrat zeigte sich zwar eine leicht verbesserte postischämische Nierenfunktion, diese aber in sehr geringem und nicht signifikantem Ausmaß, sodass man eher von einem zufälligen und nicht nephroprotektiven Ergebnis sprechen muss. Unter Clofibrat kam es zu einer Verschlechterung der postischämischen Nierenfunktion.

$\mathrm{Da}$ vor allem die Inkubation der eEOCs mit 10- $\mu \mathrm{M}$-Fenofibrat zu positiven

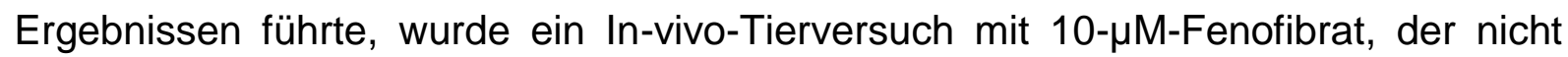
Bestandteil dieser Arbeit war, den hier beschriebenen Versuchen angestellt. Jedoch zeigte sich auch hier keine Stimulation der In-vivo-Nephroprotektion von eEOCs (Patschan et al. 2014).

Im Rahmen der In-vitro-Versuchsreihe konnten folgende Erkenntnisse gewonnen werden:

Fenofibrat fungiert als dosisabhängiger Modulator der eEOC-Funktion. Geringe und mittlere Konzentrationen zeigen tendenziell einen positiveren, also eher nephroprotektiven Einfluss auf die eEOC-Funktion, als es Fenofibrat in hoher Konzentration tut. 1-, 5- und $10-\mu \mathrm{M}$-Fenofibrat steigert das In-vitroMigrationsverhalten und vor allem das Zellüberleben in signifikantem Ausmaß. Hinzukommend wird die proangiogene Aktivität der Zellen signifikant durch Fenofibrat in mittlerer Konzentration $(10 \mu \mathrm{M})$ erhöht, jedoch in geringen und hohen Konzentrationen wiederum verschlechtert. In hoher Konzentration von $50 \mu \mathrm{M}$ verschlechtert es die Funktionsweise der eEOCs in fast allen drei Versuchen, teilweise sogar in signifikantem Ausmaß (Versuch 2: Zellüberleben und Versuch 3: Proangiogener Effekt). Das rechnerisch gesteigerte Migrationsverhalten (Versuch 1: Migrationsverhalten) beläuft sich auf lediglich 0,45\%-Punkte zur Kontrollgruppe und wird nicht als Steigerung gewertet. Für $50-\mu \mathrm{M}$-Fenofibrat lässt sich also festhalten: Die funktionelle Kompetenz der eEOCs wird entweder signifikant verschlechtert, oder es zeigt sich kein nennenswerter Einfluss.

Clofibrat verschlechtert die Funktionsweise der eEOCs sowohl in vivo als auch in vitro, sodass man zutreffender von einem "nephrodeletären Potenzial“ sprechen müsste. Im Versuch 1 der In-vitro-Versuchsreihe kam es sogar zu einer kompletten Desintegration des Zellverbandes vom Kulturboden, sodass eine Auswertung unmöglich wurde. Diese Desintegration werten wir als Zeichen einer Destruktion. Hinzukommend war der proangiogene Effekt der eEOCs im Versuch 3 deutlich und statistisch signifikant reduziert. Das minimal bessere Zellüberleben (Reduktion der toten Zellen um unter $1 \%$ im Rahmen des Versuches 2) entkräftet die Argumente unserer Meinung nach nicht. 
Die Ergebnisse der Versuche lassen sich untereinander annähernd zufriedenstellend erklären: Bei einem „negativen“ Ergebnis im Rahmen des Tierversuches konnte auch im Rahmen der in-vitro-Experimente von vorzugsweise "negativen“ Resultaten ausgegangen werden. Die erhöhte Serumkreatininkonzentration, also eine schlechtere postischämische Nierenfunktion in vivo, lässt sich durch eine geringere postischämische Zellmigration, erhöhten Zelltod und weniger VEGF im Zellmedium erklären. Ebenso sollten die Ergebnisse der drei In-vitro-Versuche untereinander kausal erklärbar sein. Bei verringertem Migrationsverhalten war mit vermehrtem Zelltod und geringeren VEGF-Konzentrationen zu rechnen.

Für Clofibrat lässt sich dieses Schema erkennen. Die erhöhte Konzentration von Kreatinin im Serum deckt sich kausal mit der erhöhten Rate toter Zellen und der geringeren VEGF-Konzentration im Zellmedium. Die Desintegration des Zellverbandes machte leider eine Quantifizierung und Auswertung des In-vitroVersuches 1 unmöglich. Die komplette Ablösung werten wir aber als "negatives", also nephrodeletäres Zeichen.

Für Fenofibrat in hoher Konzentration $(50 \mu \mathrm{M})$ lässt sich dieses Schema annähernd innerhalb der In-vitro-Versuche erkennen. Bei unverändertem Migrationsverhalten ist zumindest die Rate toter Zellen größer und die Konzentration von VEGF geringer. In der Tierversuchsreihe zeigt sich wiederum eine leicht verbesserte postischämische Nierenfunktion, diese aber in geringem und nicht signifikantem Ausmaß, sodass wir das Ergebnis nicht als "postitiv“, also nicht als eine Stimulation der Nephroprotektion werten. Im Kontrast dazu stehen die Ergebnisse der In-vitro-Versuchsreihe hinsichtlich 1-, 5- und 10- $\mu \mathrm{M}$-Fenofibrat: Hier zeigt sich nämlich eine Aktivierung der Zellmigration, eine erhöhtes Zellüberleben anhand der verringerten Apoptoserate und für $10-\mu \mathrm{M}$-Fenofibrat eine erhöhte Proangiogenität. Die Reduktion der VEGFKonzentration bei der Inkubation mit 1- und $5-\mu \mathrm{M}$-Fenofibrat beläuft sich auf wenige $\mathrm{pg} / \mathrm{ml}$ und ist statistisch nicht signifikant, sodass diese Ergebnisse, analog zu den Ergebnissen der In-vivo-Tierversuchsreihe und des In-vitro-Versuches 1, nicht als "negativ" gewertet werden. Diese Unterschiede lassen sich hinreichend durch die deutlich niedrige Konzentration von Fenofibrat pro Volumen erklären. 


\subsection{Schlussfolgerung, Beantwortung der zu Anfang gestellten Fragen und Aussicht}

Durch die vorliegende Arbeit konnte ein relevanter Beitrag zur Grundlagenforschung im Bereich der therapeutischen Anwendung von endothelialen Vorläuferzellen im Rahmen des ischämisch bedingten akuten Nierenversagens geleistet werden:

Die PPARa-Aktivierung durch die Substanzklasse der Fibrate, namentlich Fenofibrat und Clofibrat, resultiert in keiner Stimulation der nephroprotektiven Effekte von syngenen eEOCs im murinen Modell des iANVs.

Fenofibrat fungiert als dosisabhängiger Modulator der eEOC-Funktion in vitro. Clofibrat verschlechtert die Funktionsweise der eEOCs in vitro ubiquitär, sodass man zutreffender von einem „nephrodeletären Potenzial“ sprechen müsste.

Die in Kapitel 2.8 gestellten Fragen sollen an dieser Stelle beantwortet werden.

- Das nephroprotektive Potenzial von eEOCs in vivo wird durch eine Invitro-Vorbehandlung mit den PPARa-Agonisten Feno- und Clofibrat beeinflusst. Es zeigte sich bei Fenofibrat in hoher $(50 \mu \mathrm{M})$ Konzentration eine leichte Verbesserung der postischämischen Nierenfunktion. Bei Clofibrat $(1 \mathrm{mM})$ zeigte sich dagegen eine Einschränkung der postischämischen Nierenfunktion, somit protektiven Funktionsweise der eEOCs.

- Im murinen Modell des iANVs kommt es zu funktionellen Veränderungen, jedoch in nicht einheitlichem Ausmaß. Wie oben beschrieben, wurde die postischämische Nierenfunktion unter Fenofibrat leicht verbessert, unter Clofibrat aber verschlechtert.

- Das Migrationsverhalten der eEOCs in vitro wird durch eine Vorbehandlung mit den PPARa-Agonisten Feno- und Clofibrat beeinflusst. Unter der Einfluss von Fenofibrat kam es in geringen $(1,5 \mu \mathrm{M})$ und mittleren $(10 \mu \mathrm{M})$ Konzentrationen zu einer stärkeren Migration, in hoher $(50 \mu \mathrm{M})$ Konzentration hatte es keinen nennenswerten Einfluss auf das Migrationsverhalten. Unter dem Einfluss von Clofibrat ( $1 \mathrm{mM})$ hingegen zeigte sich eine komplette Desintegration des Zellverbandes von den Kulturplattenböden. Daher war eine prozentuale Auswertung nicht möglich. 
- Das Überleben der eEOCs in vitro wird durch eine Vorbehandlung mit den PPARa-Agonisten Feno- und Clofibrat beeinflusst. Besonders Fenofibrat in geringen $(1,5 \mu \mathrm{M})$ und mittleren $(10 \mu \mathrm{M})$ Konzentrationen steigerte die Überlebensfähigkeit der eEOCs deutlich und in statistisch signifikantem Ausmaß. In höherer Konzentration von $50 \mu \mathrm{M}$ verschlechterte es die Funktionsweise der eEOCs leicht. Unter dem Einfluss von Clofibrat (1 mM) zeigte sich eine allenfalls minimale Reduktion von toten Zellen zur Kontrollgruppe von unter $1 \%$, sodass wir das Ergebnis als Zeichen dafür werten, dass 1-mM-Clofibrat keinen Einfluss auf das Überleben syngener eEOCs in vitro hat.

- Der proangiogene Effekt der eEOCs, genauer die Freisetzung des Wachstumsfaktors VEGF in vitro, wird durch eine Vorbehandlung mit den PPARa-Agonisten Feno- und Clofibrat beeinflusst. In geringen Konzentrationen $(1,5 \mu \mathrm{M})$, wie auch signifikant in hoher Konzentration $(50 \mu \mathrm{M})$ verschlechterte Fenofibrat die proangiogene Aktivität der eEOCs. Im Kontrast dazu steigerte Fenofibrat in mittlerer Konzentration von $10 \mu \mathrm{M}$ die proangiogene Aktivität der Zellen in signifikantem Ausmaß. Unter dem Einfluss von 1-mM-Clofibrat zeigte sich eine signifikant geringere Aktivität.

Diese Arbeit dokumentiert, dass die Mechanismen der PPARa-Aktivierung, deren Modulation und Folgen nicht zufriedenstellend erforscht sind, denn die verantwortlichen Mechanismen, für die im Rahmen dieser Arbeit erhobenen Ergebnisse, lassen sich im einzelnen nicht vollständig erklären. Hier sei noch einmal auf die pleiotropen Effekte der PPARa-Agonisierung und die Modulation durch sogenannte Coexpressoren und -repressoren hingewiesen (Pourcet et al. 2010).

Einen großen Unterschied zu den in der Literatur auffindbaren Studien markiert der Versuch der "indirekten“ PPARa-Agonisierung über die Vorinkubation von eEOCs. Bis dato finden sich vor allem positive Ergebnisse im Rahmen von Studien der "direkten“ Applikation von PPARa-Agonisten, sowohl bei akuten (Chen et al. 2009, Patel et al. 2009, Sivarajah et al. 2002) als auch bei chronischen renalen Dysfuntionen (Gilde et al. 2003, Ismail-Beigi et al. 2010, Keech et al. 2005, Park et al. 2006, Robinson und Grieve 2009, Scott et al. 2005, Scott et al. 2009, Wierzbicki 2010, Zambon et al. 2006). Unser Versuchsaufbau beschränkte sich somit auf eine Zellreihe (Endothel(vorläufer)zellen) und konnte nicht das gesamte Wirkspektrum von PPARa ausnutzen. Unsere Ergebnisse zeigen ebenfalls, dass es Vorteile der „direkten“ PPARa-Agonisierung zu geben scheint. Da PPARa an vielen unterschiedlichen Stoffwechselwegen, diversen Reaktionen im Organismus und Wechselwirkungen zwischen Zelltypen beteiligt ist, scheint auch eher das Zusammenspiel aller Genprodukte gute Effekte erzielen zu können. Die Tatsache, dass die PPARs fast in allen Geweben des Organismus' vorkommen und sie unter Umständen den gesamten Körpermetabolismus modulieren, stützt die geäußerte Vermutung. 
Im Rahmen des iANVs ist der Begriff „Apoptose“ scheinbar für die Tubuli reserviert. Vereinzelt findet man in der Literatur aber auch für das vaskuläre Endothel die Endstrecke aus vorzeitiger Zellalterung und Apoptose nach einer akuten Schädigung (Goligorsky 2005). PPAR $\alpha$ verringert die Konzentration zellschädigender ROS und hemmt die apoptoseinduzierende TGF- $\beta$-Signalkaskade und die TNF- $\alpha$-Produktion (Chen et al. 2009, Gilde et al. 2003, Li et al. 2010). Trotz fehlendem positiven Effekt auf die postischämische Nierenfunktion in vivo, spielt die Apoptose unter Umständen auch bei vaskulären Endothelzellen eine nicht unerhebliche Rolle. Zumindest könnte man dies aufgrund der konzentrationsabhängigen Veränderung des Zellüberlebens im Rahmen des In-vitro-Versuches 2 (Kapitel 3.2.3) vermuten.

Bis jetzt ist auch der grundlegende Mechanismus der PPARa-induzierten Stimulation des Migrationsverhaltens ungeklärt. Ob es, wie auch bei 8-O-cAMP, über eine $\beta 1$-Integrin-Umverteilung zur vermehrten in-vitro-Migration und gegebenenfalls auch vermehrtem Postischemic Cellular Homing in vivo kommt, bleibt vorerst unbekannt.

Für die weitere Forschung, also um pleiotrope Effekte zu verringern, Modulation auszuschließen und Ungenauigkeiten zu vermeiden, wäre es dementsprechend von immenser Wichtigkeit, die zell- (Endothel(vorläufer)zellen) und organspezifische (Niere) sowie universelle Wirkweise von Peroxisomen weiter zu spezifizieren und allgemein gültige, standardisierte PPARa-Agonisten und ein einheitliches Schema der PPARa-Aktivierung zu verwenden.

Weiterhin diskussionswürdig ist die Annahme, dass die wissenschaftlich beschriebenen Effekte der PPARa-Aktivierung auf Endothelzellen auch auf die für diese Arbeit verwendeten endothelialen Vorläuferzellen angewandt werden können. Die Tatsache, dass eEOCs eher der hämatopoetischen Zellinie, anstatt der vaskulären entstammen (Bailey et al. 2004, Grant et al. 2002) und sich die Ergebnisse dieser Arbeit (,indirekt“) und Veröffentlichungen der "direkten“ PPARaAktivierung stark unterscheiden, liegt die Vermutung nahe, dass die Effekte nicht pauschal übernommen werden können. Zum Beispiel exprimieren eEOCs zwar ähnliche Zelladhäsionsmoleküle (PECAM-1), wie reife Endothelzellen (ICAM-1, VCAM-1), die ebenfalls an der Interaktion zwischen Endothelzellen und der Leukozyten-Migration beteiligt sind (Baldwin et al. 1994), jedoch zeigt sich keine direkte Modulation durch PPARa. Weitere Versuche hinsichtlich der Auswirkung einer PPARa-Agonisierung auf endothliale Vorläuferzellen (eEOCs) könnten helfen diese Fragen zu klären. Ein neuer Versuchsaufbau, in dem neben der eEOCApplikation und gegebenenfalls auch der Vorinkubation, PPARa-Agonisten "direkt" systemisch injiziert würden, könnte ebenfalls interessante Ergebnisse liefern. 
Des Weiteren wäre es interessant zu untersuchen, was für Auswirkungen die Therapie mit einer anderen Gruppe von endothelialen Progenitorzellen im Rahmen des iANVs hätte. Die zweite Hauptgruppe der EPCs beschreibt die late Endothelial Outgrowth Cells - IEOCs. Wie im Kapitel 2.4.2 dargestellt, sind IEOCs, im Gegensatz zu eEOCs, den Endothelzellen phänotypisch ähnlicher (Lin et al. 2000) und weisen eine funktionell höhere Vaskulogeneseaktivität und ein stärkeres Proliferationsverhalten auf (Case et al. 2007, Xu 2007, Yoder et al. 2007).

Aktuelle Arbeiten der Forschungsgruppe von Herrn Prof. Patschan befassen sich mit diesem Thema. Für eine Darstellung der Resultate ist es allerdings noch zu früh.

Abschließend sei noch einmal darauf hingewiesen, dass für ein besseres Handling in der klinischen Praxis unverändert die Aufgabe besteht, einen direkten, sensitiveren, spezifischeren und zeitnäheren Biomarker des renalen Zellschadens zu finden. Das Serumkreatinin ist bekanntermaßen nur indirekter Marker der renalen Funktion und wird von vielen Faktoren beeinflusst. Der „Kreatinin-blinde Bereich“ stellt für die Diagnose leichter Nierenfunktionseinschränkungen eine besondere Herausforderung dar. Hinsichtlich des ANVs sind es die beiden tubulären Zellzyklusarrestmarker IGFBP7 und TIMP-2 im Urin, die dem Serumkreatinin in vielen Studien signifikant überlegen sind (Bihorac et al. 2014, Gocze et al. 2015, Kashani et al. 2013). Besonders im Hinblick auf den demographischen Wandel und der damit steigenden Inzidenz des iANVs könnten diese neuen Marker die Problematik bezüglich früher Diagnosestellung, Einleitung der Therapie und Reduktion der Sterblichkeit erheblich entschärfen (Elasy und Anderson 1996, Pascual et al. 1995, Siew et al. 2011). 


\section{Zusammenfassung}

Die in der vorliegenden Arbeit dargestellten Versuche wurden im Rahmen eines Forschungsprojektes zur Untersuchung der therapeutischen Wertigkeit endothelialer Vorläuferzellen beim akuten ischämischen Nierenversagen (iANV) durchgeführt.

Es wurde nach stimulierenden Faktoren gesucht, die den 2006 erstmals wissenschaftlich beschriebenen und reproduzierbaren, nephroprotektiven Effekt von endothelialen Vorläuferzellen (early Endothelial Outgrowth Cells - eEOCs) (Patschan et al. 2006a, Patschan et al. 2006b) beim iANV begünstigen.

Veröffentlichungen aus den Jahren 2010, 2012 und 2013 haben gezeigt, dass sich der nephroprotektive Effekt der eEOC-Therapie durch In-vitro-Vorbehandlung der Zellen mit dem Integrinrezeptoraktivator 8-pCPT-2'-O-Me-cAMP (8-O-cAMP), dem Hormon Melatonin, dem Wachstumsfaktor Angiopoetin-1 und dem Bone Morphogenetic Protein-5 steigern (Patschan et al. 2010, Patschan et al. 2012a, Patschan et al. 2013b, Patschan et al. 2013c) und durch Angiopetin-2 modulieren lässt (Patschan et al. 2013a).

Im Rahmen dieser Arbeit wurde zur pharmakologischen Vorbehandlung Fenofibrat und Clofibrat eingesetzt, die beide Agonisten am Peroxisom-Proliferator-aktivierten Rezeptor alpha (kurz PPARa) sind.

Der therapeutische Nutzen der PPARa-Agonisierung im Rahmen von renalen und kardiovaskulären Pathologien konnte in diversen tierexperimentellen Versuchen (Chen et al. 2009, Li et al. 2004, Lopez-Hernandez und Lopez-Novoa 2009, Park et al. 2006, Patel et al. 2009, Portilla et al. 2000, Sivarajah et al. 2002, Wilmer et al. 2002) sowie in großen klinischen Studien (ACCORD, FIELD) (Gilde et al. 2003, Ismail-Beigi et al. 2010, Keech et al. 2005, Scott et al. 2005, Scott et al. 2009, Wierzbicki 2010, Zambon et al. 2006) nachgewiesen werden.

Die Experimente umfassten eine In-vivo-Tierversuchsreihe sowie drei In-vitroVersuche.

In der Tierversuchsreihe wurde ein ischämisch bedingtes akutes Nierenversagen bei 8 - 12 Wochen alten, männlichen C57BI/6N-Mäusen simuliert. Dieses wurde durch 40-minütiges Abklemmen der linken renalen Hilusgefäße bei simultaner Totalnephrektomie rechts induziert.

Die Kontrolltiere (Gruppe 1) ausgenommen, wurde mit der Reperfusion ein Bolus von $50 \mu \mathrm{l}$ intravasal appliziert. Die Versuchstiere erhielten je nach Gruppe physiologische Kochsalzlösung (Gruppe 2), $5 \times 10^{5}$ unbehandelte eEOCs/50 $\mu$ l (Gruppe 3), $5 \times 10^{5}$ mit $50-\mu M$-Fenofibrat vorbehandelte eEOCs / $50 \mu \mathrm{l}$ (Gruppe 4) oder $5 \times 10^{5}$ mit 1-mM-Clofibrat vorbehandelte eEOCs / $50 \mu \mathrm{l}$ (Gruppe 5).

Die Qualität der Behandlung, also die postischämische Nierenfunktion nach simuliertem iANV, wurde mittels enzymatischer Kreatininbestimmung in $\mathrm{mg} / \mathrm{dl}$ nach 48 Stunden im murinen Serum bestimmt. 
Um einen genaueren Eindruck der zellulären Konsequenzen einer Fibrat-Behandlung von eEOCs zu erhalten, wurden folgende drei Parameter in vitro erhoben:

- Migrationsverhalten (Versuch 1: Computergestützte Bestimmung der prozentualen Reduktion einer zellfreien Wundfläche),

- Zellüberleben (Versuch 2: Durchflusszytometrische Bestimmung des Vorliegens toter Zellen im Verhältnis zur Gesamtzellzahl mittels Annexin-V-Markierung und PI-Anfärbung) sowie

- Proangiogenität (Versuch 3: ELISA-Verfahren zur Konzentrationsbestimmung von VEGF im Überstand einer Zellkultur in pg / ml).

Die Konzentrationen der Stimulationslösungen lagen für Fenofibrat bei 1, 5, 10 und $50 \mu \mathrm{M}$ und für Clofibrat bei $1 \mathrm{mM}$.

Überraschenderweise hat sich gezeigt, dass die PPARa-Aktivierung durch Fenofibrat und Clofibrat in keiner Stimulation der nephroprotektiven Effekte von syngenen eEOCs im murinen Modell des iANVs resultiert.

Fenofibrat fungiert als dosisabhängiger Modulator der eEOC-Funktion in vitro. Geringe und mittlere Konzentrationen zeigen tendenziell einen positiveren, also eher nephroprotektiven Einfluss auf die eEOC-Funktion, als es Fenofibrat in hoher Konzentration tut. In geringer und mittlerer Konzentration von 1, 5 und $10 \mu \mathrm{M}$ steigert es das Migrationsverhalten und vor allem das Zellüberleben in signifikantem Ausmaß. Hinzukommend wird die proangiogene Aktivität der Zellen signifikant durch Fenofibrat in mittlerer Konzentration $(10 \mu \mathrm{M})$ erhöht, jedoch in geringen und hohen Konzentrationen wiederum verschlechtert. Für Fenofibrat in hoher Konzentration von $50 \mu \mathrm{M}$ lässt sich festhalten: Die funktionelle Kompetenz der eEOCs wird entweder signifikant verschlechtert, oder es zeigt sich kein nennenswerter Einfluss.

Clofibrat verschlechtert die Funktionsweise der eEOCs in allen Versuchsreihen, sowohl in vivo, also auch in vitro, sodass man zutreffender von einem „nephrodeletären Potenzial“ sprechen müsste.

Durch die vorliegende Arbeit konnte ein relevanter Beitrag zur Grundlagenforschung im Bereich der therapeutischen Anwendung von endothelialen Vorläuferzellen beim ischämisch bedingten akuten Nierenversagen geleistet werden.

Die im Rahmen dieser Dissertation beschriebenen Ergebnisse wurden bereits veröffentlicht (Patschan et al. 2014). 


\section{Anhang}

\subsection{Abkürzungsverzeichnis}

\begin{tabular}{|c|c|}
\hline ACS & Acyl-CoA-Synthetase \\
\hline ACSL & Acyl-CoA-Ligase \\
\hline ADPS & $\begin{array}{l}\text { N-Ethyl-N-(3-Sulfopropyl)-3-methoxyaniline sodium salt } \\
\text { (N-Ethyl-N-(3-Sulfopropyl)-3-Methoxyanilin Natriumsalz) }\end{array}$ \\
\hline ADQI & Acute Dialysis Quality Initiative \\
\hline$A G$ & Antigen \\
\hline AK & Antikörper \\
\hline AKI & Acute Kidney Injury (akute Nierenschädigung) \\
\hline AKIN & Acute Kidney Injury Network \\
\hline ANV & akutes Nierenversagen \\
\hline Annexin V & auch Annexin A5 (zelluläres Protein der Annexin Familie) \\
\hline AP & alkalische Phosphatase \\
\hline Apo & Apolipoprotein \\
\hline ATN & Acute Tubular Necrosis (akute Tubulusnekrose) \\
\hline ATP & Adenosintriphosphat \\
\hline ATPase & Adenosintriphosphatasen \\
\hline BD & Eigenname „Becton Dickinson“ \\
\hline BMP (5) & $\begin{array}{l}\text { Bone Morphogenetic Protein (5) } \\
\text { (morphogenetisches Knochenprotein (5)) }\end{array}$ \\
\hline $\mathbf{C a C l}_{2}$ & Kalziumchlorid \\
\hline CAMP & zyklisches AMP (Adenosinmonophosphat) \\
\hline CBP & CREB-Binding Protein (CREB-Bindungsprotein) \\
\hline CD & $\begin{array}{l}\text { Cluster of Differentiation } \\
\text { (Unterscheidungsgruppen, Oberflächenmerkmal von Zellen) }\end{array}$ \\
\hline CF & Clofibrat \\
\hline c-kit & Tyrosinkinase KIT \\
\hline CoA & Coenzym A \\
\hline CREB & cAMP Response-Element Binding Protein \\
\hline CRP & C-reaktives Protein \\
\hline CYP & Cytochrom P \\
\hline $\mathrm{DHA}$ & Docosahexaensäure \\
\hline DMSO & Dimethylsulfoxid \\
\hline EBM-2 & Endothel-Basal-Medium-2 \\
\hline ED & (microvascular) Endothelial Cell Dysfunction \\
\hline EHSPT & N-Ethyl-N-(2-hydroxy-3-sulfopropyl)-m-toluidin \\
\hline ELISA & $\begin{array}{l}\text { Enzyme-Linked Immunosorbent Assay } \\
\text { (AK-basiertes Nachweisverfahren) }\end{array}$ \\
\hline
\end{tabular}


(e/l)EOC (early/late) Endothelial Outgrowth Cell

(frühe/späte endotheliale Vorläufer-, Stammzelle)

EPC Endothelial Progenitor Cell (endotheliale Vorläuferzelle)

ESRD End Stage Renal Disease

FADH2 reduzierte Form des Flavin-Adenin-Dinukleotides (FAD)

FATP Fatty Acid Transport Protein

FACS Flourescence Activated Cell Sorter

FCS Flourescence Correlation Spectroscopy

(Floureszenzkorrelationsspektroskopie)

FF Fenofibrat

FITC Flourescein Isothiocyanate (fluoreszierendes Isothiozynanat)

G-CSF Granulocyte Colony-Stimulating Factor

(Granulozyten-Kolonie-stimulierender Faktor)

GF Growth Factor (Wachstumsfaktor)

GFR glomeruläre Filtrationsrate

GM-CSF Granulocyte-Macrophage Colony-Stimulating Factor

(Granulozyten-Makrophagen-Kolonie-stimulierender Faktor)

H+ Hydron, Kation des Wasserstoffs $(\mathrm{H})$

$\mathrm{HCl} \quad$ Hydrochlorid

HDL High Density Lipoprotein

HEPES 4-(2-hydroxyethyl)-1-piperazineethanesulfonic acid

2-(4-(2-Hydroxyethyl)-1-Piperazinyl)-Ethansulfonsäure (Puffersubstanz)

HGF Hepatocyte Growth Factor (Hepatozyen-Wachstumsfaktor)

HUVEC Human Umbilical Vein Endothelial Cell

(Endothelzelle der humanen Nabelschnurvene)

HRP Horseradish Peroxidase

(Meerrettich-Peroxidase, Reporter-Molekül an Streptavidin)

iANV ischämisches akutes Nierenversagen

INFy Interferon Gamma

iNOS inducible Nitric Oxide Synthase

(induzierbare Stickstoffmonooxid-Synthase in Makrophagen und

Mikrogliazellen)

IGFBP7 Insulin-like Growth-Factor Binding Protein 7

I/R Ischämie / Reperfusion

Kat.-Nr. Katalognummer

KDIGO Kidney Disease: Improving Global Outcomes

KDR / Flk-1 Name des VEGF-Rezeptor Typ 2

kgKG Kilogramm Körpergewicht

KHK Koronare Herzkrankheit

LPS Lipopolysaccharid

MAPC Multipotent Adult Progenitor Cell (adulte multipotente Progenitorzelle)

MMP Matrix-Metalloproteinase

MMS Makrophagen-Monozyten-System

MNC Mononuclear Cells (mononukleäre Zellfraktion) 


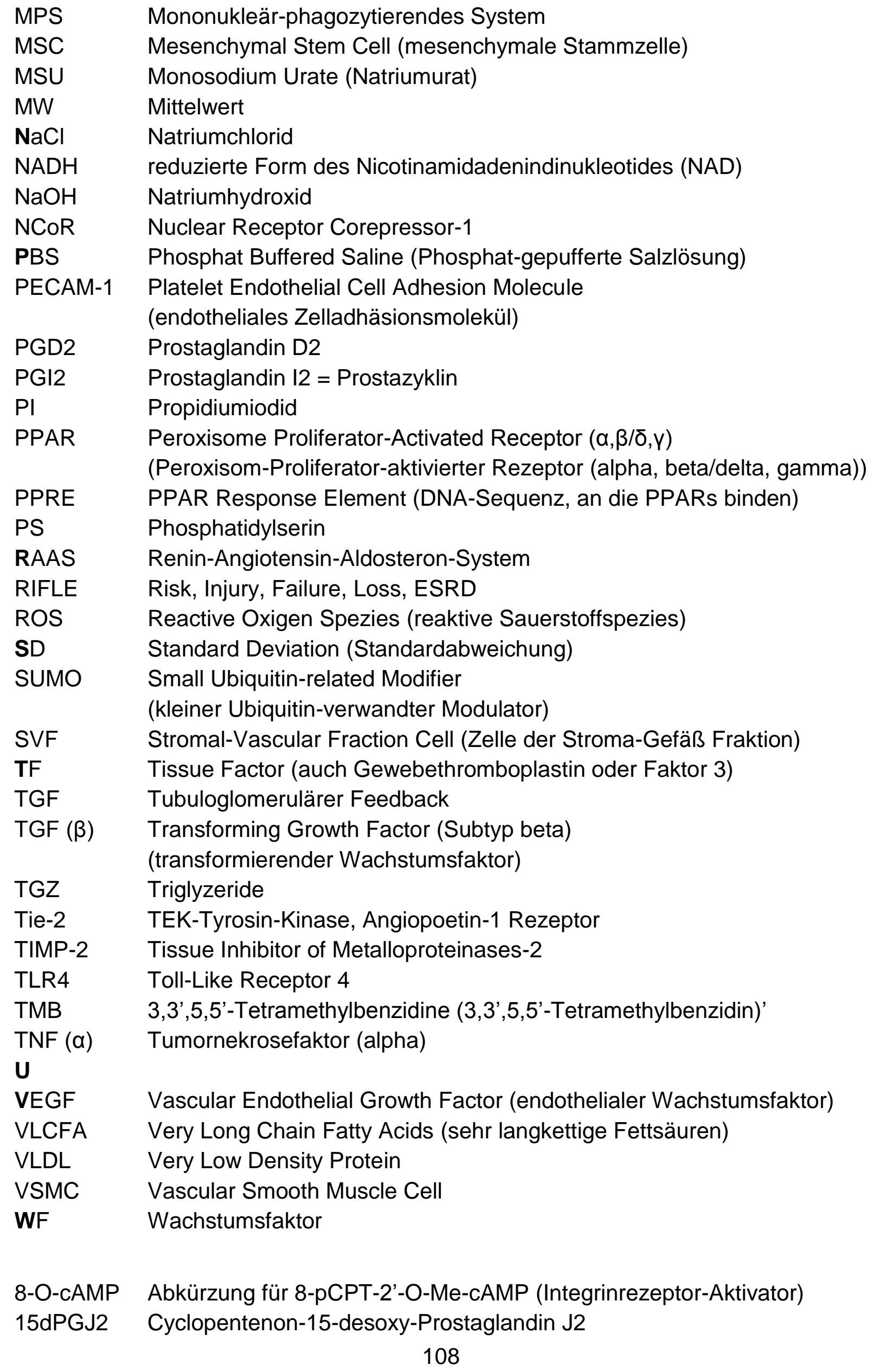




\subsection{Abbildungsverzeichnis}

Abbildung 1: Postischämische Nierenfunktion: Kreatininkonzentration im Serum



Abbildung 2: Fotos Gruppe 1 - unbehandelte Kontrollen, Ansatz 1 ..................... 71

Abbildung 3: Fotos Gruppe 1 - unbehandelte Kontrollen, Ansatz 2 ....................... 71

Abbildung 4: Fotos Gruppe 1 - unbehandelte Kontrollen, Ansatz 3 ...................... 72

Abbildung 5: Fotos Gruppe 1 - unbehandelte Kontrollen, Ansatz 4 ....................... 72

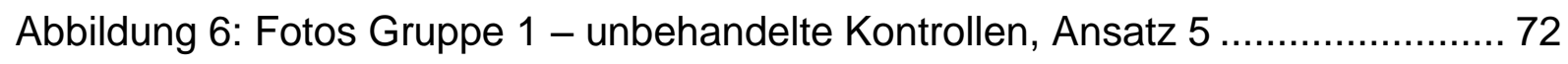

Abbildung 7: Fotos Gruppe 1 - unbehandelte Kontrollen, Ansatz 6 ...................... 73

Abbildung 8: Fotos Gruppe 2 - $50 \mu \mathrm{M}$ Fenofibrat-vorbehandelte Zellen, Ansatz 1 .. 73

Abbildung 9: Fotos Gruppe 2 - $50 \mu \mathrm{M}$ Fenofibrat-vorbehandelte Zellen, Ansatz 2 .. 73



Abbildung 11: Fotos Gruppe 2 - $50 \mu \mathrm{M}$ Fenofibrat-vorbehandelte Zellen, Ansatz 474

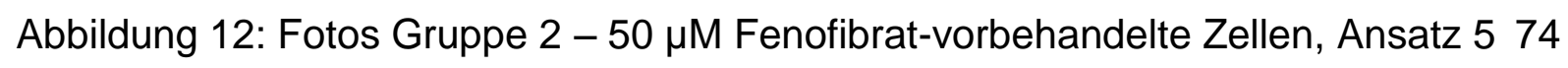

Abbildung 13: Prozentuale Reduktion der Wundflächengröße nach 24 Stunden in \% (In-vitro-Versuch 1, Teil 1)................................................................... 77

Abbildung 14: Prozentuale Reduktion der Wundflächengröße nach 24 Stunden in \%

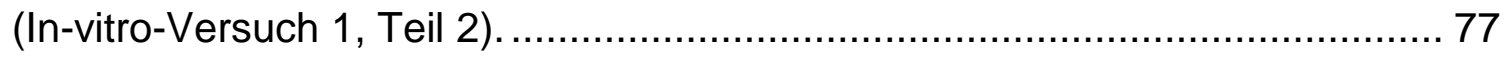

Abbildung 15: Prozentualer Anteil toter Zellen an der Gesamtzellzahl in \%

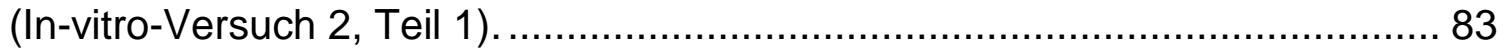

Abbildung 16: Prozentualer Anteil toter Zellen an der Gesamtzellzahl in \%



Abbildung 17: Ergebnisse der VEGF-Konzentration im Überstand in $\mathrm{pg} / \mathrm{ml}$

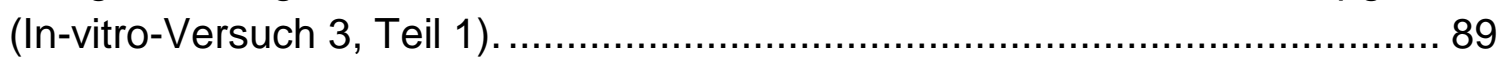

Abbildung 18: Ergebnisse der VEGF-Konzentration im Überstand in $\mathrm{pg} / \mathrm{ml}$

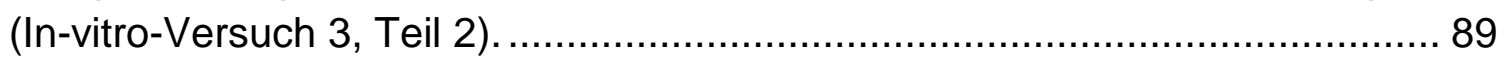




\subsection{Tabellenverzeichnis}

Tabelle 1: Liste der verwendeten Werkzeuge und Geräte................................... 57

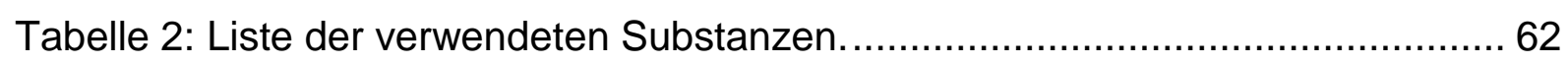

Tabelle 3: Postischämische Nierenfunktion: Kreatininkonzentration im Serum

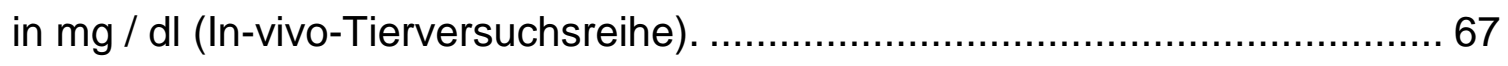

Tabelle 4: Wundflächenreduktion in \% (In-vitro-Versuch 1, Teil 1)......................... 75

Tabelle 5: Wundflächenreduktion in \% (In-vitro-Versuch 1, Teil 2)......................... 76

Tabelle 6: Prozentualer Anteil toter Zellen an der Gesamtzellzahl in \% (In-vitro-Versuch 2, Teil 1) .................................................................... 81

Tabelle 7: Prozentualer Anteil toter Zellen an der Gesamtzellzahl in \% (In-vitro-Versuch 2, Teil 2) ................................................................. 82

Tabelle 8: VEGF-Konzentration im Überstand in pg / ml (In-vitro-Versuch 3, Teil 1).87 Tabelle 9: VEGF-Konzentration im Überstand in pg / $\mathrm{ml}$ (In-vitro-Versuch 3, Teil 2).88

Tabelle 10: Zusammenfassung aller Versuche. 93 


\section{Literaturverzeichnis}

Adams V, Lenk K, Linke A, Lenz D, Erbs S, Sandri M, Tarnok A, Gielen S, Emmrich F, Schuler G (2004): Increase of circulating endothelial progenitor cells in patients with coronary artery disease after exercise-induced ischemia. Arterioscler Thromb Vasc Biol 24 (4), 684-690

Arakawa R, Tamehiro N, Nishimaki-Mogami T, Ueda K, Yokoyama S (2005): Fenofibric acid, an active form of fenofibrate, increases apolipoprotein A-I-mediated high-density lipoprotein biogenesis by enhancing transcription of ATP-binding cassette transporter $\mathrm{A} 1$ gene in a liver $\mathrm{X}$ receptor-dependent manner. Arterioscler Thromb Vasc Biol 25(6), 1193-1197

Asahara T, Murohara T, Sullivan A, Silver M, van der Zee R, Li T, Witzenbichler B, Schatteman G, Isner J M (1997): Isolation of Putative Progenitor Endothelial Cells for Angiogenesis. Science 275(5302), 964-966

Asahara T, Masuda H, Takahashi T, Kalka C, Pastore C, Silver M, Kearne M, Magner M, Isner J M (1999): Bone Marrow Origin of Endothelial Progenitor Cells Responsible for Postnatal Vasculogenesis in Physiological and Pathological

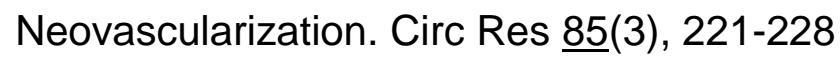

Bailey A S, Jiang S, Afentoulis M, Baumann C I, Schroeder D A, Olson S B, Wong M $\mathrm{H}$, Fleming W H (2004): Transplanted adult hematopoietic stems cells differentiate into functional endothelial cells. Blood 103(1), 13-19

Baldwin H S, Shen H M, Yan H C, DeLisser H M, Chung A, Mickanin C, Trask T, Kirschbaum N E, Newman P J, Albelda S M (1994): Platelet endothelial cell adhesion molecule-1 (PECAM-1/CD31): alternatively spliced, functionally distinct isoforms expressed during mammalian cardiovascular development. Development $\underline{120}(9)$, $2539-2553$

Beeri R, Symon Z, Brezis M, Ben-Sasson S A, Baehr P H, Rosen S, Zager R A (1995): Rapid DNA fragmentation from hypoxia along the thick ascending limb of rat kidneys. Kidney Int $\underline{47}(6), 1806-1810$ 
Bellomo R, Ronco C, Kellum J, Mehta R, Palevsky P, Acute Dialysis Quality Initiative workgroup (2004): Acute renal failure - definition, outcome measures, animal models, fluid therapy and information technology needs: the Second International Consensus Conference of the Acute Dialysis Quality Initiative (ADQI) Group. Critical Care $\underline{8}(4)$, R204-R212

Beltrami A P, Barlucchi L, Torella D, Baker M, Limana F, Chimenti S, Kasahara H, Rota M, Musso E, Urbanek K (2003): Adult cardiac stem cells are multipotent and support myocardial regeneration. Cell 114(6), 763-776

Berger J P, Akiyama T E, Meinke P T (2005): PPARs: therapeutic targets for metabolic disease. Trends Pharmacol Sci 26(5), 244-251

Bienholz A, Kribben A (2013): KDIGO-Leitlinien zum akuten Nierenversagen. Der Nephrologe $\underline{8}(3)$, 247-251

Bihorac A, Chawla L S, Shaw A D, Al-Khafaji A, Davison D L, Demuth G E, Fitzgerald R, Gong M N, Graham D D, Gunnerson K (2014): Validation of cell-cycle arrest biomarkers for acute kidney injury using clinical adjudication. Am J Respir Crit Care 189(8), 932-939

Bonventre J V (1993): Mechanisms of ischemic acute renal failure. Kidney Int $\underline{43}(5)$, $1160-1178$

Brady H R, Singer G G (1995): Acute renal failure. The Lancet $\underline{346}$ (8989), 1533-1540

Braissant O, Foufelle F, Scotto C, Dauca M, Wahli W (1996): Differential expression of peroxisome proliferator-activated receptors (PPARs): tissue distribution of PPARalpha, -beta, and -gamma in the adult rat. Endocrinology 137(1), 354-366

Brezis M, Rosen S (1995): Hypoxia of the Renal Medulla - Its Implications for Disease. N Engl J Med 332(10), 647-655

Brodsky S V, Yamamoto T, Tada T, Kim B, Chen J, Kajiya F, Goligorsky M S (2002): Endothelial dysfunction in ischemic acute renal failure: rescue by transplanted endothelial cells. Am J Physiol Renal Physiol 282(6), F1140-F1149 
Brown J D, Plutzky J (2007): Peroxisome proliferator-activated receptors as transcriptional nodal points and therapeutic targets. Circulation $\underline{115}(4), 518-533$

Calkin A C, Giunti S, Jandeleit-Dahm K A, Allen T J, Cooper M E, Thomas M C (2006): PPAR-alpha and -gamma agonists attenuate diabetic kidney disease in the apolipoprotein E knockout mouse. Nephrol Dial Transplant 21(9), 2399-2405

Cameron J S (1986): Acute Renal Failure - the Continuing Challenge. Q J Med $\underline{59}(1)$, 337-343

Case J, Mead L E, Bessler W K, Prater D, White H A, Saadatzadeh M R, Bhavsar J R, Yoder M C, Haneline L S, Ingram D A (2007): Human CD34+AC133+VEGFR-2+ cells are not endothelial progenitor cells but distinct, primitive hematopoietic progenitors. Exp Hematol $\underline{35}(7), 1109-1118$

Cerasola G, Cottone S, Mule G (2010): The progressive pathway of microalbuminuria: from early marker of renal damage to strong cardiovascular risk predictor. J Hypertens $\underline{28}(12), 2357-2369$

Chawla L S, Amdur R L, Amodeo S, Kimmel P L, Palant C E (2011): The severity of acute kidney injury predicts progression to chronic kidney disease. Kidney Int $\underline{79}(12)$, 1361-1369

Chen H H, Chen T W, Lin H (2009): Prostacyclin-induced peroxisome proliferatoractivated receptor-alpha translocation attenuates NF-kappaB and TNF-alpha activation after renal ischemia-reperfusion injury. Am J Physiol Renal Physiol 297(4), F1109-1118

Cheng C F, Chen H H, Lin H (2010): Role of PPARalpha and Its Agonist in Renal Diseases. PPAR research 2010, 345098

Chinetti G, Griglio S, Antonucci M, Torra I P, Delerive P, Majd Z, Fruchart J C, Chapman J, Najib J, Staels B (1998): Activation of proliferator-activated receptors alpha and gamma induces apoptosis of human monocyte-derived macrophages. $J$ Biol Chem $\underline{273}(40), 25573-25580$ 
Chinetti G, Lestavel S, Bocher V, Remaley A T, Neve B, Torra I P, Teissier E, Minnich A, Jaye M, Duverger N (2001): PPAR-alpha and PPAR-gamma activators induce cholesterol removal from human macrophage foam cells through stimulation of the ABCA1 pathway. Nat Med $\underline{7}(1), 53-58$

Conger J D, Robinette J B, Hammond W S (1991): Differences in vascular reactivity in models of ischemic acute renal failure. Kidney Int 39(6), 1087-1097

Corwin H L, Teplick R S, Schreiber M J, Fang L S T, Bonventre J V, Coggins C H (1987): Prediction of Outcome in Acute Renal Failure. Am J Nephrol $\underline{7}(1), 8-12$

Delerive P, De Bosscher K, Besnard S, Vanden Berghe W, Peters J M, Gonzalez F J, Fruchart J C, Tedgui A, Haegeman G, Staels B (1999): Peroxisome proliferatoractivated receptor alpha negatively regulates the vascular inflammatory gene response by negative cross-talk with transcription factors NF-kappaB and AP-1. J Biol Chem 274(45), 32048-32054

Devarajan P (2006): Update on mechanisms of ischemic acute kidney injury. J Am Soc Nephrol 17(6), 1503-1520

DiRenzo J, Soderstrom M, Kurokawa R, Ogliastro M H, Ricote M, Ingrey S, Horlein A, Rosenfeld M G, Glass C K (1997): Peroxisome proliferator-activated receptors and retinoic acid receptors differentially control the interactions of retinoid $X$ receptor heterodimers with ligands, coactivators, and corepressors. Mol Cell Biol 17(4), 21662176

Dressel U, Allen T L, Pippal J B, Rohde P R, Lau P, Muscat G E (2003): The peroxisome proliferator-activated receptor beta/delta agonist, GW501516, regulates the expression of genes involved in lipid catabolism and energy uncoupling in skeletal muscle cells. Mol Endocrinol 17(12), 2477-2493

Dreyer C, Krey G, Keller H, Givel F, Helftenbein G, Wahli W (1992): Control of the peroxisomal beta-oxidation pathway by a novel family of nuclear hormone receptors. Cell $\underline{68}(5), 879-887$

Elasy T A, Anderson R J (1996): Changing Demography of Acute Renal Failure. Semin Dial $\underline{9}(6), 438-443$ 
Esson M L, Schrier R W (2002): Diagnosis and treatment of acute tubular necrosis. Ann Intern Med 137(9), 744-752

Fang Y, Ding X, Zhong Y, Zou J, Teng J, Tang Y, Lin J, Lin P (2010): Acute kidney injury in a Chinese hospitalized population. Blood Purif $\underline{30}(2), 120-126$

Fiedler M: Licht im „Kreatinin-blinden“ Bereich. In: Roche Diagnostics Deutschland GmbH - Geschäftsführer Schinecker T (Hrsg.): Diagnostik im Dialog - News der Roche Diagnostics Deutschland $\mathrm{GmbH}, \underline{46}$, Roche Diagnostics Deutschland GmbH, Mannheim 2015, 17-19

Frederiksen K S, Wulff E M, Sauerberg P, Mogensen J P, Jeppesen L, Fleckner J (2004): Prediction of PPAR-alpha ligand-mediated physiological changes using gene expression profiles. J Lipid Res $\underline{45}(3)$, 592-601

Gilde A J, van der Lee K A, Willemsen P H, Chinetti $G$, van der Leij F R, van der Vusse G J, Staels B, van Bilsen M (2003): Peroxisome proliferator-activated receptor (PPAR) alpha and PPARbeta/delta, but not PPARgamma, modulate the expression of genes involved in cardiac lipid metabolism. Circ Res 92(5), 518-524

Gocze I, Koch M, Renner P, Zeman F, Graf BM, Dahlke MH, Nerlich M, Schlitt HJ, Kellum JA, Bein T (2015): Urinary biomarkers TIMP-2 and IGFBP7 early predict acute kidney injury after major surgery. PLoS One 10(3):e0120863

Goligorsky M S (2005): Endothelial cell dysfunction: can't live with it, how to live without it. Am J Physiol Renal Physiol 288(5), F871-F880

Goligorsky M S, DiBona G F (1993): Pathogenetic role of Arg-Gly-Asp-recognizing integrins in acute renal failure. off. Proc Natl Acad Sci U S A $\underline{90}(12), 5700-5704$

Goligorsky M S, Yasuda K, Ratliff B (2010): Dysfunctional endothelial progenitor cells in chronic kidney disease. J Am Soc Nephrol 21(6), 911-919

Grant M B, Stratford May W, Caballero S, Brown G A J, Guthrie S M, Mames R M, Byrne B J, Vaught T, Spoerri P E, Peck A B (2002): Adult hematopoietic stem cells provide functional hemangioblast activity during retinal neovascularization. Nat Med $\underline{8}(6), 607-612$ 
Grino J M (1994): BN 52021: a platelet activating factor antagonist for preventing post-transplant renal failure. A double-blind, randomized study. The BN 52021 Study Group in Renal Transplantation. Ann Intern Med 121(5), 345-347

Guan Y, Zhang Y, Davis L, Breyer M D (1997): Expression of peroxisome proliferator-activated receptors in urinary tract of rabbits and humans. Am J Physiol $\underline{273}(6 \mathrm{Pt} 2), \mathrm{F} 1013-\mathrm{F} 1022$

Gulati S, Singh A K, Irazu C, Orak J, Rajagopalan P R, Fitts C T, Singh I (1992): Ischemia-reperfusion injury: biochemical alterations in peroxisomes of rat kidney. Arch Biochem Biophys. 295(1), 90-100

Gulick T, Cresci S, Caira T, Moore D D, Kelly D P (1994): The peroxisome proliferator-activated receptor regulates mitochondrial fatty acid oxidative enzyme gene expression. Proc Natl Acad Sci U S A 91(23), 11012-11016

Hammerman M R, Miller S B (1994): Therapeutic use of growth factors in renal failure. J Am Soc Nephrol $\underline{5}(1), 1-11$

Heeschen C, Aicher A, Lehmann R, Fichtlscherer S, Vasa M, Urbich C, Mildner-Rihm C, Martin H, Zeiher A M, Dimmeler S (2003): Erythropoietin is a potent physiologic stimulus for endothelial progenitor cell mobilization. Blood 102(4), 1340-1346

Herold G: Innere Medizin. Gerd Herold (Verlag), Köln 2012

Heyman S N, Rosenberger C, Rosen S (2010): Experimental ischemia-reperfusion: biases and myths-the proximal vs. distal hypoxic tubular injury debate revisited. Kidney Int $\underline{77}(1), 9-16$

Hiasa K, Ishibashi M, Ohtani K, Inoue S, Zhao Q, Kitamoto S, Sata M, Ichiki T, Takeshita A, Egashira K (2004): Gene transfer of stromal cell-derived factor-1alpha enhances ischemic vasculogenesis and angiogenesis via vascular endothelial growth factor/endothelial nitric oxide synthase-related pathway: next-generation chemokine therapy for therapeutic neovascularization. Circulation 109(20), 2454-2461

Hoste E A, Kellum J A (2006): RIFLE criteria provide robust assessment of kidney dysfunction and correlate with hospital mortality. Crit Care Med 34(7), 2016-2017 
Hoste E A, Clermont G, Kersten A, Venkataraman R, Angus D C, De Bacquer D, Kellum J A (2006): RIFLE criteria for acute kidney injury are associated with hospital mortality in critically ill patients: a cohort analysis. Crit Care 10(3), R73

Hou S H, Bushinsky D A, Wish J B, Cohen J J, Harrington J T (1983): Hospitalacquired renal insufficiency: A prospective study. Am J Med 74(2), 243-248

Ince C, Ergin B, van Elsas A (2013): Recombinant alkaline phosphatase modulates inflammation and injury in two rat models of AKI. J Am Soc Nephrol 24, 380A

Ingram D A, Caplice N M, Yoder M C (2005): Unresolved questions, changing definitions, and novel paradigms for defining endothelial progenitor cells. Blood $\underline{106}(5), 1525-1531$

Ismail-Beigi F, Craven T, Banerji M A, Basile J, Calles J, Cohen R M, Cuddihy R, Cushman W C, Genuth S, Grimm R H (2010): Effect of intensive treatment of hyperglycaemia on microvascular outcomes in type 2 diabetes: an analysis of the ACCORD randomised trial. Lancet $\underline{376}(9739), 419-430$

Issemann I, Green S (1990): Activation of a member of the steroid hormone receptor superfamily by peroxisome proliferators. Nature 347(6294), 645-650

Kashani K, Al-Khafaji A, Ardiles T, Artigas A, Bagshaw SM, Bell M, Bihorac A, Birkhahn R, Cely CM, Chawla LS (2013): Discovery and validation of cell cycle arrest biomarkers in human acute kidney injury. Crit Care 17(1):R25

Keech A, Simes R J, Barter P, Best J, Scott R, Taskinen M R, Forder P, Pillai A, Davis T, Glasziou P (2005): Effects of long-term fenofibrate therapy on cardiovascular events in 9795 people with type 2 diabetes mellitus (the FIELD study): randomised controlled trial. Lancet $\underline{366}(9500), 1849-1861$

Kellerman P S, Clark R A, Hoilien C A, Linas S L, Molitoris B A (1990): Role of microfilaments in maintenance of proximal tubule structural and functional integrity. Am J Physiol 259(2 Pt 2), F279-F285

Kellum J A, Angus D C (2002): Patients are dying of acute renal failure. Crit Care Med $\underline{30}(9), 2156-2157$ 
Kellum J A, Levin N, Bouman C, Lameire N (2002): Developing a consensus classification system for acute renal failure. Curr Opin Crit Care $\underline{8}(6), 509-514$

Khakoo A Y, Finkel T (2005): Endothelial Progenitor Cells*. Annu Rev Med $\underline{56}(1), 79-$ 101

Klausner J M, Paterson I S, Goldman G, Kobzik L, Rodzen C, Lawrence R, Valeri C R, Shepro D, Hechtman H B (1989): Postischemic renal injury is mediated by neutrophils and leukotrienes. Am J Physiol $\underline{256}$ (5 Pt 2), F794-F802

Kribben A, Feldkamp T, Horbelt M, Lange B, Pietruck F, Herget-Rosenthal S, Heemann U, Philipp T (2003): ATP protects, by way of receptor-mediated mechanisms, against hypoxia-induced injury in renal proximal tubules. J Lab Clin Med. 141(1), 67-73

Kriz W, Bankir L (1988): A standard nomenclature for structures of the kidney. The Renal Commission of the International Union of Physiological Sciences (IUPS). Kidney Int. $\underline{33}(1), 1-7$

Kuo M C, Patschan D, Patschan S, Cohen-Gould L, Park H C, Ni J, Addabbo F, Goligorsky M S (2008): Ischemia-induced exocytosis of Weibel-Palade bodies mobilizes stem cells. J Am Soc Nephrol 19(12), 2321-2330

Lafrance J P, Miller D R (2010): Defining acute kidney injury in database studies: the effects of varying the baseline kidney function assessment period and considering CKD status. Am J Kidney Dis $\underline{56}(4), 651-660$

Lambiase P D, Edwards R J, Anthopoulos P, Rahman S, Meng Y G, Bucknall C A, Redwood S R, Pearson J D, Marber M S (2004): Circulating humoral factors and endothelial progenitor cells in patients with differing coronary collateral support. Circulation 109(24), 2986-2992

Langenberg C, Wan L, Egi M, May C N, Bellomo R (2006): Renal blood flow in experimental septic acute renal failure. Kidney Int $\underline{69}(11), 1996-2002$

Lapergue B, Mohammad A, Shuaib A (2007): Endothelial progenitor cells and cerebrovascular diseases. Prog Neurobiol 83(6), 349-362 
Latruffe N, Cherkaoui Malki M, Nicolas-Frances V, Jannin B, Clemencet M C, Hansmannel F, Passilly-Degrace P, Berlot J P (2001): Peroxisome-proliferatoractivated receptors as physiological sensors of fatty acid metabolism: molecular regulation in peroxisomes. Biochem Soc Trans $\underline{\underline{29}}(\mathrm{Pt} 2), 305-309$

Leaf A (1973): Cell swelling. A factor in ischemic tissue injury. Circulation $\underline{48}(3), 455-$ 458

Levy E M, Viscoli C M, Horwitz R I (1996): The effect of acute renal failure on mortality: A cohort analysis. JAMA $\underline{275}(19), 1489-1494$

Li L, Emmett N, Mann D, Zhao X (2010): Fenofibrate attenuates tubulointerstitial fibrosis and inflammation through suppression of nuclear factor-kappaB and transforming growth factor-beta1/Smad3 in diabetic nephropathy. Exp Biol Med (Maywood) 235(3), 383-391

Li S, Basnakian A, Bhatt R, Megyesi J, Gokden N, Shah S V, Portilla D (2004): PPAR-alpha ligand ameliorates acute renal failure by reducing cisplatin-induced increased expression of renal endonuclease G. Am J Physiol Renal Physiol 287(5), F990-F998

Liano F, Pascual J, Group M A R F S (1996): Epidemiology of acute renal failure: a prospective, multicenter, community-based study. Kidney Int $\underline{50}, 811-818$

Liao J, Soltani Z, Ebenezer P, Isidro-Carrion A A, Zhang R, Asghar A, Aguilar E, Francis J, Hu X, Ferder L (2010): Tesaglitazar, a dual peroxisome proliferatoractivated receptor agonist (PPAR alpha/gamma), improves metabolic abnormalities and reduces renal injury in obese Zucker rats. Nephron. Exp Nephrol 114(2), e61e68

Lieberthal W, Nigam S K (1998): Acute renal failure. I. Relative importance of proximal vs. distal tubular injury. Am J Physiol 275(5), 623-631

Lin Y, Weisdorf D J, Solovey A, Hebbel R P (2000): Origins of circulating endothelial cells and endothelial outgrowth from blood. J Clin Invest 105(1), 71-77 
Lopez-Hernandez F J, Lopez-Novoa J M (2009): Potential utility of PPARalpha activation in the prevention of ischemic and drug-induced acute renal damage. Kidney Int $\underline{76}$ (10), 1022-1024

Lüllmann-Rauch R: Taschenlehrbuch Histologie. 3. Auflage; Georg Thieme Verlag KG, Stuttgart 2009

Malis C D, Leaf A, Varadarajan G S, Newell J B, Weber P C, Force T, Bonventre J V (1991): Effects of dietary omega 3 fatty acids on vascular contractility in preanoxic and postanoxic aortic rings. Circulation $\underline{84}(3), 1393-1401$

Martin G, Schoonjans K, Lefebvre A M, Staels B, Auwerx J (1997): Coordinate regulation of the expression of the fatty acid transport protein and acyl-CoA synthetase genes by PPARalpha and PPARgamma activators. J Biol Chem 272(45), 28210-28217

Mason J, Joeris B, Welsch J, Kriz W (1989): Vascular congestion in ischemic renal failure: the role of cell swelling. Miner Electrolyte Metab 15(3), 114-124

Mehta R, Kellum J, Shah S, Molitoris B, Ronco C, Warnock D, Levin A, Acute Kidney Injury Network (2007): Acute Kidney Injury Network: report of an initiative to improve outcomes in acute kidney injury. Crit Care 11(2), R31

Mias C, Trouche E, Seguelas M H, Calcagno F, Dignat-George F, Sabatier F, Piercecchi-Marti M D, Daniel L, Bianchi P, Calise D (2008): Ex vivo pretreatment with melatonin improves survival, proangiogenic/mitogenic activity, and efficiency of mesenchymal stem cells injected into ischemic kidney. Stem Cells $\underline{26}(7), 1749-1757$

Molitoris B A (1991): Ischemia-induced loss of epithelial polarity: potential role of the actin cytoskeleton. Am J Physiol 260(6 Pt 2), F769-F778

Molitoris B A, Dahl R, Geerdes A (1992): Cytoskeleton disruption and apical redistribution of proximal tubule $\mathrm{Na}(+)-\mathrm{K}(+)-A T P a s e$ during ischemia. Am $\mathrm{J}$ Physiol $\underline{263}(3 \mathrm{Pt}$ 2), F488-F495 
Moubarik C, Guillet B, Youssef B, Codaccioni J L, Piercecchi M D, Sabatier F, Lionel P, Dou L, Foucault-Bertaud A, Velly L (2011): Transplanted late outgrowth endothelial progenitor cells as cell therapy product for stroke. Stem Cell Rev $\underline{7}(1)$, 208-220

Muerhoff A S, Griffin K J, Johnson E F (1992): The peroxisome proliferator-activated receptor mediates the induction of CYP4A6, a cytochrome P450 fatty acid omegahydroxylase, by clofibric acid. J Biol Chem 267(27), 19051-19053

Murohara T (2010): Cord blood-derived early outgrowth endothelial progenitor cells. Microvasc Res $\underline{79}(3), 174-177$

Murugan R, Kellum J A (2011): Acute kidney injury: what's the prognosis? Nature reviews. Nephrology $\underline{7}(4), 209-217$

Myers B D, Moran S M (1986): Hemodynamically Mediated Acute Renal Failure. N Engl J Med 314(2), 97-105

Nakaya K, Tohyama J, Naik S U, Tanigawa H, MacPhee C, Billheimer J T, Rader D J (2011): Peroxisome proliferator-activated receptor-alpha activation promotes macrophage reverse cholesterol transport through a liver $\mathrm{X}$ receptor-dependent pathway. Arterioscler. Thromb Vasc Biol 31(6), 1276-1282

Park C W, Zhang Y, Zhang X, Wu J, Chen L, Cha D R, Su D, Hwang M T, Fan X, Davis L, Striker G, Zheng F, Breyer M, Guan Y (2006): PPARalpha agonist fenofibrate improves diabetic nephropathy in db/db mice. Kidney Int 69(9), 15111517

Pascual J, Liaño F, Ortuño J (1995): The elderly patient with acute renal failure. J Am Soc Nephrol $\underline{6}(2), 144-153$

Patel N S, di Paola R, Mazzon E, Britti D, Thiemermann C, Cuzzocrea S (2009): Peroxisome proliferator-activated receptor-alpha contributes to the resolution of inflammation after renal ischemia/reperfusion injury. J Pharmacol Exp Ther $\underline{328}(2)$, 635-643 
Patschan D, Krupincza K, Patschan S, Zhang Z, Hamby C, Goligorsky M S (2006a): Dynamics of mobilization and homing of endothelial progenitor cells after acute renal ischemia: modulation by ischemic preconditioning. Am J Physiol Renal Physio 291(1), F176-F185

Patschan D, Plotkin M, Goligorsky M S (2006b): Therapeutic use of stem and endothelial progenitor cells in acute renal injury: ca ira. Curr Opin Pharmacol $\underline{6}(2)$, 176-183

Patschan D, Patschan S, Gobe G G, Chintala S, Goligorsky M S (2007): Uric acid heralds ischemic tissue injury to mobilize endothelial progenitor cells. J Am Soc Nephrol 18(5), 1516-1524

Patschan D, Patschan S, Henze E, Wessels J T, Koziolek M, Muller G A (2009): LDL lipid apheresis rapidly increases peripheral endothelial progenitor cell competence. $J$ Clin Apher 24(5), 180-185

Patschan D, Patschan S, Wessels J T, Becker J U, David S, Henze E, Goligorsky M S, Muller G A (2010): Epac-1 activator 8-O-cAMP augments renoprotective effects of syngeneic [corrected] murine EPCs in acute ischemic kidney injury. Am J Physiol Renal Physiol 298(1), F78-F85

Patschan D, Hildebrandt A, Rinneburger J, Wessels J T, Patschan S, Becker J U, Henze E, Kruger A, Muller G A (2012a): The hormone melatonin stimulates renoprotective effects of "early outgrowth" endothelial progenitor cells in acute ischemic kidney injury. Am J Physiol Renal Physiol 302(10), F1305-F1312

Patschan D, Patschan S, Muller G A (2012b): Microvasculopathy in ischemic acute kidney injury: consequences and therapeutic implications. Panminerva Med $\underline{54}(1)$, 45-52

Patschan D, Backhaus R, Elle H J, Schwarze K, Henze E, Becker J U, Patschan S, Muller G A (2013a): Angiopoietin-2 modulates eEOC-mediated renoprotection in AKI in a dose-dependent manner. J Nephrol $\underline{26}$ (4), 667-674 
Patschan D, Rinneburger J, Idrizi N, Backhaus R, Schwarze K, Henze E, Patschan S, Muller G A (2013b): Angiopoietin-1 treated early endothelial outgrowth cells (eEOCs) are activated in vitro and reduce renal damage in murine acute ischemic kidney injury (iAKI). BMC Nephrol 14, 227

Patschan D, Schwarze K, Lange A, Meise N, Henze E, Becker J U, Patschan S, Müller G A (2013c): Bone Morphogenetic Protein-5 and early Endothelial Outgrowth Cells (eEOCs) in acute ischemic kidney injury (AKI) and 5/6-chronic kidney disease. Am J Physiol Renal Physiol 305(3), F314-322

Patschan D, Schwarze K, Henze E, Patschan S, Scheidemann R, Muller GA (2014): Fibrate treatment of eEOCs in murine AKI. J Nephrol 27(1), 37-44

Pickkers P, Heemskerk S, Schouten J, Laterre P F, Vincent J L, Beishuizen A, Jorens P G, Spapen H, Bulitta M, Peters W H (2012): Alkaline phosphatase for treatment of sepsis-induced acute kidney injury: a prospective randomized doubleblind placebo-controlled trial. Crit Care $\underline{16}(1), \mathrm{R} 14$

Planat-Benard V, Silvestre J-S, Cousin B, André M, Nibbelink M, Tamarat R, Clergue M, Manneville C, Saillan-Barreau C, Duriez M (2004): Plasticity of Human Adipose Lineage Cells Toward Endothelial Cells: Physiological and Therapeutic Perspectives. Circulation $\underline{109}(5), 656-663$

Portilla D, Dai G, Peters J M, Gonzalez F J, Crew M D, Proia A D (2000): Etomoxirinduced PPARalpha-modulated enzymes protect during acute renal failure. Am J Physiol Renal Physiol 278(4), F667-F675

Pourcet B, Pineda-Torra I, Derudas B, Staels B, Glineur C (2010): SUMOylation of human peroxisome proliferator-activated receptor alpha inhibits its trans-activity through the recruitment of the nuclear corepressor NCoR. J Biol Chem 285(9), 59835992

Povsic T J, Goldschmidt-Clermont P J (2008): Endothelial progenitor cells: markers of vascular reparative capacity. Ther Adv Cardiovasc Di. 2(3), 199-213

Racusen L C, Fivush B A, Li Y L, Slatnik I, Solez K (1991): Dissociation of tubular cell detachment and tubular cell death in clinical and experimental "acute tubular necrosis". Lab Invest 64(4), 546-556 
Rafii S, Lyden D (2003): Therapeutic stem and progenitor cell transplantation for organ vascularization and regeneration. Nat Med $\underline{9}(6), 702-712$

Rakhshandehroo M, Knoch B, Muller M, Kersten S (2010): Peroxisome proliferatoractivated receptor alpha target genes. PPAR research $\underline{2010}$

Rangel-Frausto M S, Pittet D, Costigan M, Hwang T, Davis C S, Wenzel R P (1995): The natural history of the systemic inflammatory re-sponse syndrome (SIRS): a prospective study. JAMA $\underline{273}(2), 117-123$

Rehman J, Li J, Orschell C M, March K L (2003): Peripheral blood "endothelial progenitor cells" are derived from monocyte/macrophages and secrete angiogenic growth factors. Circulation 107(8), 1164-1169

Reyes M, Dudek A, Jahagirdar B, Koodie L, Marker P H, Verfaillie C M (2002): Origin of endothelial progenitors in human postnatal bone marrow. J Clin Invest 109(3), 337-346

Riedemann N C, Guo R F, Ward P A (2003): The enigma of sepsis. J Clin Invest $\underline{112}(4), 460-467$

Risau W (1997): Mechanisms of angiogenesis. Nature $\underline{386}(6626), 671-674$

Robinson E, Grieve D J (2009): Significance of peroxisome proliferator-activated receptors in the cardiovascular system in health and disease. Pharmacol Ther 122(3), 246-263

Romagnani P, Annunziato F, Liotta F, Lazzeri E, Mazzinghi B, Frosali F, Cosmi L, Maggi L, Lasagni L, Scheffold A (2005): CD14+CD34low Cells With Stem Cell Phenotypic and Functional Features Are the Major Source of Circulating Endothelial Progenitors. Circ Res 97(4), 314-322

Rosen S, Heyman S N (2001): Difficulties in understanding human "acute tubular necrosis": limited data and flawed animal models. Kidney Int $\underline{60}(4), 1220-1224$ 
Ruan X Z, Moorhead J F, Fernando R, Wheeler D C, Powis S H, Varghese Z (2003): PPAR agonists protect mesangial cells from interleukin 1beta-induced intracellular lipid accumulation by activating the ABCA1 cholesterol efflux pathway. J Am Soc Nephrol $\underline{14}(3)$, 593-600

Ruidera E, Irazu C E, Rajagopalan P R, Orak J K, Fitts C T, Singh I (1988): Fatty acid metabolism in renal ischemia. Lipids. $\underline{23}(9), 882-884$

Safirstein R, Bonventre $\mathrm{J}$ V: Molecular response to ischemic and nephrotoxic acute renal failure. In: Schlöndorff D, Bonventre J V (Hrsg.): Molecular nephrology: Kidney function in health and disease. Marcel Dekker, New York 1995. 839-854

Schmid-Schonbein G W (1987): Capillary plugging by granulocytes and the no-reflow phenomenon in the microcirculation. Fed Proc 46 (7), 2397-2401

Schmidt R F, Lang F, Heckmann M: Physiologie des Menschen mit Pathophysiologie, 31. Auflage, Springer Medizin Verlag, Heidelberg 2010

Schoonjans K, Peinado-Onsurbe J, Lefebvre A M, Heyman R A, Briggs M, Deeb S, Staels B, Auwerx J (1996): PPARalpha and PPARgamma activators direct a distinct tissue-specific transcriptional response via a PPRE in the lipoprotein lipase gene. EMBO J 15(19), 5336-5348

Schumer M, Colombel M C, Sawczuk I S, Gobe G, Connor J, O'Toole K M, Olsson C A, Wise G J, Buttyan R (1992): Morphologic, biochemical, and molecular evidence of apoptosis during the reperfusion phase after brief periods of renal ischemia. Am J Pathol 140(4), 831-838

Schuster M D, Kocher A A, Seki T, Martens T P, Xiang G, Homma S, Itescu S (2004): Myocardial neovascularization by bone marrow angioblasts results in cardiomyocyte regeneration. Am J Physiol Heart Circ Physiol 287(2), H525-H532

Schuster N, Krieglstein K (2002): Mechanisms of TGF-beta-mediated apoptosis. Cell Tissue Res $\underline{307}(1), 1-14$ 
Scott R, Best J, Forder P, Taskinen M R, Simes J, Barter P, Keech A (2005): Fenofibrate Intervention and Event Lowering in Diabetes (FIELD) study: baseline characteristics and short-term effects of fenofibrate [ISRCTN64783481]. Cardiovasc Diabetol $\underline{4}: 13$

Scott R, O'Brien R, Fulcher G, Pardy C, D'Emden M, Tse D, Taskinen M R, Ehnholm C, Keech A (2009): Effects of fenofibrate treatment on cardiovascular disease risk in 9,795 individuals with type 2 diabetes and various components of the metabolic syndrome: the Fenofibrate Intervention and Event Lowering in Diabetes (FIELD) study. Diabetes Care 32(3), 493-498

Sevanian A, Kim E (1985): Phospholipase A2 dependent release of fatty acids from peroxidized membranes. J Free Radic Biol Med 1(4), 263-271

Shu H, Wong B, Zhou G, Li Y, Berger J, Woods J W, Wright S D, Cai T Q (2000): Activation of PPARalpha or gamma reduces secretion of matrix metalloproteinase 9 but not interleukin 8 from human monocytic THP-1 cells. Biochem Biophys Res Commun 267(1), 345-349

Siew E D, Ware L B, Ikizler T A (2011): Biological markers of acute kidney injury. J Am Soc Nephrol 22(5), 810-820

Singh P, Okusa M D (2011): The role of tubuloglomerular feedback in the pathogenesis of acute kidney injury. Contrib Nephrol 174, 12-21

Sivarajah A, Chatterjee P K, Hattori Y, Brown P A, Stewart K N, Todorovic Z, MotaFilipe H, Thiemermann C (2002): Agonists of peroxisome-proliferator activated receptor-alpha (clofibrate and WY14643) reduce renal ischemia/reperfusion injury in the rat. Med Sci Monit $\underline{8}(12)$, BR532-BR539

Spencer A J, LeFurgey A, Ingram P, Mandel L J (1991): Elemental microanalysis of organelles in proximal tubules. II. Effects of oxygen deprivation. J Am Soc Nephrol 1(12), 1321-1333

Srisawat N, Hoste E E, Kellum J A (2010): Modern classification of acute kidney injury. Blood Purif 29(3), 300-307 
Srisawat N, Kellum J A (2011): Acute kidney injury: definition, epidemiology, and outcome. Curr Opin Crit Care. 17(6), 548-555

Sugimoto H, LeBleu V S, Bosukonda D, Keck P, Taduri G, Bechtel W, Okada H, Carlson W, Jr., Bey P, Rusckowski M (2012): Activin-like kinase 3 is important for kidney regeneration and reversal of fibrosis. Nat Med 18(3), 396-404

Tenenbaum A, Fisman E Z (2012): Balanced pan-PPAR activator bezafibrate in combination with statin: comprehensive lipids control and diabetes prevention? Cardiovasc Diabetol $\underline{11}, 140$

Thakar C V, Christianson A, Freyberg R, Almenoff P, Render M L (2009): Incidence and outcomes of acute kidney injury in intensive care units: a Veterans Administration study. Crit Care Med $\underline{37}(9), 2552-2558$

Tögel F, Hu Z, Weiss K, Isaac J, Lange C, Westenfelder C (2005): Administered mesenchymal stem cells protect against ischemic acute renal failure through differentiation-independent mechanisms. Am J Physiol Renal Physiol 289(1), FF3142

Togel F E, Westenfelder C (2012): Kidney protection and regeneration following acute injury: progress through stem cell therapy. Am J Kidney Dis $\underline{60}(6), 1012-1022$

Tugwood J D, Issemann I, Anderson R G, Bundell K R, McPheat W L, Green S (1992): The mouse peroxisome proliferator activated receptor recognizes a response element in the 5 ' flanking sequence of the rat acyl CoA oxidase gene. EMBO J 11(2), 433-439

Turney J H (1990): Why is mortality persistently high in acute renal failure? Lancet $\underline{335}(8695), 971$

Uchino S, Kellum J A, Bellomo R, Doig G S, Morimatsu H, Morgera S, Schetz M, Tan I, Bouman C, Macedo E (2005): Acute renal failure in critically ill patients: a multinational, multicenter study. JAMA 294(7), 813-818 
Uchino S, Bellomo R, Goldsmith D, Bates S, Ronco C (2006): An assessment of the RIFLE criteria for acute renal failure in hospitalized patients. Crit Care Med 34(7), 1913-1917

Urbich C, Dimmeler S (2004a): Endothelial Progenitor Cells: Characterization and Role in Vascular Biology. Circ Res 95(4), 343-353

Urbich C, Dimmeler S (2004b): Endothelial Progenitor Cells: Functional Characterization. Trends Cardiovasc Med 14(8), 318-322

Vasko R (2016): Peroxisomes and Kidney Injury. Antioxidants \& redox signaling. PubMed PMID: 26972522. Epub 2016/03/15. (Antioxidants \& redox signaling, im Druck)

Vetterlein F, Petho A, Schmidt G (1986): Distribution of capillary blood flow in rat kidney during postischemic renal failure. Am J Physiol 251(3 Pt 2):H510-H519

Vu-Dac N, Schoonjans K, Laine B, Fruchart J C, Auwerx J, Staels B (1994): Negative regulation of the human apolipoprotein A-I promoter by fibrates can be attenuated by the interaction of the peroxisome proliferator-activated receptor with its response element. J Biol Chem 269(49), 31012-31018

Vu-Dac N, Schoonjans K, Kosykh V, Dallongeville J, Fruchart J C, Staels B, Auwerx $J$ (1995): Fibrates increase human apolipoprotein A-II expression through activation of the peroxisome proliferator-activated receptor. J Clin Invest $\underline{96}(2), 741-50$

Vukicevic S, Basic V, Rogic D, Basic N, Shih M S, Shepard A, Jin D, Dattatreyamurty B, Jones W, Dorai H, Ryan S, Griffiths D, Maliakal J, Jelic M, Pastorcic M, Stavljenic A, Sampath T K (1998): Osteogenic protein-1 (bone morphogenetic protein-7) reduces severity of injury after ischemic acute renal failure in rat. J Clin Invest 102(1), 202-214

Wakui S, Yokoo K, Muto T, Suzuki Y, Takahashi H, Furusato M, Hano H, Endou H, Kanai Y (2006): Localization of Ang-1, -2, Tie-2, and VEGF expression at endothelial-

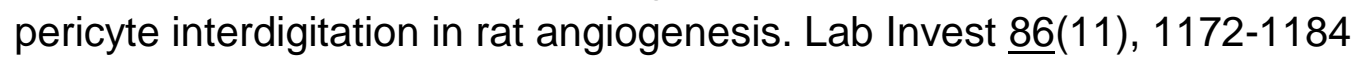


Wan L, Bagshaw S M, Langenberg C, Saotome T, May C, Bellomo R (2008): Pathophysiology of septic acute kidney injury: what do we really know? Crit Care Med $\underline{36}$ (4 Suppl), S198-S203

Wang S H, Lin S J, Chen Y H, Lin F Y, Shih J C, Wu C C, Wu H L, Chen Y L (2009): Late outgrowth endothelial cells derived from Wharton jelly in human umbilical cord reduce neointimal formation after vascular injury: involvement of pigment epitheliumderived factor. Arterioscler. Thromb Vasc Biol 29 (6), 816-822

Wang Y X, Lee C H, Tiep S, Yu R T, Ham J, Kang H, Evans R M (2003): Peroxisome-proliferator-activated receptor delta activates fat metabolism to prevent obesity. Cell $\underline{113}(2), 159-170$

Wardle E N (2004): PPAR: Receptors that Regulate Inflammation. Saudi J Kidney Dis Transpl $\underline{15}(1), 1-6$

Weisman H F, Bartow T, Leppo M K, Marsh H C, Jr., Carson G R, Concino M F, Boyle M P, Roux K H, Weisfeldt M L, Fearon D T (1990): Soluble human complement receptor type 1: in vivo inhibitor of complement suppressing post-ischemic myocardial inflammation and necrosis. Science 249(4965), 146-151

Wierzbicki A S (2010): Fibrates: no ACCORD on their use in the treatment of dyslipidaemia. Curr Opin Lipidol 21 (4), 352-358

Wilmer W A, Dixon C L, Hebert C, Lu L, Rovin B H (2002): PPAR-alpha ligands inhibit $\mathrm{H} 2 \mathrm{O} 2$-mediated activation of transforming growth factor-beta1 in human mesangial cells. Antioxid Redox Signal $\underline{4}(6), 877-884$

Woodrow G, Turney J H (1992): Cause of death in acute renal failure. Nephrol Dial Transplant $\underline{7}(3), 230-234$

Xu Q (2007): Progenitor cells in vascular repair. Curr Opin Lipidol 18(5), 534-539

Yamamoto T, Tada T, Brodsky S V, Tanaka H, Noiri E, Kajiya F, Goligorsky M S (2002): Intravital videomicroscopy of peritubular capillaries in renal ischemia. Am J Physiol Renal Physiol 282(6), F1150-F1155 
Yki-Jarvinen H (2004): Thiazolidinediones. N Engl J Med $\underline{351(11), ~ 1106-1118 ~}$

Yoder M C, Mead L E, Prater D, Krier T R, Mroueh K N, Li F, Krasich R, Temm C J, Prchal J T, Ingram D A (2007): Redefining endothelial progenitor cells via clonal analysis and hematopoietic stem/progenitor cell principals. Blood 109(5), 1801-1809

Zambon A, Gervois P, Pauletto P, Fruchart J C, Staels B (2006): Modulation of hepatic inflammatory risk markers of cardiovascular diseases by PPAR-alpha activators: clinical and experimental evidence. Arterioscler Thromb Vasc Biol 26 6 (5), 977-986 


\section{Danksagung}

Für die Möglichkeit der Anfertigung dieser spannenden Promotionsarbeit bedanke ich mich herzlichst bei meinem Doktorvater Herrn Professor Dr. med. Daniel Patschan, Oberarzt der Klinik für Nephrologie und Rheumatologie der Universitätsmedizin Göttingen. Besonderen Dank verdient er aufgrund seiner hervorragenden und vor allem ausdauernden Betreuung über die Jahre, in denen er stets zuverlässig Unterstützung bot, konstruktive Vorschläge unterbreitete und Fragen beantwortete.

Weiterhin danke ich herzlichst Frau Katrin Schwarze und Frau Elvira Henze für die große Hilfsbereitschaft und Flexibilität bei den Tierversuchen und im Labor. 